\title{
MÉTODO DE ANÁLISE ESTATÍSTICA PARA COMBINAÇÃO DE CULTIVARES EM CONSÓRCIO
}

\author{
ISAIAS OLIVIO GERALDI
}

Orientador: Prof. Dr. ROLAND VENCOVSKY

Tese a presentada à Escola Superior de Agricultura "Luiz de Queiroz", da Uni versi dadede São Paulo, para obtenção do título- de Doutor em Agronomia. Área' de Concentração: Genética e Melho. ramento de Plantas.

P I R A C I C A B A

Estado de São Paulo - Brasil

Setembro, 1983 


\section{AGRADECIMENTOS}

0 autor manifesta os mais sinceros agradecimentos às seguintes pessoas e instituições:

- Prof. Dr. Roland Vencousky, pelos ensinamentos e pela orientação na realização deste trabalho;

- Prof. Dr. Magno Antonio Patto Ramalho, pelas sugestões na elaboração do plano de tese e pelo auxílio prestado na condução dos experimentos;

- Professores do Departamento de Genética da ESALQ, pelos ensinamentos; em especial ao Prof. Dr. José Branco de Miranda Filho e ao Prof. Dr. Natal Antonio Vello;

- Empresa Brasileira de Pesquisa Agropecuária (EMBRAPA), pelas facilidades concedidas e pelo apoio prestado à carreira científica;

- Centro Nacional de Pesquisa de Milho e Sorgo e Centro Nacional de Pesquisa de Arroz e Feijão, da EMBRAPA, na pessoa de seus diretores, Dr. Roland Vencousky e Dr. Almiro Blumenschein, respectivamente, pelo financiamento desta pesquisa e pela oportunidade de realização dos ensaios nas suas dependências. 


\section{INDI CE}

Pāgina

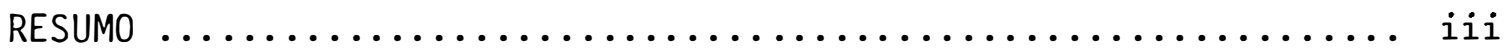

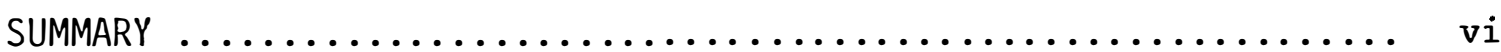

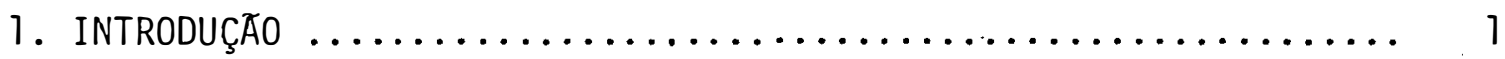

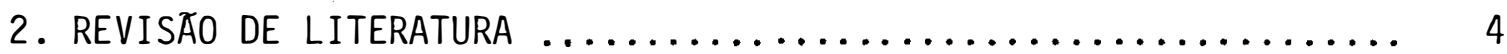

2.1. Metodologia para a anālise de dados experimentais obtidos com culturas consorciadas .................. 4

2.1.1. Comparação direta das produções nos dois sistemas ............................... 5

2.1.2. Comparação atravēs de indices ............... 7

2.1.3. Utilização das produções equivalentes ........... 10

2.1.4. Anālise de regressão ..................... 13

2.1.5. Anālise multivariada ..................... 15

2.1.6. Metodologia dos cruzamentos dialélicos ......... 16

2.2. Comportamento das cultivares de milho e feijão

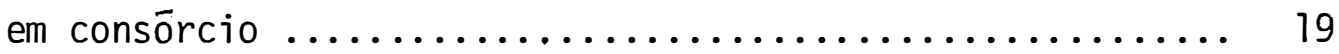

2.2.1. Efeito do sistema consorciado sobre o milho ...... 20

2.2.2. Efeito do sistema consorciado sobre o feijão ...... 23

2.2.3. Efeito de uma espécie sobre a outra em consórcio ................................ 24

2.2.4. Interação entre cultivares e sistemas de cul tivo .............................. 26

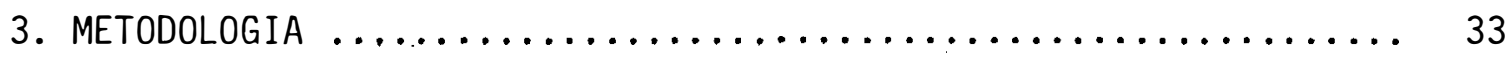

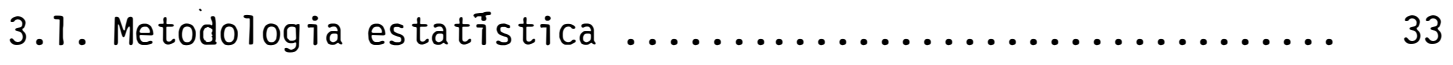

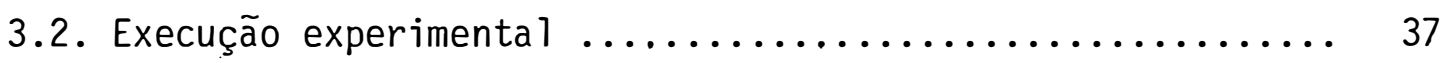

3.3. Anāilise estatîstica dos dados .................... 40

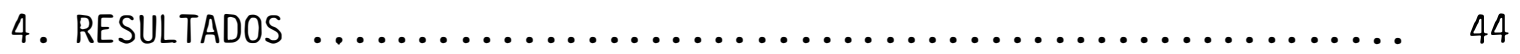

4.1. Metodologia Estatîstica ....................... 44

4.2. Anālise estatîstica dos dados experimentais ........... 51 
Pāgina

4.2.1. Anālise geral dos dados ................... 51

4.2.2. Análise dos dados de acordo com a metodologia proposta ........................... 52

4.2.2.1. Avaliação das médias dos tratamentos separadamente para da espécie ....... 52

4.2.2.2. Avaliação das médias dos tratamentos conjuntamente para as duas espécies e dos efeitos gerais de con sōrcio .......................... 55

4.2.2.3. Avaliação dos tratamentos com base nos parâmetros do modelo proposto ....... 59

4.2.3. Anālises utilizando outras metodologias ......... 64

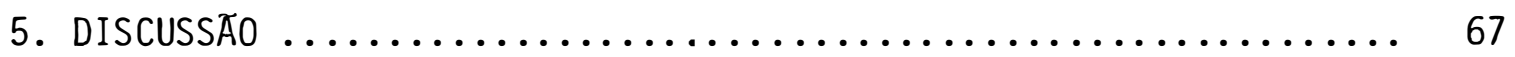

5.1. Avaliação do material com base na metodologia pro-

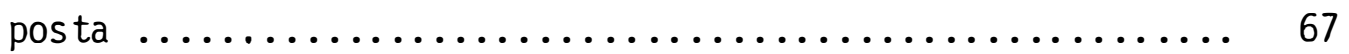

5.2. Avaliação da metodologia do presente trabalho em comparação com outras convencionais ............... 79

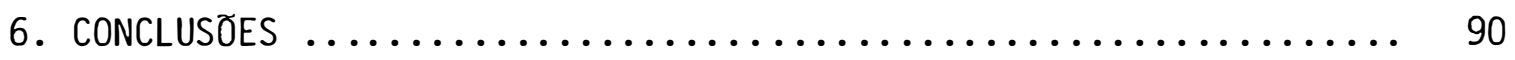

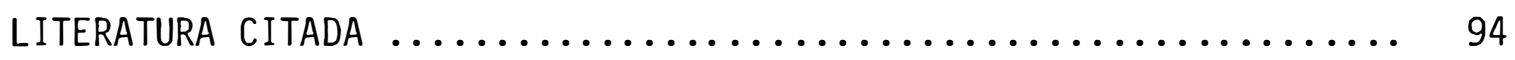

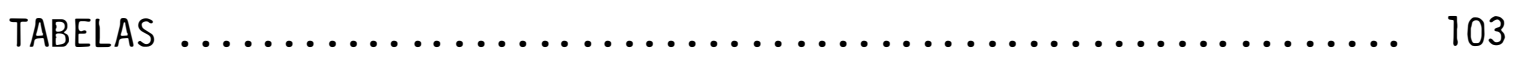




\section{METODO DE ANĀLISE ESTATISTICA PARA COMBINAÇÃO DE CULTIVARES EM CONSORCIO}

Autor: Isaias Olívio Geraldi

Orientador: Roland Vencovsky

\section{RESUMO}

0 presente trabalho teve como objetivo principal elaborar uma metodologia estatístico-experimental para avaliar o comportamento de cultivares de duas espécies diferentes combinadas em consórcio, e paralelamente testar esta metodologia, no estudo de uma amostra de cultivares de milho e de feijão avaliadas em consórcio e em monocultivo.

A metodologia proposta pressupõe que as cultivares das duas espécies em consórcio sejam combinadas segundo o arranjo dialélico, e que a produção de grãos de ambas seja transformada em uma variável comum, através da relação de preços entre elas no mercado. 0 modelo matemático empregado corresponde a uma adaptação do modelo de GARDNER e EBERHART (1966) para os cruzamentos dialélicos. Com base neste modelo, foram obtidas as fórmulas para a estimação dos componentes de médias e das somas de quadrados, utilizando-se o método dos quadrados mínimos. Fo ram adaptados ainda ao estudo de competição os conceitos empregados em genética para os cruzamentos dialélicos, entre eles, os efeitos da capacidade geral de competição, capacidade específica de competição e efeito 
geral de consórcio que mede a capacidade de complementação entre as duas espēcies.

Os ensaios de avaliação foram realizados no ano agrícola de 1979/80 em Sete Lagoas (MG), utilizando-se seis cultivares de feijão - de diferentes hābitos de crescimento e seis cultivares de milho de diferentes portes e graus de variabilidade genética, que permitiram 36 combinações diferentes em consórcio. Estes 36 tratamentos foram avaliados em um látice simples duplicado $6 \times 6$ (quatro repetições), enquanto que as cultivares em monocultivo foram avaliadas em delineamentos em blocos casualizados com quatro repetições.

$\grave{A}$ metodologia elaborada mostrou-se bastante abrangente pa ra explicar o comportamento das cultivares de milho e feijão em consōrcio, em relação ao comportamento das, mesmas em monocultivo, bem como na detecção de algumas propriedades das cultivares, favoráveis para o culti vo no sistema consorciado. A comparação desta metodologia com algumas outras convencionais mostrou que, entre outros aspectos, o efeito geral de consórcio $\left(c_{i j}\right)$ é mais eficiente que a razão da ārea equivalente (RAE) para a comparação da eficiência biológica das diferentes combinações.

As melhores combinações de milho e feijão em consörcio fọ ram aquelas onde ocorreu uma alta complementação entre as cultivares (al to efeito geral de consōrcio), ao contrārio das piores combinações. No geral, as combinações favoráveis envolveram cultivares com alta capacidade geral de competição e vice-versa. Algumas exceções ocorreram devido à magnitude da capacidade específica de competição. 
Para as cultivares de milho constatou-se a ocorrência de uma boa concordância entre o comportamento em consōrcio e em monocultivo, ao passo que para as cultivares de feijão não houve boa concordância, indicando, para esta espécie, interação entre cultivares e sistemas de cultivo. Entre as características responsāveis por um bom desempenho em consórcio, para as cultivares de feijão, puderam ser detectadas as se guintes: alta produtividade em monocultivo, baixa redução da produção em consórcio, pouca interferência com o milho (baixa agressividade) e precocidade. Recomendou-se que tais características sejam tomadas como critérios de seleção em um programa de melhoramento para consōrcio. 
vi

\section{METHOD OF STATISTICAL ANALYSIS FOR COMBINATION OF CULTIVARS UNDER INTERCROPPING}

Author: Isaias 01İvio Geraldi Adviser: Roland Vencovsky

\section{SUMMARY}

The main objective of the present work was the development of a methodology on a statistical and experimental basis, in order to evaluate the performance of cultivars of two different species when grown under intercropping system. An application of the methodology was studied by using maize and common bean cultivars grown under intercropping and sole cropping systems.

The methodology is applied under the assumption that the cultivars of both. species are arranged according to a diallel scheme, and their yields are transformed into a common variable through a relation based on the market value of each crop. The mathematical model comes from an adaptation of GARPNER and EBERHART's (1966) model for diallel crosses. The formulas for estimation of the components of means and for the sums of squares were obtained through the least square procedure. The concepts as developed for diallel crosses also were adapted for the studies of competition between species, including the effects of general competition ability, specific competition ability and the general effect of 
intercropping which measures the ability of complementation between the two species.

The yield trials were carried out at Sete Lagoas (MG) on 1979/80, and comprised six bean cultivars of different types and six maize cultivars differing for plant height and genetic variability, thus totalizing 36 intercrop combinations. The 36 entries were evaluated in 6 x 6 duplicated simple lattice (four replications) while the corresponding sole crops were evaluated in a completely randomized block design with four replications.

The methodology showed to be highly effective for the explanation of the performance of the intercropped maize and bean cultivars relative to sole crops, as well as for the identification of some characters which are favored by the intercropping system. The comparison of this methodology with the conventional ones showed that among other aspects, the general effect of intercropping $\left(c_{i j}\right)$ is more efficient than the land equivalent ratio ( $L E R$ ) for the comparison of the biological efficiency of different combinations.

The best combinations of maize and bean under intercropping were those where a high complementation between the cultivars (high general effect of intercropping) have ocurred, on the contrary of the poorer combinations. In general, the most favorable combinations involved cultivars with high general competition ability and vice-versa. Some exceptions ocurred because of the magnitude of specific competition ability. 
For the maize cultivars a good agreement was observed between their performance under intercropping and in sole crops, while for the bean cultivars such agreement was at a lower level, thus indicating the interaction between cultivars and cropping system for that species. Among the characteristics indicative of good performance of bean cultivars under intercropping, the following were detected: high yield in sole crops, low yield reduction under intercropping, low interference with maize (low agressivity) and earliness. We recomended such characteristics to be taken as selection criteria in a breeding program for intercrops. 


\section{INTRODUÇÃO}

0 emprego de culturas consorciadas é uma prática bastante comum na América Latina, principalmente pelos pequenos proprietários, onde predomina a agricultura de subsistência. Com isso os agricultores visam, basicamente, diminuir o risco de insucesso, utilizar a terra de maneira mais intensiva, utilizar permanentemente a mão de obra familiar, ga rantir uma dieta mais variada e uma estabilidade de rendimentos. Em outras palavras, visam tirar o máximo proveito dos seus recursos limitados: terra, capital e nível de tecnologia.

Entretanto, só mais recentemente a pesquisa científica começou a dar maior ênfase a este sistema de cultivo. Consequentemente, na literatura faltam muitas informações a respeito do mesmo e as informações disponíveis são muitas vezes inconsistentes ou contraditōrias.

O sistema consorciado carece inclusive de uma metodologia apropriada para anālise. Isto porque esta anālise è mais complexa que a dos experimentos em monocultivo, devido ao caráter multivariado dos dados. Este problema é particularmente sério para o consórcio de espécies 
cujo produto comercial difere quento ao valor nutritivo, energético, mone tário, etc., o que dificulta o julgamento de uma parcela como um todo. Para contornar este problema tem sido sugerida a utilização de uma variāvel comum a ambas as espécies, que pode ser a produção de um constituinte qualquer (matéria seca, nitrogênio, proteína, energia, nutrientes digestíveis totais, etc.), ou a produção de grãos de ambas as espécies em equivalentes de uma delas, obtida através do ajuste pela relação de preços entre elas no mercado (KASS, 1978). A grande vantagem, qualquer que seja a variável utilizada, é que deste modo os dados das duas espécies se tornam comparáveis e, consequentemente, pode ser aplicada uma análise uni variada. Entretanto, este procedimento tem sido frequentemente criticado, visto que o julgamento através de um constituinte qualquer é um julga mento parcial, ao passo que a relação de preços entre as duas espécies é instāvel.

Dentre os sistemas consorciados, um dos mais comuns é o do milho (Zea mays L.) com feijão (Phaseolus vulgaris L.). Estima-se que $80 \%$ do feijão e $50 \%$ do milho produzido na América Latina ocorre no sistema con sorciado (FRANCIS et alii, 1976a). No caso particular do Brasil, estimase que $70 \%$ a $90 \%$ do feijão é produzido em consórcio, principalmente com o milho (MEDINA, 1972; OLIARI et alii, 1975; VIEIRA, 1980). A razão disso é que esta combinação acarreta uma maior produção de alimentos por unidade de ārea e, consequentemente, um maior retorno (FRANCIS e SANDERS, 1978; RAMALHO et alii, 1982), além, evidentemente, das outras vantagens inerentes ao consórcio. Isto porque neste sistema é possível manter a produtividade do milho em níveis semelhantes ao monocultivo e, deste modo, a pro dução de feijão passa a ser uma quantidade adicional de alimentos. 
A grande maioria das cultivares de milho e feijão disponíveis foram selecionadas em condições de monocultivo, com o uso de tecnologia mais avançada, condições estas bastante diferentes das que ocorrem em consórcio. A avaliação destas cultivares em consórcio tem produzido resultados inconsistentes, de modo que não existem informações generalizą das e conclusivas ainda a respeito da interação entre cultivares e sistemas de cultivo. Evidentemente, este tipo de informação é fundamental para a obtenção de cultivares promissoras para o consórcio, pois caso ocorra interação, tais cultivares devem ser selecionadas em condições de consórcio.

Em vista destes fatos, os objetivos do presente trabalho compreendem basicamente os seguintes:

a. elaborar uma metodologia para a análise estatística de dados experimentais obtidos em culturas consorciadas, quando se tem vários tratamentos de cada espécie combinados em um arranjo dialélico;

b. testar esta metodologia no estudo de uma amostra de cul tivares de feijão e de uma amostra de cultivares de milho combinadas em consórcio;

c. verificar a influência da variação na relação de preços entre as duas espécies sobre as estimativas dos parâmetros e a análise da variância;

d. obter subsídios para trabalhos de melhoramento, através de estudos da interação entre cultivares e sistemas de cultivo. 


\section{REVISAOO DE LITERATURA}

Os trabalhos existentes na literatura relativos ao cultivo consorciado abrangem evidentemente as mais diversas āreas. No presente trabalho serão abordados aqueles relacionados aos seguintes aspectos: a) metodologia para a análise de dados experimentais obtidos com culturas consorciadas; b) comportamento das cultivares de milho e feijão em consōrcio.

2.1. Metodologia para a anāilise de dados experimentais obtidos com cul turas consorciadas

A anālise de dados experimentais obtidos em experimentos com culturas consorciadas é mais complexa que a dos experimentos em monocultivo, devido ao caráter multivariado daqueles. Este fato não acarreta grandes problemas quando se trata do consórcio de plantas forrageiras ou de determinados cereais de grãos pequenos, em que para efeito de ordem prática não há separação das duas espécies na colheita, e a avaliação é feita através da produção total da parcela (KASS, 1978). Por outro lado, 
no consórcio de espécies de naturezas diferentes, como é o caso do milho com feijão, tem-se em cada parcela a produção de grãos de duas espécies que diferem quanto ao valor nutritivo, energético, monetário, etc.

Um tipo de análise recomendado inicialmente é a análise da variância separada para cada espécie, que sem dúvida alguma fornece algumas informaçộes de interesse. Neste caso, porém, devido ao caráter univariado dos dados, a anālise não acarreta nenhuma dificuldade. Ela permi te obter informações quanto à variação entre cultivares, entre sistemas de cultivo (consórcio vs monocultivo), bem como quanto à interação entre cultivares e sistemas. Desta maneira, pode-se detectar os melhores tratamentos para cada espécie em separado. E muito comum ainda o cálculo da correlação das médias dos tratamentos nos dois sistemas, podendo esta ser determinada através de um coeficiente de correlação linear simples ( $r$ ), ou através do coeficiente de correlação de posição de Spearman $\left(r_{S}\right)$. Exemplos deste tipo de anālise foram apresentados por WIJESINHA et alii (1982) e RAMALHO et alii. (1983).

Esta anālise, porém, não satisfaz inteiramente, pelas razões jā expostas, visto que interessa também o julgamento da parcela conjunta, e esta contém dois ou mais dados de naturezas diferentes. Neste ca so têm sido utilizados diversos procedimentos, que serão relatados a seguir.

2.1.1. Comparação direta das produções nos dois sistemas

Este é um procedimento bem simples e serve para comparar as diferentes combinações em consórcio, bem como a eficiência do consórcio 
frente ao monocultivo. Neste sentido, KASS (1978) discute as seguintes alternativas:

a) Comparação da produção de apenas uma das espécies - Esta alternativa é válida quando uma das espécies é considerada de maior impor tância, sendo que no julgamento é dada uma grande ênfase a esta espécie. E uma situação mais comum quando a espécie principal é consorciada com uma leguminosa, em solos de baixa fertilidade, ou em solos que tenham sido exauridos por um cultivo intensivo (AGBOOLA e FAYEMI, 1972). Alguns resultados da literatura indicaram que esta prática realmente traz bons resultados para a espécie principal, em culturas intensivas e na ausência de fertilização.

b) Comparação com a média das produçōes em monocultivo Esta alternativa só tem validade quando as duas espécies são de algum modo similares, e utilizadas com a mesma finalidade. E o caso, por exemplo, do consōrcio em pastagens (DONALD, 1963) e também com certos cereais de grãos pequenos que, utilizados para alimentação, não são separados após a colheita, como é o caso de aveia e cevada (JENSEN, 1952).

c) Comparação baseada na divisão equitativa da ārea em monocultivo - Este método foi recomendado por Evans (1960), citado por KASS (1978). Neste caso, a produção em consórcio deve ser comparada com a pro dução em monocultivo, admitindo-se que a ārea de plantio é dividida equitativamente para ambas as espécies. WILLEY e OSIRU (1972) criticaram este método, pois afirmam que não há razão alguma para supor que as duas es pécies devam ser distribuídas em áreas iguais em monocultivo. Alguns resultados na literatura mostraram uma superioridade do consórcio frente ao 
monocultivo, utilizando este tipo de ănálise.'

d) Comparação baseada na proporção constante nos dois sis temas - Este método foi proposto por WILLEY e OSIRU (1972). Neste caso, a produção em consórcio deve ser comparada com a produção em monocultivo, admitindo-se que para isso a área é dividida entre as duas espécies, de maneira a proporcionar a mesma proporção de produção obtida entre as duas no consórcio. Os resultados apresentados por estes autores mostraram uma superioridade do consōrcio em relação ao monocultivo. Porém, de acordo com KASS (1978), este método não tem sido utilizado.

\subsubsection{Comparação atravēs de indices}

A comparação da eficiência do consórcio frente ao monocultivo é frequentemente feita através de índices. 0 mais comumente utiliza do é o RAE (Razão da Ārea Equivalente), que em inglês é conhecido como LER ('Land Equivalent Ratio'), e é obtido pela seguinte expressão, confor me definição de WILLEY e OSIRU (1972):

$$
R A E=R_{a}+R_{b}=\frac{C_{a}}{M_{a}}+\frac{C_{b}}{M_{b}}
$$

Neste indice, $\mathrm{R}_{\mathrm{a}}$ representa o quociente entre a produção da espécie 'a' em consórcio e a produção da mesma em monocultivo, o mesmo valendo para a espécie 'b'. Consequentemente, o RAE mede a ärea de terra necessária em monocultivo para a obtenção da mesma produção de ambas as es pécies em consórcio. Um RAE de 1,50 indica, por exemplo, que a vantagem relativa do consórcio é de $50 \%$ e, deste modo, seria necessária uma ārea 50\% maior em monocultivo para a obtenção da mesma produção obtida em consōrcio. Embora o índice anterior refira-se a apenas duas espécies, o mesmo 
pode também ser aplicado para três ou mais espécies.

O RAE tem sido amplamente utilizado pela maioria dos pesquisadores devido principalmente à sua simplicidade. Entretanto, ele apresenta um inconveniente muito grande, devido ao fato de ser uma razão e, deste modo, altos índices podem ser obtidos devido não somente a uma alta produção em consórcio, como também a uma baixa produção em monocultivo. Consequentemente, não é adequado para a comparação de diferentes combinações. Com o objetivo de contornar este problema, MEAD e WILLEY (1980) e MEAD e RILEY (1981) sugeriram o uso de um padrão como denominador do RAE, isto é, uma produção em monocultivo constante para todas as observações. Para tal sugeriram as seguintes alternativas: a) a produção média em monocultivo dos tratamentos utilizados; b) a produção do melhor tratamento em monocultivo e c) a produção em monocultivo de algum tratamento utiliza do como testemunha. HUXLEY e MAINGU (1978) ressaltam ainda que, em qualquer caso, é importante que as produções em monocultivo sejam avaliadas na densidade ótima para a espécie.

Entretanto, embora a padronização da produção em monocultivo permita a comparação da eficiência biológica das diferentes combinações, ela não leva em conta a proporção relativa de cada espécie. Deste mo do, duas combinações com a mesma eficiência biológica podem ser constituídas de diferentes proporções de cada espécie e, consequentemente, não ser perfeitamente comparāveis. Além disso, as combinações de maior eficiência biológica podem, devido a este aspecto, não ser as preferidas pelos agricultores. Visando contornar este problema, MEAD e STERN (1979), MEAD e WILLEY (1980) e MEAD e RILEY (1981) sugerem o uso do índice RAEe ('Razão 
da Ārea Equivalente Efetiva'). Este İndice coloca todas as combinações nu ma situação diretamente comparāvel, pois no cālculo do mesmo está implícito que a proporção relativa a ser atingida para as duas espécies é igual para todas as combinações. MEAD e RILEY (1981) e RAMALHO et alii apresentaram resultados utilizando este procedimento.

Embora a realização da anālise da variância seja um procedimento bastante útil quando se deseja comparar diferentes tratamentos, ela não tem sido comumente utilizada para a comparação dos índices RAE's. Isto decorre do próprio desconhecimento da natureza da distribuição desta variável. De acordo com MARSAGLIA (1965), a distribuição da razão de duas variāveis que têm distribuição normal pode adquirir muitas formas diferentes. Além disso, o uso de denominadores diferentes para cada combinação pode produzir resultados mais, variados ainda, de modo que estes efeitos po dem invalidar completamente os testes de hipóteses na análise da variância. Neste sentido, OYEJOLA e MEAD (1982) estudaram o efeito de seis métodos de determinação do RAE sobre a anālise da variância. Os seis métodos diferiam inicialmente quanto à natureza do denominador no cálculo do RAE, a saber: a) utilização da'média de todos os tratamentos em monocultivo para todas as combinações; b) utilização, para cada combinação, da média do tratamento correspondente em monocultivo e c) utilização da média do melhor tratamento em monocultivo para todas as combinações. Além disso, estes três procedimentos foram aplicados considerando-se cada repetição em separado, bem como a média de todas as repetições, o que totalizou seis métodos de padronização. A conclusão geral desses autores foi que quanto maior a padronização do denominador, maior a vantagem, tanto em 
termos de normalidade, quanto em termos de precisão nas comparações. Consequentemente, recomendaram que o cálculo do RAE visando a comparação en tre diferentes combinações, seja feito com base em uma produção comum em monocultivo, e que a mesma produção seja utilizada para todas as repetições.

Além do RAE existem outros índices propostos para avaliar o grau de competição entre combinações em consórcio: a) o índice $k$ ou Coeficiente de Reunião Relativo ('Relative Crowding Coefficient') proposto por de Wit (1960) e desenvolvido por HALL (1974); b) o índice IC ou Indice de Competição ('Competition Index') de DONALD (1963); c) o índice A ou Coeficiente de Agressividade ('Coefficient of Agressivity') de McGILCHRIST e TRENBATH (1971) e o Índice RC ou Razão Competitiva ('Competitive Ratio') de WILLEY e RAO (1980). Estes índices foram discutidos por KASS (1978); WILLEY (1979); WILLEY e RAO (1980) e MEAD e RILEY (1981). Além disso, estes últimos autores relacionaram todos eles ao RAE. Por outro lado, WILLEY (1979) fez uma comparação entre os índices k, A e RAE e concluiu que, pela quantidade de informações, o RAE é o mais útil dos três, visto que dá uma idéia mais clára a respeito da magnitude da vantagem na produção. De acordo com este autor, entretanto, o uso do índice RAE não elimina a necessidade de se apresentar as produções absolutas das duas espécies, isto é, esta medida só tem valor prático quando relacionada aos níveis reais de produção.

\section{2.].3. Uti]ização das produções equivalentes}

Este procedimento corresponde a se fazer uma avaliação das duas espécies em consórcio com base em uma variāvel comum a ambas, que 
pode ser a produção de matéria seca, a produção de nitrogênio, a produção de nutrientes digestíveis totais, a produção de proteína, a produção de energia, etc. KASS (1978) fez um apanhado dos resultados utilizando tais procedimentos. De acordo com este autor, uma outra alternativa para o cálculo das produções equivalentes baseia-se no valor monetário de ambas as espécies. Corresponde a se utilizar um fator de correção para a produção de grãos que é a relação de preços entre as duas espécies no mercado. A maior crítica a esta alternativa decorre do fato que o valor monetário das espécies é instável, mas apesar disso a mesma tem sido frequentemente sugerida nos ültimos anos. A grande vantagem, qualquer que seja a variável utilizada, é que deste modo pode ser aplicada uma análise univariada, e a anālise conjunta, envolvendo o consórcio e o monocultivo, po de ser feita sem maiores problemas (RAMALHO et alii, 1983).

WIJESINHA et alii (1982) utilizaram este procedimento para avaliar um ensaio em consórcio envolvendo dois genótipos de milho e quatro de feijão. Consideraram que o preço do feijão (F) era três vezes superior ao do milho (M), de modo que a produção (P) da parcela ficou sendo $3 P_{F}+P_{M}$ equivalentes de milho. Com base nesta variāvel, os autores discutiram as possíveis alternativas para a escolha dos melhores tratamentos, supondo situações onde o objetivo principal é a maximização da recei ta, ou então onde o mais importante é a obtenção de uma determinada produ् çao de uma das espécies. Para isso, evidentemente, foram levados em conta o valor monetário de cada tratamento, juntamente com as produções sepa radas de cada tratamento em cada espécie. 
RAMALHO et alii (1983) utilizaram esta metodologia em um experimento envolvendo duas cultivares de milho e uma de feijão, em cinco arranjos diferentes de plantio. Para a relação de preços utilizada, isto é, 4,5, verificaram, por exemplo, que em média a consorciação proporcionou uma renda bruta $15,5 \%$ e $18,2 \%$ superior ao monocultivo de milho e feijão, respectivamente. A utilização da cultivar de milho Cargili 111 proporcionou um retomo $13,2 \%$ superior ao obtido com a cultivar $\mathrm{Br}-105$.

FRANCIS e SANDERS (1978) também utilizaram a relação de prẹ ços em um estudo envolvendo os resultados de vinte experimentos com milho e feijão conduzidos no Centro Internacional de Agricultura Tropical (CIAT). Neste caso, porém, foi feito um estudo econômico completo, devido aos diferentes custos de produção dos diferentes sistemas, principalmente o do monocultivo do feijão trepador que deve ser estaqueado, bem como devido aos diferentes graus de risco de cada sistema. Em condiçõoes de altos ní veis de produção verificaram que o monocultivo do feijão foi mais lucrati vo para uma relação de preços acima de 4:1, ao passo que para uma relação de preços abaixo de 4:1 o consórcio foi mais lucrativo. A monocultura do milho foi o sistema que deu o menor retorno para todo o intervalo de preços considerado, isto é, $1: 1$ a 8:1. Entretanto, quando se consideraram os níveis de produção normalmente obtidos na América Latina, mantendo-se os mesmos custos de produção, o monocultivo do feijão só se tornou vantajoso a partir da relação de preços 8:1. Este fato, aliado ao menor custo de produção e ao menor risco explica, segundo estes autores, a predominân cia do cultivo consorciado entre os agricultores. Tendência semelhante a esta também foi verificada por WILLEY e OSIRU (1972). 


\subsubsection{Anālise de regressão}

Este método corresponde a uma anālise da interação entre genótipos e ambientes pelo processo introduzido por YATES e COCHRAN (1938), e empregado por FINLAY e WILKINSON (1963) para o estudo da estabilidade fenotípica de cultivares em relação a vários ambientes. Neste ca so, a adaptação de cada cultivar é estabelecida em função da regressão li near de sua produção em relação à produção média de todas as cultivares do experimento: Para o caso do consōrcio, os ambientes são substituídos pelas espécies associadas e, deste modo, são estabelecidas as regressões lineares de todas as espécies em relação às médias das espécies associadas.

BREESE e HILL (1973) e HILL (1973) apresentaram anālises bem detalhadas sobre a aplicação deste método em experimentos de competiçao envolvendo espécies forrageiras. Os exemplos apresentados se referem tanto à competição interespecífica como intraespecífica. Verificaram que proporções altamente significativas das interações entre espécies principais (linhas) e espécies associadas (colunas) puderam ser explicadas como sendo devidas a diferenças entre as inclinações das linhas de regressão. Consequentemente, propuseram três parâmetros para explicar o comportamento das espécies em competição: a média das espécies (v), o coeficiente de regressão (b) e o efeito médio das espécies associadas (a), que medem, respectivamente, o vigor geral das espécies, sua sensitividade à competição e sua agressividade. Dessa maneira, a produção da espécie 'i' em associação com a espécie ' $j$ ' pode ser explicada pela seguinte equação: $Y_{i j}=u+v_{i}+b_{i} a_{j}$, sendo que para explicar as produções das espécies 
em monocultivo substitui-se ' $i$ ' por ' $j$ ' e vice-versa. Para o caso de com petição intraespecífica, evidentemente, o termo espécie é substituído por genótipo. A capacidade geral de competição é atribuída a estes três parâmetros, enquanto que a capacidade específica de competição é atribuída aos desvios da regressão. Com base neste modelo, os autores estabeleceram ainda as condições em que ocorre superioridade do consórcio sobre o monocultivo (complementação), tanto em relação à média das duas espécies em monocultivo, como em relação à espécie mais produtiva em monocultivo. Foram feitas analogias também dos graus de complementação com os graus de dominância utilizados em genética, isto é, complementação parcial, comple mentação completa e sobre-complementação, para os casos em que a mistura produz menos, igual ou mais que a média em monocultivo, respectivamente.

JENSEN e FEDERER (1964) também utilizaram métodos de regressão linear para estudar o efeito de competição entre genótipos de tri go de portes diferentes. Verificaram que em média os efeitos competitivos associados com o porte das plantas acarretaram, para os genótipos mais altos, quando em competição, um incremento na produção que era aproximadamente o dobro da redução ocorrida nos genótipos mais baixos. Deste modo, os efeitos do aumento e depressão não foram totalmente compensatórios, sendo o aumento maior que o decréscimo, e havendo, portanto, uma certa complementação. NORRINGTON-DAVIES (1967a e 1976b) denominaram este efeito de alfa-compensatório.

DAVIS (1981), após constatar ausência de interação entre genōtipos de milho e de feijão trepador, realizou um estudo de regressão linear para as cultivares de feijão, utilizando as médias das cultivares 
de milho. Constatou a ocorrência de uma relação negativa entre os rendimentos de feijão e de milho. O coeficiente de regressão linear foi de -1,92, o que indica que para cada aumento de uma unidade no rendimento do feijão espera-se uma redução aproximada de duas unidades no rendimento do milho. E interessante ressaltar que a interceptação da linha de regressão foi um bom prognóstico (margem de erro menor que 3\%) do rendimento do milho em monocultivo, indicando realmente a ocorrência de um grau de competição muito estreito entre as duas espécies. Em outros trabalhos, envolvendo outras cultivares, os coeficientes de regressão linear foram de $-1,62$ e $-0,62$, respectivamente.

\subsubsection{Anālise multivariada}

Evidentemente os métodos de análise multivariada deveriam ser bem adequados a estudos de consorciação, devido ao carāter multivariado dos dados. Entretanto, de acordo com PEARCE e GILLIVER (1978), a anālise multivariada não tem sido utilizada em consōrcio, pelo fato de que provavelmente poucos pesquisadores estão habituados a raciocinar em termos de geometria multidimensional, o que dificulta a interpretação dos dados da análise multivariada. Mesmo assim, PEARCE e GILLIVER (1978, 1979) apresentaram duas metodologias relativamente simples de análise bivariada aplicadas a dados de consórcio de milho com mandioca, e mostraram a aplicabilidade das mesmas quanto aos seguintes aspectos: estabilidade de recomendação em relação à oscilação de preços, vantagem do consórcio frente ao monocultivo e maximização do rendimento para uma proporção especificada de produção de ambas as espécies. 
MEAD e RILEY (1981) aplicaram a análise bivariada em um ex perimento envolvendo quatro genótipos de milheto e quatro genótipos de sorgo, segundo um arranjo fatorial. Relacionaram algumas dificuldades do método, e ressaltaram o fato de não ser possível uma análise comparando as produções em consórcio e em monocultivo, que é um dos objetivos princí pais na análise de dados obtidos com culturas consorciadas. WIJESINHA et alii (1982) também chamaram a atenção para este problema. Estes autores aplicaram o método de análise bivariada em um ensaio envolvendo duas cultivares de milho e quatro de feijão. Pelas razões já expostas, as comparações ficaram restritas apenas às oito combinações em consórcio: Neste caso, foi possível verificar que para a produção de grãos, o milho teve uma participação de apenas $25 \%$ na discriminação entre os tratamentos, sen do o feijão a espécie mais importante para esta finalidade. MEAD e RILEY (1981) ressaltaram ainda que a validade dos métodos de análise multivaria da para o estudo de espécies consorciadas, somente poderá ser melhor determinada quando tais métodos tịveram sido utilizados mais extensivamente pelos pesquisadores. De qualquer modo, sigeriram o uso simultâneo da RAE, visando a obtenção de informações mais completas, e para tal ressaltaram a necessidade de investigações das relações entre o RAE e os métodos de anālise multivariada.

\subsubsection{Metodologia dos cruzamentos dialēlicos}

Este tipo de análise pode ser utilizado quando os tratamen tos são combinados em um arranjo dialélico. O termo dialélico é utilizado devido à analogia com os cruzamentos dialélicos empregados em genética. 
Este arranjo corresponde a um arranjo fatorial, em que são avaliadas expe rimentalmente todas as combinações possíveis dos tratamentos dois a dois, bem como todos os tratamentos em monocultivo.

SAKAI (1961) estudou o comportamento de nove variedades de trigo dispostas em um arranjo dialélico. Estimou os parâmetros da capacidade geral de competição de cada variedade e os parâmetros da capacidade específica de competição de cada combinação. As variações devidas a ambos os efeitos foram altamente significativas na anālise da variância, indicando que algumas variedades foram fortes competidoras e outras, fracas competidoras, em todas ou em determinadas combinações.

McGILCHRIST (1965) apresentou uma metodologia para a análi se de dialélicos de competição, com base nos dados de WILLIAMS (1962), re ferentes a um ensaio de competição de sete espécies diferentes. 0 modelo matemático adotado por este autor inclui: a média das variedades $\left(S_{i}\right)$, o efeito de competição da espécie $i\left(k_{i}\right)$, o efeito de depressão da espécie $i\left(\lambda_{j}\right)$ e um efeito específico $\left(\theta_{i j}+\tau_{i j}\right)$ da combinação de duas espécies. 0 efeito $k_{i}$ representa o incremento de produção da espécie 'i' quando cul tivada com a espécie 'j', em relação à sua produção em monocultivo, enquanto que o efeito $\lambda_{i}$ representa a depressão que a espécie ' $i$ ' acarreta na espécie 'j', em relação à sua produção em monocultivo. Com base na significância da anālise da variância e nas estimativas dos parâmetros, o autor detectou quais foram as espécies melhor sucedidas em competição e quais não foram e, consequentemente, aquelas que devem ser cultivadas em consórcio. 
NORRINGTON-DAVIES (1967a e 1967b) aplicaram o método de DURRANT (1965) na análise de dialélicos de competição entre genótipos de uma mesma espécie (cevada), bem como entre cinco espécies diferentes de plantas forrageiras. Este método baseia-se na anālise da tabela dialélica e interpretação gráfica de JINKS (1954) e HAYMAN (1954), bem como na anālise biométrica de MATHER (1949). Verificaram a ocorrência de um padrão semelhante de resposta tanto para o caso de competição intraespecífica, como para o caso de competição interespecífica. O efeito de competição foi do tipo alfa-compensatório, de modo que o tratamento mais produ tivo em monocultivo teve, quando consorciado, um incremento na produção maior que o decréscimo ocorrido no tratamento menos produtivo.

HILL e SHIMAMOTO (1973) aplicaram o método de JINKS e HAYMAN (1953) para estudar os efeitos de competição entre cinco genótipos de azevēm perene. Constataram a ocorrência de uma variação considerável pàra capacidade de competição, relacionando-a ao tipo de fol ha e ao hábito de crescimento do genōtipo. Verificaram também que a capacidade de competição não foi relacionada diretamente à produtividade em monocultivo.

FEDERER (1979) e FEDERER et alii (1982) utilizaram o arran jo dialélico para o estudo de competição entre cultivares de feijão que eram facilmente distinguidos pela cor das sementes, mas supondo situações onde era possível individualizar as produções das misturas, e outras situações, onde isso não era possível. Apresentaram uma metodologia para a análise da variância bem como para a estimação dos parâmetros do efeito geral da mistura e do efeito específico da mistura, conceitos estes relacionados aos da capacidade geral e específica de combinação utilizados 
no melhoramento genético.

HAMBLIN et alii (1976) sugeriram a utilização do esquema dialélico para a realização de seleção simultaneamente para produção e ca pacidade cológica de competição entre duas espécies. Neste caso, partindo-se de 'N' tratamentos de uma espécie (espécie teste) e de 'n' tratamen tos de uma outra espécie (espécie associada) tem-se um total de 'Nn' tratamentos. Através da anālise da variância pode-se testar a significância para as fontes de variação 'espécies', e 'interação entre espécies' e, deste modo, determinar se a seleção pode ser feita independentemente para cada espécie ou não. No trabalho em questão o autor supõe que o programa se refere a populações segregantes de espécies autógamas e, deste modo, o mesmo procedimento pode ser repetido para as gerações seguintes, até atin gir a homozigose.

Outros modelos desenvolvidos especificamente para a análise de dialélicos de competição foram apresentados -por WILLIAMS (1962) e MCGILCHRIST e TRENBATH (1971).

\subsection{Comportamento das cultivares de milho e feijão em consōrcio}

Basicamente, as cultivares de milho e feijão disponíveis foram selecionadas em condições de monocultivo. Desta maneira, torna-se importante fazer uma anālise do comportamento destas em, consórcio em relação ao comportamento das mesmas em monocultivo 


\subsubsection{Efeito do sistema consorciado sobre o milho}

Quanto à produtividade do milho em consórcio, existe uma série de evidências na literatura, sendo muitas delas contraditórias. Alguns trabalhos mostram que a produtividade do milho diminui quando consorciado com o feijão. DAVIS (1981) encontrou uma relação muito estreita entre a capacidade competitiva do feijão, definida como sendo a produtivi dade do feijão em consórcio em relação à do monocultivo, e a redução da produtividade do milho. WIJESINHA et alii (1982) testaram duas cultivares de portes diferentes em consórcio com feijão, sendo uma variedade de porte baixo (variedade Piranão) e um híbrido comercial de porte alto ou normal (híbrido da Agroceres). Constataram que para a variedade Piranão

praticamente não houve alteração na produtividade em relação aos dois sis temas, enquanto que para o híbrido houve uma redução significativa da pro dução em consórcio, sendo esta $74 \%$ da produção em monocultivo. Tem-se que considerar, porém, que em monocultivo o híbrido foi mais produtivo que a variedade, ao passo que em consórcio a produção de ambos foi semelhante. Em diversos outros trabalhos relatados por FRANCIS et alii (1976a), SANTA CECILIA (1977) e BEZERRA NETO (1978) também foram constatadas reduções na produtividade do milho em consórcio. Entretanto, de acordo com BEZERRA NETO (1978), muitas vezes esta redução da produtividade do milho em consôrcio se deve a uma menor densidade utilizada, o que evidentemente con-. funde os efeitos.

Porém, a grande maioria dos autores relata a não ocorrência de redução na produtividade do milho em consórcio. SANTA CECILIA e VIEIRA (1978) não detectaram alterações significativas na produtividade 
do milho em consórcio, tanto para o plantio das 'águas' como para o plantio das 'secas'. Tem-se que considerar, porém, que, no primeiro caso, a densidade utilizada para o feijão foi baixa (60.000 plantas por hectare), enquanto que no segundo caso a semeadura foi feita na época da maturação do milho, de modo que em ambos os casos não era esperada uma competição muito forte. AIDAR e VIEIRA (1979) e AIDAR et alii (1979) estudaram o comportamento do milho consorciado, em diferentes populações, isto é: $20.000,40.000$ e 60.000 plantas por hectare. Verificaram que, tanto para o plantio das 'águas' como para o plantio das 'secas', o rendimento do mi Tho não foi prejudicado. CRUZ et alii (1982) avaliaram cultivares de mi1ho de porte normal, porte baixo e precoces em consórcio. Não constataram reduções significativas na produtividade do milho em consórcio, embora o grupo de cultivares de porte baixo tenha apresentado o pior desempenho. Outros autores também relataram a não redução da produtividade do milho com consórcio (WILLEY e OSIRU, 1972; ANDRADE et alii, 1974; FRANCIS et alii, 1976a, 1976c, 1978a e 1978c).

FRANCIS et alii (1976a) fizeram uma avaliação ampla de cul tivares de milho em monocultivo e em consórcio com cultivares de feijão de hābito de crescimento arbustivo e trepador. Para as cinco cultivares de milho testadas com as cultivares de feijão arbustivo não foram detectadas diferenças significativas entre os dois sistemas, sendo que a produ् tividade em consórcio variou de $91 \%$ a $123 \%$ da produtividade em monocultivo. Para as 25 cultivares de milho testadas com as cultivares de feijão trepador foram obtidos os seguintes resultados quanto à produtividade do 
milho: em três casos o consórcio superou o monocultivo de forma significa tiva, em um caso o monocultivo superou o consórcio de forma significativa e em 21 casos não foram detectadas diferenças significativas entre os dois sistemas. A produtividade do consórcio em relação à do monocultivo variou ỉ $74 \%$ a $126 \%$. Estes autores concluiram que pode-se admitir a não ocorrência de alteração na produtividade do milho em relação aos dois sistemas. RAMALHO et alii (1982) fizeram um estudo semelhante com os dados obtidos em 17 experimentos, em diferentes locais do Brasil. A produtividade de milho em consórcio em relação à do monocultivo variou de $81,7 \%$ a 114,9\%, com uma média de 96,5\%. Alguns autores relataram ainda a ocorrência de aumentos significativos na produtividade do milho em consórcio (WILLEY e OSIRU, 1972; FRANCIS et alii, 1976a e 1976b).

Evidentemente, a ocorrência de alguns resultados conflitantes deve-se muitas vezes aos diferentes sistemas de plantio utilizados para as duas espécies, bem como às diferentes densidades de plantio utilizadas nos dois sistemas, de modo que os dados da literatura nem sempre são perfeitamente comparáveis. As evidências disponíveis indicam, porém, que com as populações de feijão normalmente utilizadas, esta espécie não compete com o milho (SILVA e VIEIRA, 1981 e VIEIRA et alii, 1982). Segundo VIEIRA (1980) isto se deve ao fato de o milho ser uma espécie fortemen te competitiva. Outra razão provável é que em se tratando de duas espécies diferentes (uma gramínea e uma leguminosa), as exigências nutricionais são diferentes. Além disso, entre essas espécies ocorre uma complementação temporal (WILLEY, 1979), isto é, uma defasagem no ciclo das mesmas, de modo que os períodos de atividade metabólica mais intensa não são coincidentes. 


\subsubsection{Efeito do sistema consorciado sobre o feijão}

Quanto ao feijão, hā uma concordância praticamente total dos resultados da literatùra, mostrando que a produtividade do mesmo . em consórcio é menor que em monocultivo (SANTA CECILIA, 1977). Isto se deve principalmente ao efeito de sombreamento do milho sobre o feijão, isto é, a uma competição por luz (AKINOLA e FAYEMI, 1971; WILLEY e OSIRU, 1972; CROOKSTON et alii, 1975) e também devido ao fato de o milho ser uma espēcie fortemente competitiva (WILLEY e OSIRU, 1972; FISHER, 1974; VIEIRA, 1980). Consequentemente, quanto menor a população de plantas de milho, maior o rendimento do feijão (SANTA CECILIA e VIEIRA, 1978; AIDAR e VIEIRA, 1979; AIDAR et alii, 1979; SILVA e VIEIRA, 1981; VIEIRA et alii, 1982). Isto é válido, evidentemente, quando se faz o plantio simultâneo de ambas as espécies, pois quando o feijão é plantado após a maturação fisiológica do milho, a sua produção é normalmente pouco afetada. Em vista destes fa tos, a consorciação do milho com feijão é considerada como vantajosa pela maioria dos autores, pois além das demais vantagens inerentes ao consórcio, è possível manter a produtividade do milho em níveis semelhantes à do monocultivo e, deste modo, a produção de feijão passa a ser um rendimento extra (RAMALHO et alii, 1982).

A redução do rendimento do feijão em consórcio varia, evidentemente, com os diferentes sistemas utilizados. Porém, ela é normalmente maior para as cultivares de feijão de hābito trepador. Têm sido observadas, para as cultivares de feijão de hábito de crescimento trepador e arbustivo, respectivamente, reduções em torno de $85 \%$ e $56 \%$ (FRANCIS et 
$a l i i, 1976 c$ ), 50\% e 30\% (FRANCIS et alii, 1976b e 1978c); 70\% e 40\% (FRANCIS et alii, 1978b e 1978c). Este fato, segundo estes autores, é consequência do maior período de crescimento do feijão trepador e a uma competição mais direta por luz durante este período. E interessante ressaltar ainda que os experimentos que compararam cultivares de feijão de diferentes hābitos de crescimento mostraram que a variação entre os mesmos em consórcio é bem menor que a variação observada em monocultivo, isto é, a discriminação das cultivares em consórcio é menor (FRANCIS et alii, $1978 c)$

\subsubsection{Efeito de uma espécie sobre a outra em consōrcio}

Em experimentos de consórcio tem-se que considerar também um outro aspecto, muito importante na determinação do tipo mais adequado de planta, que é o efeito de uma espécie sobre a outra (KASS, 1978). Este aspecto é importante principalmente para o feijão, que è a espécie domina da, e assim torna-se importante verificar se as diferentes cultivares de milho agem de maneira diferencial sobre as de feijão. Alguns estudos foram realizados, comparando principalmente cultivares de milho de diferentes portes. ANDRADE et alii (1974), comparando variedades de milho de porte normal (Piramex) e porte baixo (Piranão), não constataram diferenças na produtividade do feijão. Segundo estes autores, a vantagem aparente da variedade Piranão quanto ao sombreamento, devido ao menor porte, seria anulada pela maior largura e concentração das folhas próximas ao so 1o. BEZERRA NETO (1978) também comparou variedades de porte normal (Centralmex e Erecta) com uma variedade de porte baixo (Piranão). Verificou 
que a produtividade do feijão foi maior quando associado à variedade Piranão e menor quando associado à variedade Centralmex. Entretanto, com a produtividade do milho aconteceu o contrário e, deste modo, este resultado pode ter sido devido a diferenças na capacidade competitiva das variedades de milho e não unicamente devido a diferenças no sombreamento causa das pelos diferentes portes.

Por outro lado, CRUZ et alii (1982) avaliaram 15 cultivares de milho em consórcio, sendo estas divididas em três grupos: porte normal, porte baixo e precoce. Constataram que o menor porte das plantas não contribui para uma maior produtividade do feijão, sendo esta menor justamente com os milhos de porte baixo. FRANCIS et alii (1976c) verificaram que o milho braquítico causou maior prejuízo na produção do feijão, tanto arbustivo, como trepador. DAVIS (1981) também constatou um efeito diferencial das variedades de milho sobre o rendimento de cultivares de feijão de hābito trepador.

Quanto ao efeito das cultivares de feijão de diferentes portes sobre o rendimento do milho, existem algumas evidências também con traditórias. FRANCIS et alii (1978b e 1978c) verificaram que, no geral, a produtividade do milho não foi afetada diferencialmente pelas cultivares de feijão, tanto arbustivo como trepador. Por outro lado, DAVIS (1981) constatou um efeito diferencial das cultivares de feijão de hábito trepador sobre as de milho.

Em vista destes resultados, pode-se admitir que não existem evidências generalizadas e conclusivas a respeito da influência das 
diferentes cultivares de uma espécie sobre as diferentes cultivares da ou tra.

\subsubsection{Interação entre cultivares e sistemas de cultivo}

Um dos aspectos mais importantes em consórcio e onde ainda persistem muitas dưvidas é quanto ao aspecto varietal. Como se sabe, só mais recentemente os sistemas consorciados têm sido estudados pela pesqui sa científica. Consequentemente, as cultivares utilizadas em consōrcio normalmente são aquelas desenvolvidas para as condições de monocultivo, com o uso de tecnologia mais' avançada, condições estas bastante diferentes das que normalmente ocorrem em consórcio. Deste modo, torna-se impor tante verificar se ocorre ou não interação entre cultivares e sistemas, pois em caso positivo, evidentemente, as cultivares apropriadas para consórcio deveriam ser melhoradas especificamente para este fim. A avaliação das cultivares disponíveis em consórcio, porém, tem produzido resultạ dos um tanto contraditórios.

Existem, evidentemente, diversos procedimentos para se ava liar a interação entre genótipos e sistemas. Um deles é a simples comparação das cultivares nos dois sistemas, para constatar a ocorrência ou não de correspondência entre as médias ou entre a classificação delas. Ou tra maneira, segundo FRANCIS (1981) é a determinação da correlação entre os dois sistemas para as médias dos tratamentos, podendo esta ser determi nada através de um coeficiente de correlação linear simples (r) ou através do coeficiente de correlação de posição de Spearman $\left(r_{S}\right)$, cujas signi ficâncias podem ainda ser verificadas. Ainda, segundo este autor, um 
outro procedimento para se constatar a ocorrência de interação entre cultivares e sistemas é a própria análise da variância, com o desdobramento do quadrado médio da interação.

Para o milho, que é a espécie dominante, espera-se evidentemente um maior grau de correspondência entre os dois sistemas. Enquanto ANDRADE et alii (1974) e FRANCIS et alii (1976a) verificaram que o ren dimento de cultivares de porte normal e porte baixo foram semelhantes quan do consorciados com o feijão, PINCHINAT e DESIR (1976) constataram uma superioridade de $18 \%$ para as cultivares de porte normal. Entretanto, conforme jā foi ressaltado anteriormente, este tipo de comparação não é satisfatório, pois o efeito do porte das plantas fica confundido com as diferenças genéticas entre as cultivares.

FRANCIS et alii (1976a e 1976b), em um trabalho realizado no CIAT constataram, para 15 variedades de milho, correlação não significativa entre os rendimentos das cultivares em monocultivo e em consórcio, tanto com o feijão arbustivo $\left(r=0,23^{\mathrm{ns}}\right)$, como com feijão trepador $\left(r=0,46^{n s}\right)$. Este tipo de resultado indica a ocorrência de interação en tre cultivares e sistemas de cultivo para o milho. Por outro lado, RAMALHO et alii (i982) verificaram uma boa concordância entre as médias de 17 cultivares de milho em monocultivo e em consórcio com feijão ( $r=0,92$; $\left.r_{S}=0,92\right)$.

FRANCIS (1981) realizou um estudo semelhante, porém mais amplo, envolvendo resultados de diversos trabalhos. Em cada trabalho foram avaliadas em torno de 20 cultivares de milho, variando também o tipo 
de feijão de um trabalho para outro. Houve uma boa concordância entre o coeficiente de correlação simples ( $r$ ) e o coeficiente de Spearman ( $\left.r_{S}\right)$, tanto em magnitude, como em significância. Entretanto, as correlações fo ram inconsistentes para os diferentes trabalhos, variando de $0,40^{\text {ns }}$ a $0,90^{* *}$ (para $r$ ) e de $0,27^{\text {ns }}$ a $0,83^{* *}$ (para $r_{S}$ ). Estes mesmos dados foram submetidos ainda a uma anālise de variância. Houve uma tendência de o quadrado médio de interação não ser significativo para as situações onde a correlação foi alta, e significativo para as situações onde a correlação foi baixa, havendo, portanto, uma certa concordância. DAVIS (1981) também constatou uma não significância para o quadrado médio da interação entre genótipos e sistemas para o milho.

FRANCIS et alii (1976a e 1976b) e FRANCIS (1981) relataram que quando foram comparados dois sistemas de consórcio as correlações foram mais consistentes $\left(r=0,66^{* *}, r=0,68^{* *}\right.$ e $\left.r=0,93^{* *}\right)$. Entretanto, esta conclusão se baseou apenas no resultado de três trabalhos, o que dificulta sua generalização.

Este tipo de estudo tem sido feito mais intensamente para o feijão, que é a espécie dominada, e que portanto tem o comportamento mais alterado em consórcio. SANTA CECILIA (1977) observou que a cultivar Rico-23, de boa produtividade em monocultivo, mostrou-se inadequada para o consórcio, dentro de um grupo estudado. SANTA CECILIA e VIEIRA (1978) verificaram que a cultivar Manteigão Fosco não foi afetada significativamente pela variação na densidade do milho, ao contrārio de outras, o que indica que a mesma é mais tolerante à competição com o milho e, portanto, mais adapțada às condições de consōrcio. Ainda, de acordo com estes 
autores, as cultivares de hábito trepador só devem ser :itilizadas no plan tio das 'sêcas', quando as plantas de milho, jā plename desenvolvidas, servem-1hes de tutoras. BEZERRA NETO et alii (1980) constataram uma inversão de comportamento para as cultivares de feijão nos:dois sistemas, visto que duas das cultivares bem produtivas em monocultivo foram as piores em consórcio.

Os estudos de correlação realizados para feijão mostraram novamente uma inconsistência dos resultados. BUEST (1973) e SILVA (1980) verificaram a ocorrência de correlação não signi hacativa entre os dois sistemas $\left(r=0,26^{n s}\right.$ e $r=0,12^{n s}$, respectivamente $\%$, Por outro lado, FRANCIS et alii (1976b) obtiveram correlações altas ent os dois sistemas, tanto para o feijão arbustivo $(r=0,90 * *)$, como pra o feijão trepador $\left(r=0,91^{* *}\right)$. FRANCIS et alii (1978b) avaliaram intivares de feijão nos dois sistemas e em três estações. Em duas delas foram obtidas correlações significativas ( $\mathrm{r}=0,81 * *$ e $\mathrm{r}=0,90 * *)$, 3o passo que em uma delas foi obtida uma correlação não significativa $\left(r=0,41^{\mathrm{ns}}\right)$. MONTEIRO et alii (1981) constataram, para 20 cultivares de feijão, a ocorrência de correlação significativa em um local, mas não em outro. Correlações signi ficativas foram apresentadas ainda por FRANCIS et alii (1978c) para o feijão arbustivo $(r=0,51 * *$ e $r=0,91 * *)$. Em todos os casos o coeficiente de correlação de Spearman foi bastante similar. E interessante ressaltar ainda a grande variação ocorrida para a magnitude dos coeficientes de cor relação.

FRANCIS (1981) fez um apanhado dos resultados de diferentes trabalhos de feijão. Em 11 trabalhos analisados o coeficiente de 
correlação variou de $0,24^{\mathrm{ns}}$ a $0,91^{* *}$, enquanto que o coeficiente de corre lação de Spearman variou de $0,09^{\mathrm{nS}}$ a $0,88^{* *}$, havendo ainda uma boa concor dância entre ambos. Estes autores chamaram a atenção para o fato de que em alguns casos, as correlações obtidas para os mesmos tratamentos avalia dos em estações consecutivas foram inconsistentes. Estes dados foram submetidos ainda a uma análise da variăncia para testar o quadro médio da interação. Também aqui houve uma grande variação entre os trabalhos, pois enquanto que para alguns deles o quadrado médio da interação não foi significativo, para outros foi altamente significativo. Além disso, não houve uma boa concordância com os coeficientes de correlação, pois em alguns casos a correlação foi alta (entre 0,80 e 0,90 ), mas o quadrado médio da interação fọi altamente significativo. Em outros casos aconteceu o con-' trärio. Situação semelhante foi observada por RAMALHO et alii (1983), on de o coeficiente de correlação entre os dois sistemas, para 40 cultivares de feijão, foi de $0,64 * *$, mas o quadrado médio da interação foi altamente significativo. DAVIS (1981) também constatou na anālise da variância uma interação muito forte entre cultivares e sistemas de cultivo.

Para o caso do feijão também, as correlações entre dois sistemas de consórcio foram mais consistentes ( $r=0,67 *$ a $0,89 * *)$, com exceção de um caso $\left(r=0,26^{\mathrm{ns}}\right)$. Este caso corresponde à comparação entre cultivares de feijão associados com milho de porte normal e com milho de porte baixo (FRANCIS, 1981). Entretanto, esta informação também é baseada em um número restrito de trabalhos, isto é, apenas quatro.

Com base nestes resultados, torna-se difícil tirar conclusões generalizadas a respeito da interação entre cultivares e sistemas de 
cultivo. Conforme foi verificado, nem sempre há concordância entre o coe ficiente de correlação e a significância do quadrado médio da interação na análise da variância. Em vista disso, FRANCIS (1981) relata que o coe ficiente de correlação não é bem apropriado para avaliar a ocorrência de interação e que a análise da variância, com o desdobramento do quadrado médio da interação, deve ser preferível, por dar resultados mais consistentes.

A grande maioria dos autores parece concordar que o proble ma de interação é menos grave para o milho, que é a espécie dominante, do que para o feijão, que é a espécie dominada. Mesmo assim, SANTA CECILIA (1977) relata que há poucos trabalhos que procuram avaliar o melhor tipo de milho para o consórcio. Por outro lado, alguns autores afirmam que realmente existem diferenças entre as cultivares de feijão quanto à adap tabilidade ao consórcio, e que portanto não se sabe ainda quais as cultivares de feijão mais indicadas para este sistema (SANTA CECILIA e VIEIRA, 1980; SILVA, 1980; VIEIRA, 1980; VIEIRA et alii, 1982). Segundo DONALD (1963), HAMBLIN et alii (1976) e DAVIS (1981), a produtividade e a habili dade de competição ecológica são características distintas', pois uma cultivar de baixa produção mas vegetativamente vigorosa pode ter a mesma capacidade de competição que uma cultivar vegetativamente vigorosa e de alta produção. Consequentemente, cultivares promissoras para o consórcio devem ser melhoradas especificamente para este fim (FYFE e ROGERS, 1965; DIJKSTRA e de VOS, 1972).

Deste modo, fica evidente a necessidade de se obterem maio res subsídios a respeito da interação entre cultivares e sistemas de 
cultivo para a associação milho-feijão. Segundo KASS (1978), è muito importante nesse tipo de estudo, entre outras coisas, determinar o efeito de uma espécie sobre outra, para se detectar o melhor tipo de planta para o consórcio, visto que em muitos casos os resultados observados contrariam os esperados, porque as espécies são avaliadas separadamente. Para a associação milho-feijão existem alguns poucos trabalhos relacionando es te aspecto, conforme $\mathrm{jā}$ mencionado anteriormente, mas estas informações não são conclusivas. Ainda, segundo este autor, è muito importante também o conhecimento do valor monetário das duas espécies, pois devido às diferenças destes, muitas vezes um aumento na produção de uma das espécies pode não ser vantajoso se a produção da espécie associada for reduzida. Entre os tópicos sugeridos por este autor para as pesquisas futuras estão os seguintes: a) um melhor entendimento das interações envol.vidas nos sistemas de consórcio, a fim de melhorar a eficiência das pesquisas em melhoramento de plantas para este sistema; b) o desenvolvimento de uma metodologia adequada para a comparação dos sistemas consorciado e em monocultivo. 


\section{METODOLOGIA}

\subsection{Metodologia estatística}

Partindo-se de I cultivares de uma espécie A e de J cultivares de uma espécie B, tem-se IJ combinações interespecíficas possíveis destas cultivares duas a duas, que constituem um arranjo fatorial, com dois fatores. A avaliação experimental destes IJ tratamentos em consórcio e dos I + J tratamentos em monocultivo constitui um tipo de arranjo dialélico parcial de competição. O termo dialélico é utilizado devido à analogia deste arranjo com os cruzamentos dialélicos empregados em genética. Também, por analogia com estes, o arranjo dialélico é parcial pois são consideradas somente as combinações interespecíficas e não as intraespecíficas. Em caso contrário, seria denominado arranjo dialélico completo.

Para os cruzamentos dialélicos completos, em que tem-se a avaliação experimental de todos os cruzamentos possíveis para $\mathrm{N}$ variedades de uma espécie, isto é, $N(N-1) / 2$ cruzamentos, bem como a avaliação experimental das $\mathrm{N}$ variedades, GARDNER e EBERHART (1966) 
empregaram o seguinte modelo matemático para anālise:

$$
\left.Y_{j j^{\prime}}=u+1 / 2\left(v_{j}+v_{j}\right)\right)+\theta h_{j j^{\prime}}+\bar{e}_{j j^{\prime}}
$$

onde :

$Y_{j j}$ ' è a média do híbrido entre as variedades $j$ e j'e $j<j^{\prime}$; para representar as médias das variedades substitui-se $Y_{j j}$ ' por $Y_{j j}$ ou por $Y_{j}{ }_{j}{ }^{\prime}$;

$j=j^{\prime}=1,2, \ldots, N$ variedades

u é a média das variedades

$v_{j}$ ou $v_{j}$ ' é o efeito da variedade $j$ ou $j^{\prime}$;

$\mathrm{h}_{\mathrm{j}}$ ' é o efeito de heterose que aparece no híbrido entre as variedades $j$ e $j^{\prime}$;

$\theta \quad \bar{e}$ um coeficiente condicional: $\operatorname{para} j=j^{\prime}, \quad \theta=0$; $\operatorname{para} j \neq j^{\prime}, \theta=1$.

$\bar{e}_{j j}$ ' é o erro experimental associado com a média $Y_{j j}$ '

Também, de acordo com este modelo, o efeito de heterose $\left(h_{j j},\right)$ é subdividido em:

$h_{j j^{\prime}}=\bar{h}+h_{j}+h_{j}{ }^{\prime}+s_{j j^{\prime}}$

onde :

$\overline{\mathrm{h}}$ é a heterose média;

$h_{j}$ ou $h_{j}$ é a heterose de variedades, que é a contribuição da variedade $j$ ou $j$ ' para a heterose; 

$s_{j j}$ ' é a heterose específica, ou a capacidade específica de combinação entre as variedades $j$ e $j^{\prime}$.

Deste modo, o modelo completo de GARDNER e EBERHART (1966) para o dialélico completo é o seguinte:

$$
y_{j j^{\prime}}=u+1 / 2\left(v_{j}+v_{j}{ }^{\prime}\right)+\theta\left(\bar{h}+h_{j}+h_{j}{ }^{\prime}+s_{j j^{\prime}}\right)+\bar{e}_{j j^{\prime}}
$$

GARDNER (1967) apresenta as fórmulas para estimação dos parâmetros bem como das somas de quadrados, com base neste modelo.

De acordo com o modelo de GRIFFING (1956) para os cruzamentos dialélicos tem-se ainda o parâmetro da capacidade geral de combinação para cada variedade $\left(g_{j}\right.$ ou $\left.g_{j}\right)$, que, de acordo com o modelo de GARDNER e EBERHART (1966), corresponde a:

$$
g_{j}=1 / 2\left(v_{j}\right)+h_{j} \quad \text { e } \quad g_{j},=1 / 2\left(v_{j}{ }^{\prime}\right)+h_{j}
$$

Entretanto, como os dados de consórcio correspondem a um dialélico parcial, o modelo matemático precisou ser adaptado a tais condições. Também, os parâmetros do modelo foram substituídos por outros, mais representativos dos termos utilizados em consórcio. Deste modo, considerou-se o seguinte modelo matemático completo, substituindo-se $v_{j}$ e $v_{j}$, por $a_{i}$ e $b_{j} ; h_{j j}$, por $c_{i j} ; \bar{h}$ por $\bar{c} ; h_{j} e h_{j}$, por $c_{i}$ e $c_{j} ; s_{j j}$ 'por $\mathrm{d}_{\mathrm{ij}}$ e introduzindo-se o parâmetro ' $\mathrm{g}$ ' :

$$
\begin{aligned}
& z_{i j}=m+\alpha g+1 / 2\left(a_{i}+b_{j}\right)+\theta c_{i j}+\bar{e}_{i j} \\
& \text { onde: } \\
& c_{i j}=\bar{c}+c_{i}+c_{j}+d_{i j}
\end{aligned}
$$


e, portanto:

$$
z_{i j}=m+\alpha \bar{g}+1 / 2\left(a_{i}+b_{j}\right)+\theta\left(\bar{c}+c_{i}+c_{j}+d_{i j}\right)+\bar{e}_{i j}
$$

Como em consórcio a parcela é normalmente constituída por dois produtos de naturezas diferentes, utilizou-se um fator de correção pära tornā-los comparáveis. No presente trabalho optou-se pela re lação de preços entre as duas espécies nó mercado. Para tal, os dados de produção de grãos da espécie de maior valor monetário (B por exemplo) são multiplicados por um fator ' $\mathrm{P}$ ' que corrssponde à relação de preços entre as espécies $A\left(P_{A}\right)$ e $B\left(P_{B}\right)$, ou seja: $P=P_{B} / P_{A}$ Procedendo-se assim os dados experimentais ficam sendo equivalentes da espécie A e, deste modo, podem ser somados, para fornecer a produção global da parcela, que corresponde à variāvel $\mathrm{Z}_{i j}$.

As fórmulas para a estimação dos parâmetros bem como das somas de quadrados para a análise da variância, de acordo com este mode1o, foram obtidas utilizando-se o método dos quadrados mínimos, onde, por analogia com o modelo de GARDNER e EBERHART (1966), foram impostas as restrições:

$$
\begin{aligned}
& \sum_{i} a_{i}=\sum_{j} b_{j}=\sum_{i} c_{i}=\sum_{j} c_{j}=0 . \\
& \sum_{i} d_{i j}=0 \text { para cada } j ; \sum_{j} d_{i j}=0 \text { para cada } i
\end{aligned}
$$

As fórmulas estão apresentadas no ítem 'Resultados', bem como a interpretação dos componentes do modelo em termos de : corisórcio. Entretanto, é importante ressaltar que esta metodologia foi desenvolvida visando a utilização tanto em dialélicos parciais de competição como em dialélicos de cruzamento. Para o caso de cruzamentos dialélicos elas já 
foram utilizadas em outro trabalho e, deste modo, foram relatadas no Relatório Científico do Departamento de Genética (MIRANDA FILHO e GERALDI, 1980; GERALDI e MIRANDA FILHO, 1981). O que muda, evidentemente, de uma situação para outra é a interpretação dos componentes do modelo.

\subsection{Execução experimental}

0 material utilizado no presente trabalho compreende seis cultivares de feijão e seis cultivares de milho, relacionadas a seguir:

Cultivares de milho Cultivares de feijão $\mathrm{Ag}-401$

Goiano precoce

Br-105 Manteigão fosco 11

$\mathrm{C}-111$

Carioca

Piranão

Rico 23

$\mathrm{Br}-126$

Costa Rica

$\mathrm{Br}-104$

S. Cuva 168

As cultivares de milho abrangem diferentes portes e graus de variabilidade genética. Tem-se assim um híbrido comercial de planta baixa (híbrido da Agroceres: Ag-401), um híbrido comercial de planta alta (híbrido da Cargill: C-111), variedades de porte baixo (Br-105 e Piranão), uma variedade de porte médio $(B r-104)$ e uma variedade de porte alto $(\mathrm{Br}-126)$. O porte mais baixo da variedade $\mathrm{Br}-105$ é devido a poligenes, enquanto que o da variedade Piranão é devido a um gene braquítico 
(gene recessivo $\mathrm{br}_{2}$ ). E importante ressaltar ainda que as cultivares Br-105, $\mathrm{Br}-126$ e Br-104 correspondem respectivamente às variedades de mi 1ho Suwan, Composto Dentado ou ESALQ-VD2 e Amarillo Dentado, submetidas a seleção no Centro Nacional de Pesquisa de Milho e Sorgo (EMBRAPA) em Sete Lagoas (MG).

As cultivares de feijão abrangem os seguintes hábitos de crescimento ou tipos: tipo I (Goiano precoce e Manteigão fosco 11), tipo II (Rico 23), e tipo III (Carioca, Costa Rica e Seleção Cuva 168 ou S. Cuva 168). O tipo I corresponde a cultivares de crescimento determinado (arbustivo), o tipo II corresponde a cultivares de crescimento indeterminado e porte ereto e o tipo III corresponde a cultivares de crescimento indeterminado e häbito semi-trepador. A cultivar Goiano precoce também se diferencia das demais pela precocidade, florescendo com aproximadamente 35 a 40 dias. Não foram incluídas cultivares de feijão do tipo IV (crescimento indeterminado e hābito trepador), pois um dos objetivos do presente trabalho é a comparação das cultivares de feijão em consórcio e em monocultivo e o tipo IV preeisa ser tutorado em monocultivo. Além disso, em consórcio este tipo de cultivar é mais apropriado ao plan tio das 'secas', onde o milho jā plenamente desenvolvido serve-1he de tụ tor (SANTA CECILIA e VIEIRA, 1978).

Para o feijão, os tratamentos serão denominados de 'cultivar', que é a denominação mais comumente utilizada para esta espécie. Estes também serão comumente denominados pelo tipo (I, II ou III). Para o milho, a fim de se fazer uma distinção quanto às diferenças genéticas, será utilizada a denominação 'variedade' para as variedades de polinização 
livre e 'híbrido' para os híbridos comerciais.

Estes tratamentos (seis de milho e seis de feijão) permi tem 36 combinações diferentes em consōrcio. Estes 36 tratamentos foram ensaiados em um delineamento em látice simples duplicado $6 \times 6$, o que corresponde a quatro repetições. A avaliação das cultivares de milho e fei jão em monocultura foi feita separadamente para cada espécie, utilizando-se um delineamento em blocos casualizados, com quatro repetições.

Foram realizados três ensaios, sendo dois deles no ano agrícola de 1979/80 (em Sete Lagoas, MG e em Goiânia, G0) e o outro no ano agrícola de 1980/81 (em Sete Lagoas, MG). A adubação foi feita de acordo com a fórmula 60-60-30 de $\mathrm{N}, \mathrm{P}_{2} \mathrm{O}_{5}$ e $\mathrm{K}_{2} \mathrm{O}$, respectivamente, sendo que o nitrogênio foi aplicado no plantio (2/3) e logo após o desbaste em ambas as espécies (1/3). Entretanto, devido a problemas de ordem climātica e de solo, os dados de dois dos ensaios apresentaram uma precisão experimental muito baixa e não puderam ser utilizados. Consequentemente, no presente trabalho foi utilizado apenas o ensaio realizado em 1979/80, em Sete Lagoas, - MG.

Para os tratamentos em consórcio foram utilizadas parce las compostas de quatro linhas de seis metros de comprimento, distanciadas de um metro. Nestas linhas foram semeadas simultaneamente as duas espécies. 0 milho foi semeado em covas distanciadas de $40 \mathrm{~cm}$, ao passo que o feijão foi semeado entre as covas de milho e distanciadas destas por $10 \mathrm{~cm}$. Deste modo, entre duas covas de milho havia duas de feijão, distanciadas de $20 \mathrm{~cm}$. Para ambas as espécies foram utilizadas três sementes por cova, deixando-se duas plantas por cova após o desbaste, o 
que corresponde a 50.000 plantas por hectare para o milho e a 100.000 plantas por hectare para o feijão. Para a monocultịra do milho utilizou-se uma parcela semelhante, ao passo que para a monocultura do feijão o espaçamento entre linhas foi reduzido para $50 \mathrm{~cm}$, o que corresponde a 200.000 plantas por hectare.

Na tomada de dados das parcelas em consórcio e do milho em monocultura foram utilizadas apenas as duas linhas centrais, ignorando-se $50 \mathrm{~cm}$ em cada extremidade. Portanto, a parcela útil ficou constituída por duas linhas de cinco metros, ou seja, 50 plantas de milho e 100 de feijão, considerando-se um 'stand' ideal. Para a monocultura do feijão considerou-se uma parcela com a mesma área, correspondendo, portanto, a 200 plantas, no 'stand' ideal.

Para ambas as espécies, foram tomados os dados de peso total de grãos, 'stand' e umidade em todas as parcelas. Entretanto, de acordo com as recomendações de RAMALHO et alii (1983), não foi feito cor reção de 'stand' para nenhuma das espécies. Quanto à umidade, de acordo com as recomendações da literatura, a produção de grãos de feijão foi corrigida para $13,0 \%$ e a de milho para $15,5 \%$.

\subsection{Anāilise estatīstica dos dados}

Os dados de produção de grãos das parcelas em consórcio foram submetidos à análise da variância, de acordo com o delineamento em látice, separadamente para cada espécie. Como a eficiência do látice foi muito baixa para ambas as espécies, optou-se pela análise segundo o delineamento em blocos ao acaso. Os dados dos experimentos em monocultura 
também foram analisados segundo o delineamento em blocos ao acaso.

A seguir os dados foram submetidos a uma análise conforme a metodologia sugerida no presente trabalho. De acordo com esta, ini cialmente foi realizada uma análise de variância separadamente para cada. espécie, para os tratamentos em consórcio, de acordo com o esquema fatorial apresentado a seguir, considerando-se o modelo fixo:

\begin{tabular}{lccc}
\hline F.V. & G.L. & Q.M. & F \\
\hline Repetições & $\mathrm{r}-1$ & - & - \\
Tratamentos & $\mathrm{IJ}-1$ & $\mathrm{Q}_{\mathrm{t}}$ & $\mathrm{Q}_{\mathrm{t}} / \mathrm{Q}_{\mathrm{r}}$ \\
Cult.milho (M) & $\mathrm{I}-1$ & $\mathrm{Q}_{\mathrm{m}}$ & $\mathrm{Q}_{\mathrm{m}} / \mathrm{Q}_{\mathrm{r}}$ \\
Cult.feijão (F) & $\mathrm{J}-1$ & $\mathrm{Q}_{\mathrm{f}}$ & $\mathrm{Q}_{\mathrm{f}} / \mathrm{Q}_{\mathrm{r}}$ \\
Mx F & $(\mathrm{I}-1)(\mathrm{J}-1)$ & $\mathrm{Q}_{\mathrm{mf}}$ & $\mathrm{Q}_{\mathrm{mf}} / \mathrm{Q}_{\mathrm{r}}$ \\
Resíduo & $(\mathrm{r}-1)(\mathrm{IJ}-1)$ & $\mathrm{Q}_{\mathrm{r}}$ & \\
\hline
\end{tabular}

Em seguida foi feita uma análise conjunta para os dados das duas espécies, isto é, transformando-se os dados em equivalentes de milho, em função da relação de preços entre as duas.espécies. Para tal foi feito um levantamento dos preços do milho $\left(\mathrm{P}_{M}\right)$ e do feijão $\left(P_{F}\right)$ no mercado, envolvendo todos os Estados do Brasil, para os últimos cinco anos disponíveis (1977, a 1981), dados estes fornecidos pela Fundação Getúlio Vargas. Para 117 dados analisados, o valor de ' $\mathrm{P}$ ' $\left(\mathrm{P}=\mathrm{P}_{\mathrm{F}} / \mathrm{P}_{\mathrm{M}}\right)$ variou de 2,29 a 7,91, com uma média de 4,57, sendo que aproximadamente 90\% dos dados se encontravam no intervalo entre 2,5 e 7,5. Deste modo, neste trabalho foram utilizados três valores de ' $\mathrm{p}$ ', isto é, 3,5 e 7 , 
valores estes representativos dos extremos e da média da relação de preços entre as duas espécies. Com base nestes três valores de 'P', os dados experimentais foram arranjados em uma tabela dialélica parcial. 0 procedimento de análise desta tabela está apresentado no ítem 'Resultados'.

Com o objetivo de comparar a metodologia do presente tra balho com metodologias convencionais foram realizadas outras análises. Realizou-se uma análise de variância com a média das cultivares nos dois sistemas, separadamente para cada espécie, para testar o quadrado médio da interação entre os dois sistemas: consórcio (c) e monocultivo (m). Pa ra o caso do feijão, onde a interação foi significativa, foi feito um estudo mais detalhado da mesma, através do desdobramento do quadrado médio da interação pelo processo de ROBERTSON (1959), que devidamente adap tado às condições deste trabalho corresponde a:

$$
\mathrm{QM}_{\mathrm{cxm}}=\mathrm{A}+\mathrm{B}
$$

onde:

$$
\begin{aligned}
& A=1 / 2\left(\sqrt{Q_{c}}-\sqrt{Q_{m}}\right)^{2} e \\
& B=\sqrt{Q_{c} \cdot Q_{m}}(1-r \bar{c}, \bar{m})
\end{aligned}
$$

Nesta fórmula, $\mathrm{QM}_{\mathrm{cxm}}$ representa o quadrado médio da in teração entre os dois sistemas, $\mathrm{QM}_{c}$ e $\mathrm{QM}_{\mathrm{m}}$ representam, respectivamente, os quadrados médios para tratamentos em consórcio e em monocultivo e $\mathrm{r}_{\mathrm{c} ; \mathrm{m}}$. representa a correlação entre as médias dos tratamentos nos dois sistemas. A componente A está relacionada com a diferença na variação 
entre os tratamentos nos dois sistemas, enquanto que a componente B está relacionada com a falta de correlação entre as médias dos tratamentos nos dois sistemas. Pode-se assim determinar a contribuição relativa das duas componentes para o quadrado médio da interação.

Com a finalidade de se estudar a interação para o caso do feijão, realizou-se também uma anālise dos dados de acordo com o modelo multiplicativo de VENCOVSKY e GERALDI (1977), ou se$j a: Y_{i j}=\alpha_{i}\left(1+\beta_{j}\right)+\bar{e}_{i j}$, onde $Y_{i j}$ representa a média do tratamento ' $i$ ' no ambiente ' $j$ ', $\alpha_{i}$ representa o efeito do tratamento ' $i$ ', $\beta_{j}$ representa o efeito do ambiente ' $j$ ' e $\bar{e}_{i j}$ representa o erro experimental associado à média $Y_{i j}$. A análise com este modelo permite calcular a proporção do quadrado médio da interação obtido na anālise da variância com o modelo linear que deve-se ao efeito multiplicativo de um ambiente (sistema, no caso) sobre o outro.

Foram calculados aịnda os coeficientes de correlação linear simples ( $r$ ) e os coeficientes de correlação de posição de Spearman $\left(x_{S}\right)$ bem como os İndices 'RAE' (Razão da Ārea Equivalente) para as 36 com binações em consōrcio, de acordo com o processo relatado por WILLEY e OSIRU (1972):

$$
\operatorname{RAE}=\frac{\overline{\mathrm{C}}_{\mathrm{m}}}{\overline{\mathrm{M}}_{\mathrm{m}}}+\frac{\overline{\mathrm{C}}_{\mathrm{f}}}{\overline{\bar{M}}_{\mathrm{f}}}
$$

onde: $\bar{C}_{m}, \bar{M}_{m}, \bar{C}_{f}$ e $\bar{M}_{f}$ significam, respectivamente, média da produção de milho em consórcio, média da produção de milho em monocultivo, média da produção de feijão em consōrcio e média da produção de feijão em monocultivo. 
4. RESULTADOS

\subsection{Metodologia Estatística}

A tabẹla dialélica de médias, referente a um arranjo dia lélico parcial pode, genericamente, ser representada por:

\begin{tabular}{|c|c|c|c|c|c|c|c|}
\hline & & & Espéc & e B & & & \\
\hline & $1^{\prime}$ & $2^{\prime}$ & $3^{\prime}$ & $\ldots$ & $\mathrm{J}$ & Total & Monoc. \\
\hline 1 & $Z_{11}$ & $\mathrm{z}_{12}$ ' & $Z_{13}$ & & $\mathrm{z}_{1 \mathrm{~J}}$ & $\mathrm{z}_{1}$ & $z_{11}$ \\
\hline 2 & $Z_{21}$ & $\mathrm{Z}_{22}$ & $\mathrm{Z}_{23^{\prime}}$ & & $\mathrm{z}_{2 \mathrm{~J}}$ & $\mathrm{Z}_{2}$ & $\mathrm{Z}_{22}$ \\
\hline 3 & $Z_{31}$ & $\mathrm{Z}_{32}$ & $\mathrm{Z}_{33^{\prime}}$ & & $\mathrm{z}_{3 \mathrm{~J}}$ & $\mathrm{Z}_{3}$ & $z_{33}$ \\
\hline & & & & & & & \\
\hline$\dot{0}$ & & & & & & & \\
\hline • & & & & & & & \\
\hline I & $\mathrm{Z}_{\mathrm{II}}$ & $\mathrm{Z}_{\mathrm{I} 2}{ }^{\prime}$ & $\mathrm{Z}_{\mathrm{I} 3^{\prime}}$ & & $\mathrm{Z}_{\mathrm{IJ}}$ & $\mathrm{Z}_{\mathrm{I}}$ & $Z_{I I}$ \\
\hline Total & ${ }^{2} .1^{\prime}$ & $Z^{2} 2^{\prime}$ & $2.3^{\prime}$ & & $\mathrm{Z} . \mathrm{J}$ & $\mathrm{Z}_{\mathrm{C}}$ & $\mathrm{Z}_{\mathrm{A}}$ \\
\hline Monoc. & $z_{1}{ }^{\prime}{ }^{\prime}$ & $z_{2} 2^{\prime}$ & $z_{3} 3^{\prime}$ & & $\mathrm{z}_{\mathrm{JJ}}$. & $\mathrm{z}_{\mathrm{B}}$ & $\mathrm{Z}_{\mathrm{T}}$ \\
\hline
\end{tabular}


onde tem-se:

$\mathrm{i}=1,2,3, \ldots$, I cultivares para a espécie A;

j $\quad=1^{\prime}, 2^{\prime}, 3^{\prime}, \ldots, \mathrm{J}$ cultivares para a espécie B;

$Z_{i j}$ : média do tratamento envolvendo as cultivares 'i'e 'j', tal que $Z_{i j}=X_{i j}+\mathrm{pY}_{i j}$, onde $X_{i j}$ é a média do carater para a espécie $A, Y_{i j}$ é a média do carater para a espécie B e 'p' é a relação dos preços entre as duas espécies;

$Z_{i i}$ : média da cultivar ' $i$ ' em monocultivo $\left(z_{i j}=x_{i i}\right)$;

$\mathrm{Z}_{\mathrm{j} j}$ : média da cultivar ' $\mathrm{j}$ ' em monocultivo $\left(\mathrm{Z}_{\mathrm{j}} \mathrm{j}=\mathrm{pY}_{\mathrm{j}} \mathrm{j}\right)$;

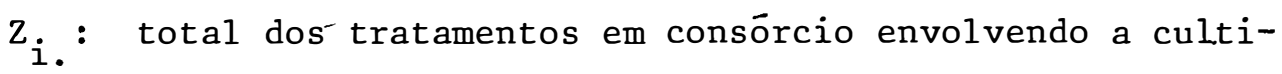
var ' $i$ ';

$Z_{. j}:$ total dos tratamentos em consórcio envolvendo a culti$\operatorname{var} ' \mathrm{j}$ ';

$\mathrm{Z}_{\mathrm{A}}$ : total das cultivares da espécie A em monocultivo;

$\mathrm{Z}_{\mathrm{B}}$ : total das cultivares da espécie $\mathrm{B}$ em monocultivo;

$\mathrm{Z}_{\mathrm{C}}$ : total dos tratamentos em consórcio: $\mathrm{Z}_{\mathrm{C}}=\mathrm{Z}$..

$\mathrm{Z}_{\mathrm{T}}$ : total geral, isto $\overline{\mathrm{e}}, \mathrm{Z}_{\mathrm{A}}+\mathrm{Z}_{\mathrm{B}}+\mathrm{Z}_{\mathrm{C}}$.

. $\quad 0$ modelo matemático utilizado foi o seguinte, excluindo

o erro experimental:

$$
z_{i j}=m+\alpha g+1 / 2\left(a_{i}+b_{j}\right)+\theta c_{i . j}+\bar{e}_{i j}
$$

onde:

$$
c_{i j}=\bar{c}+c_{i}+c_{j}+d_{i j}
$$

e portanto:

$$
z_{i j}=m+\alpha g+1 / 2\left(a_{i}+b_{j}\right)+\theta\left(\bar{c}+c_{i}+c_{j}+d_{i j}\right)+\bar{e}_{i j}
$$


Neste modelo tem-se:

$\alpha$ e $\theta$ : fatores condicionais, tal que: $\alpha=0,+1$ e -1 , respectivamente para $Z_{i j}, Z_{i i}$ e $Z_{j j}$ e $\theta=+1,0$ e 0 , respectivamente para $Z_{i j}, Z_{i j}$ e $Z_{j j}$. Para representar $Z_{j i .}$ e $Z_{j j}$ substitui-se $b_{j}$ por $a_{j}$ e $a_{i}$ por $b_{j}$, respectivamente;

m : média das cultivares da espécie A e B em monocultivo;

g : medida da diferença entre as médias dos dois grupos: A e B;

$a_{j}$. efeito da cultivar 'i' da espécie A;

$\mathrm{b}_{j} \quad$ : efeito da cultivar ' $j$ ' da espécie B;

$c_{i j} \quad$ : efeito geral do consórcio ou vantagem do consórcio frente ao monocultivo, em relação à média das cultivares correspondentes em monocultivo, tal que: $c_{i j}=Z_{i j}-1 / 2\left(z_{i j}+Z_{j j}\right)$. O fator $1 / 2$ corresponde a uma correção para o fator área, admitindo-se que se as duas espécies fossem plantadas em monocultivo, utilizar-se-ia o dobro da ārea;

c $\quad$ : efeito médio de consórcio;

$c_{i} \quad$ : efeito de consórcio da cultivar ' $i$ ' da espécie A, ou con tribuição para o efeito geral de consórcio conferido pela cultivar ' $i$ ' nas combinações em que ela participa;

$c_{j} \quad$ : efeito de consórcio da cultivar ' $j$ ' da espécie B, ou con tribuição para o efeito geral de consórcio conferido pela cultivar ' $j$ ' nas combinações em que ela participa;

$\mathrm{d}_{i j} \quad$ : efeito específico de consórcio da combinação entre as cultivares 'i' e 'j', ou contribuição para o efeito geral de consōrcio conferido pela combinação entre as 
cultivares 'i' e 'j'. Corresponde à çapacidade específi ça de competição;

$\bar{e}_{i j} \quad$ : erro experimental associado com a média $z_{i j}$.

Para a estimação dos parâmetros (componentes de médias) foram deduzidas e obtidas as seguintes expressões:

$$
\begin{aligned}
& \hat{\mathrm{m}}=1 / 2\left(\overline{\mathrm{Z}}_{\mathrm{A}}+\overline{\mathrm{Z}}_{\mathrm{B}}\right) \\
& \widehat{\mathrm{g}}=1 / 2\left(\overline{\mathrm{Z}}_{\mathrm{A}}-\overline{\mathrm{Z}}_{\mathrm{B}}\right) \\
& \hat{a}_{i}=-z_{i i}-\bar{z}_{A} \\
& \widehat{b}_{j}=z_{j j}-\bar{z}_{B} \\
& \overline{\bar{c}}=\overline{\mathrm{Z}}_{C}-\overline{\mathrm{m}} \\
& \bar{c}_{i}=\bar{z}_{i}-\bar{z}_{C}+1 / 2\left(\bar{z}_{A}-z_{i i}\right) \\
& \widehat{c}_{j}=\bar{Z}_{\cdot j}-\bar{z}_{C}+1 / 2\left(\bar{z}_{B}-Z_{j j}\right) \\
& \hat{\mathrm{d}}_{i j}=z_{i j}+\bar{z}_{C}-\bar{z}_{i \cdot}-\bar{z}_{\cdot j}
\end{aligned}
$$

Além destes parâmetros foi incluido o da capacidade geral de competição (cgc) para cada cultivar, que também por analogia com os cruzamentos dialélicos parciais (VENCOVSKY, 1978) corresponde a:

$$
\begin{aligned}
& c \widehat{c g c}_{i}=\bar{z}_{i}-\bar{z}_{c} \\
& c \hat{g}_{j}=\bar{z}_{\cdot j}-\bar{z}_{c}
\end{aligned}
$$

A capacidade geral de competição $\left(\operatorname{cgc}_{i}\right.$ ou $\left.\operatorname{cgc}_{j}\right)$ corresponde ao efeito đa cultivar ' $i$ ' ou ' $j$ ' em consörcio. De maneira semelhante ao modelo dos cruzamentos dialélicos de GARDNER e EBERHART (1966) foi constatada a seguinte correspondência: 


$$
\operatorname{cgc}_{i}=(1 / 2) a_{i}+c_{i}
$$

e

$$
c g c_{j}=(1 / 2) b_{j}+c_{j}
$$

Para a estimação da variância $\left(s^{2}\right)$ associada às estimativas (componentes de médias) foram deduzidas e obtidas as seguintes expressões:

$$
\begin{aligned}
& s^{2}(\widehat{m})=\frac{I+J}{4 I J} s^{2} \\
& s^{2}(\widehat{g})=\frac{I+J}{4 I J} s^{2} \\
& s^{2}\left(\hat{a}_{i}\right)=\frac{I-1}{I} s^{2} \\
& s^{2}\left(\hat{b}_{j}\right)=\frac{J-1}{J} s^{2} \\
& s^{2}\left(\hat{c}_{i j}\right)=\frac{3}{2} s^{2} \\
& s^{2}(\hat{\bar{c}})=\frac{4+I+J}{4 I J} s^{2} \\
& s^{2}\left(\hat{c}_{i}\right)=\frac{(I-1)(4+J)}{4 I J} s^{2} \\
& s^{2}\left(\widehat{c}_{j}\right)=\frac{(J-1)(4+I)}{4 I J} s^{2} \\
& s^{2}\left(\hat{\mathrm{d}}_{i j}\right)=\frac{(I-1)(J-1)}{I J} s^{2} \\
& s^{2}\left(c \hat{g} c_{i}\right)=\frac{(I-1)}{I J} s^{2} \\
& s^{2}\left(c \hat{g} c_{j}\right)=\frac{(J-1)}{I J} s^{2}
\end{aligned}
$$

onde $s^{2}$ é o quadrado médio residual da análise de variância da tabela dialélica (anālise com médias). 
Para o cálculo das somás de quadrados correspondentes foram deduzidas e obtidas as seguintes expressões:

SQ Grupos $=\frac{I J}{\bar{N}(4+I+J)}\left[(I+2) \bar{Z}_{A}-(J+2) \bar{Z}_{B}+(J-I) \bar{Z}_{C}\right]^{2}$

sQ Cult.esp. $A=\frac{1}{4+J}\left[\sum_{i}\left(2 z_{i i}+z_{i \cdot}\right)^{2}-(1 / I)\left(2 Z_{A}+Z_{C}\right)^{2}\right]$

SQ Cult.esp.B $=\frac{1}{4+I}\left[\sum_{j}\left(2 Z_{j j}+Z_{\cdot j}\right)^{2}-(l / J)\left(2 Z_{B}+Z_{C}\right)^{2}\right]$

$\begin{aligned} & \text { SQ Ef. geral } \\ & \text { de consorcio }\end{aligned}=\sum Z_{i j}^{2}-\frac{1}{4+J} \sum_{i}\left(2 Z_{i i}+z_{i \cdot}\right)^{2}-\frac{1}{4+I} \sum_{j}\left(2 z_{j j}+Z_{\cdot j}\right)^{2}+$

$$
\begin{aligned}
& -\frac{1}{4+J} Z_{A}^{2}-\frac{1}{4+I} Z_{B}^{2}+\frac{1}{(4+I)(4+J)} Z_{C}^{2}+ \\
& +\frac{1}{(4+I)(4+J)(4+I+J)}\left[(4+I) Z_{A}+(4+J) Z_{B}+2 Z_{C}\right]^{2}
\end{aligned}
$$

$\begin{aligned} & \text { SQ Ef. médio } \\ & \text { de consórcio }\end{aligned}=\frac{I J}{4+I+J}\left[\bar{Z}_{A}+\bar{Z}_{B}-2 \bar{Z}_{C}\right]^{2}$

SQ Ef. cons. $=\frac{J}{4+J} \sum_{i}\left[z_{i i}-\bar{Z}_{A}-2\left(\bar{Z}_{i \cdot}-\bar{Z}_{C}\right)\right]^{2}$
cult. esp. $A$

$\begin{aligned} & \text { SQ Ef. cons. } \\ & \text { cult. esp. } B\end{aligned}=\frac{I}{4+I} \sum_{j}\left[z_{j j}-\bar{Z}_{B}-2\left(\bar{Z}_{\cdot j}-\bar{Z}_{C}\right)\right]^{2}$

$\underset{\text { fico de cons. }}{\text { SQ Ef. especí }}=\sum_{i \neq j} z_{i j}^{2}-\frac{1}{J} \sum_{i} z_{i \cdot}^{2}-\frac{1}{I} \sum_{j} z_{\cdot j}^{2}+\frac{1}{I J} z_{C}^{2}$ 
onde:

$$
\begin{aligned}
& \mathrm{N}=\text { nümero total de tratamentos }=\mathrm{I}+\mathrm{J}+\mathrm{IJ} ; \\
& \overline{\mathrm{Z}}_{\mathrm{A}}=\mathrm{Z}_{\mathrm{A}} / \mathrm{I} ; \overline{\mathrm{Z}}_{\mathrm{B}}=\mathrm{Z}_{\mathrm{B}} / \mathrm{J} ; \overline{\mathrm{Z}}_{\mathrm{C}}=\mathrm{Z}_{\mathrm{C}} / \mathrm{IJ} ; \overline{\mathrm{Z}}_{\mathrm{i} .}=\mathrm{Z}_{\mathrm{i} \cdot} / \mathrm{J} ; \overline{\mathrm{Z}}_{\cdot j}=\mathrm{Z}_{\cdot \mathrm{j}} / \mathrm{I}
\end{aligned}
$$

Deste modo, o quadro da análise da variância da tabela dialélica parcial de médias ficou da seguinte forma, considerando-se o

\begin{tabular}{|c|c|c|c|}
\hline F.V. & G.L. & Q.M. & F \\
\hline Trat amentos & $\mathrm{N}-1$ & $Q_{t}$ & $Q_{t} / Q_{r}$ \\
\hline Dif. grupos & 1 & $Q_{g}$ & $Q_{g} / Q_{r}$ \\
\hline Cult. espécie A & $I-1$ & $Q_{\underline{a}}$ & $Q_{a} / Q_{r}$ \\
\hline Cult. espécie B & $\mathrm{J}-1$ & $Q_{\mathrm{b}}$ & $Q_{b} / Q_{r}$ \\
\hline Efeitos de consórcio: & - & & \\
\hline Geral & IJ & $Q_{c g}$ & $Q_{c g} / Q_{r}$ \\
\hline Médio & $i$ & $Q_{\bar{c}}$ & $Q-/ Q_{r}$ \\
\hline Cult. espécie A & $I-1$ & $Q_{c a}$ & $Q_{c: a} / Q_{r}$ \\
\hline Cult. espécie B & $\mathrm{J}-1$ & $Q_{c b}$ & $Q_{c b} / Q_{r}$ \\
\hline Especīfico & $(I-1)(J-1)$ & $Q_{c e}$ & $Q_{c e} Q_{r}$ \\
\hline Resíduo médio & $(N-3)(r-1)$ & $Q_{r}$ & \\
\hline
\end{tabular}
modelo fixo:

Nesta anālise de variância, o resíduo médio é obtido pela junção dos resíduos da análise das parcelas em consórcio com (IJ-1)( $r-1)$ graus de liberdade, da anālise de milho em monocultivo $\therefore$ com $(I-1)(r-1)$ graus de liberdade e da anālise do feijão em monocultivo com $(J-1)(r-1)$ 
graus de liberdade. Para se adaptar à anālise de uma tabela de médias, este resíduo deve ainda ser dividido pelo número de repetições ( $r$ ). Evidentemente, para se fazer esta junção é necessário que ocorra homogeneidade dos resíduos. Em caso contrārio, torna-se necessārio utilizar procedimentos estatísticos para se contornar o problema.

\subsection{Anālise estatīstica dos dados experimentais}

\subsubsection{Análise geral dos dados}

As médias obtidas para os 36 tratamentos em consórcio e para os 12 tratamentos em monocultivo, para as quatro repetições, achamse apresentados nas Tabelas 1 e 2, respectivamente, em toneladas por hec tare.

Na Tabela 3 estão apresentadas as análises de variância, separadamente por espécie e por sistema de cultivo, de acordo com o delineamento em blocos ao acaso. Observa-se que, com exceção do milho em monocultivo, o efeito de tratamentos foi altamente significativo para to dos os outros casos, isto é, feijão em monocultivo, feijão em consórcio e milho em consórcio. Nesta tabela estão apresentados ainda os coeficientes de variação experimental e a eficiência dos 1átices. A eficiência obtida para os látices foi baixa, tanto para o milho (100,3\%), quanto para o feijão $(104,8 \%)$, o que possibilitou a realização da análise da variância segundo o delineamento em blocos casualizados. Quanto aos coe ficientes de variação experimental, para o milho eles estão em torno da média obtida para as nossas condições $(18,8 \%$ e $17,2 \%$, respectivamente, 
para o consórcio e monocultivo), e, deste modo, pode-se considerar a pre cisão experimental como satisfatória. O mesmo ocorre para o feijão em monocultivo, cujo coeficiente foi de $20,1 \%$. Por outro lado, para o feijão em consórcio este coeficiente foi mais alto $(28,3 \%)$. Tem-se que con siderar, porém, que em tais condições o feijão sofreu em média uma redução de $62,7 \%$ na produção, o que evidentemente contribuiu para o aumento do coeficiente de variação.

4.2.2. Anālise dos dados de acordo com a metodologia proposta
4.2.2.1. Avaliação das médias dos tratamentos separadamen te para cada espécie

Nas Tabelas 4 e 5 estão apresentadas as médias de produção de grãos obtidos em consórcio e em monocultivo, para o milho e feijão, respectivamente, arranjadas em uma tabela dialélica. Para o milho ocorreu uma redução média em consórcio de $11,3 \%$, ao passo que para o fei jão ocorreu uma redução média de $62,7 \%$.

Na Tabela 6 estão apresentadas as análises de variância das tabelas dialélicas, separadas para cada espécie, com o desdobramento de acordo com o esquema fatorial para os tratamentos em consórcio, isto é, variação devida ao efeito da espécie principal, variação devida ao efeito da espécie associada e variação devida ao efeito específico entre as espécies (interação entre as duas espécies). Deste modo, pode ser vê rificado que para o milho houve significância para as três fontes, isto é, ocorreu variação entre as cultivares de milho em consórcio, ocorreu variação para o efeito das cultivares de feijão sobre o milho e ocorreu 
variação também para um efeito específico das combinações de milho e fei jão. Para o feijão a situação é um pouco diferente, pois somente a fonte 'cultivares de feijão' foi significativa para o nível convencional de pro babilidade (95\%). Deste modo, ocorreu variação entre as cultivares de fei jão em consórcio, mas a variação devida ao efeito de cultivares de milho sobre o rendimento do feijão não foi tão evidente $(0,10<\mathrm{P}<0,25)$ e também não ocorreu variação para combinações específicas. Tal fato pode ter sido uma consequência da menor precisão experimental para o feijão consorciado.

As cultivares de feijão mais produtivas em consórcio foram: S. Cuva 168, Rico 23 e Carioca, todas de crescimento indeterminado (tipos II e III). As cultivares menos produtivas foram: Goiano precoce e Manteigão fosco, isto é, as cultivares de tipo I (Tabela 5). Quanto à influência destas na produtividade do milho, observa-se alguns aspectos interessantes (Tabela 4): cultivares de feijão mais produtivas como S. Cuva 168 foram as que mais prejudicaram a produção do milho, ao contrário de cultivares de baixa produção, como Goiano Precoce, que causaram um menor prejuizo na produção do milho, evidenciando assim a ocorrência de competição entre o milho e o feijão. Entretanto, este não foi um com portamento padrão, pois a cultivar Carioca, de boa produção em consórcio, foi uma das que menos prejudicaram o milho, indicando que esta cultivar deve apresentar características que a tornam mais adaptadas ao cul tivo em consórcio. Fato semelhante ocorreu com a cultivar Rico 23. Por outro lado, uma situação inversa ocorreu com a cultivar Manteigão fosco, que foi a cultivar menos produtiva em consórcio e uma das que mais 
prejudicaram o milho, indicando que esta não deve ser adequada para o cultivo em consórcio. Fato semelhante ocorreu com a cultivar Costa Rica. Entretanto, tem-se que considerar que a cultivar Manteigão fosco foi bem atacada por doenças (transmitida provavelmente por sementes), o que dificulta uma generalização do seu comportamento.

As cultivares de milho mais produtivas em consórcio ( $\mathrm{Ta}-$ bela 4) foram os dois híbridos comerciais ( $\mathrm{Ag}-401$ e $\mathrm{C}-111$ ), enquanto que as menos produtivas foram as variedades Piranão e $\mathrm{Br}-105$. Quanto à influência das cultivares de milho na produtividade do feijão (Tabela 5), constata-se que os híbridos comerciais Ag-401 e C-111 foram os que causaram maior redução na produção do feijão, enquanto que a variedade Br105 foi a que causou menor redução. A variedade de milho menos produtiva, isto é, Piranão, foi mais ou menos intermediāria quanto a este fator. Portanto, estes dados indicam que, no geral, as cultivares de miTho mais produtivas prejudicaram mais o feijão e vice-versa.

Tem-se que considerar ainda a ocorrência de combinações específicas favoráveis para os dados de produção de milho (Tabela 4). Co mo exemplos, o híbrido Ag-401 foi mais produtivo justamente em combinação com a cultivar de feijão S. Cuva 168, enquanto que a variedade $\mathrm{Br}-$ 126 foi mais produtiva em combinação com a cultivar Manteigão fosco. Por outro lado, esta mesma variedade de milho e o híbrido C-11l tiveram a mais baixa produção em combinação com a cultivar de feijão Carioca. 
4.2.2.2. Avaliação das médias dos tratamentos conjuntamente para as duas espécies e dos efeitos gerais de consōrcio

As médias de produção de grãos conjuntas para as duas espécies em consórcio, e em equivalentes de milho, acham-se apresentadas nas Tabelas $7(\operatorname{para} \mathrm{p}=3), 8(\operatorname{para} \mathrm{p}=5)$ e $9(\operatorname{para} \mathrm{p}=7)$, onde ' $\mathrm{p}$ ' $\overline{\mathrm{e}}$ a relação de preços. A média de produção de grãos variou de 4,081 t/ha a $8,480 \mathrm{t} / \mathrm{ha}(\mathrm{p}=3), 4,578 \mathrm{t} / \mathrm{ha}$ a $9,495 \mathrm{t} / \mathrm{ha}(\mathrm{p}=5)$ e $5,073 \mathrm{t} / \mathrm{ha}$ a $10,510 \mathrm{t} / \mathrm{ha}$ $(p=7)$, havendo, portanto, uma discriminação muito grande entre os tratamentos, para cada situação. Pode-se verificar tambēm que houve pouca mudança na classificação dos tratamentos com a variação dos valores de ' $\mathrm{P}$ ', conforme indicam os coeficientes de correlação de Spearman: $r_{S(3,5)}=0,951 ; r_{S(3,7)}=0,868$ e $r_{S(5,7)}=0,962$, onde $r_{S(3,5)}$ significa o coeficiente de correlação de Spearman para a produção de grãos, entre os valores, de ' $\mathrm{p}$ ' 3 e 5, e assim por diante. Assim, por exemplo, as seis melhores combinações foram as seguintes, nos três casos: 1,6'; 1,3'; 3,4'; 1,4'; 3,1' e 1,1', e praticamente não houve mudanças na clas sificação das mesmas em função da variação no valor de 'p'. 0 mesmo se pode dizer das seis piores combinações, isto é, 4,2';2,2';4,5'; 2,5'; 1,5' e 6,2'. Observa-se assim uma tendência de as melhores combinações envolverem as cultivares de milho 1 ( $\mathrm{Ag}-401)$ e $3(\mathrm{C}-111)$ e as piores com binações, as cultivares $2(B r-105)$ e 4 (Piranão). Quanto ao feijão, exis te uma constância de as piores combinações envolverem as cultivares 2' (Manteigão fosco) e 5' (Costa Rica). 
E importante ressaltar que as seis melhores combinações não só maximizaram a receita bruta, como também maximizaram a produção de milho em separado. Estas forneceram as seguintes quantidades de milho e feijão, respectivamente, em t/ha: $6,96+0,51$ (para $1,6^{\prime}$ ); 6,48+0,56 $\left(\operatorname{para} 1,3^{\prime}\right) ; 6,62+0,53\left(\operatorname{para} 3,4^{\prime}\right) ; 6,59+0,51\left(\operatorname{para} 1,4^{\prime}\right) ; 7,10+0,26$ (para $\left.3,1^{\prime}\right)$ e $6,52+0,29$ (para $\left.1,1^{\prime}\right)$. Se, por outro lado, o objetivo principal for a maximização da produtividade do feijão, as seguintes com binações serão as melhores: 2,4';6,6';2,3';3,6';5,3' e 1,3'. Estas, porém, não corresponderam necessariamente às combinações de maior valor monetārio e forneceram as seguintes quantidades de milho e feijão, res, pectivamente, em $t / h a: 3,63+0,66$ (para 2,4'); 4,17+0,66 (para 6,6'); $4,42+0,65\left(\operatorname{para} 2,3^{\prime}\right) ; 4,60+0,60\left(\operatorname{para} 3,6^{\prime}\right) ; 4,49+0,58\left(\operatorname{para} 5,3^{\prime}\right)$ e $6,48+0,56\left(\operatorname{para} 1,3^{\prime}\right)$.

As estimativas do efeito geral de consōrcio $\left(c_{i j}\right)$, em valor real e em porcentagem das médias das cultivares em monocultivo, para as 36 combinações, estão apresentadas nas Tabelas 10, 11 e 12, respectivamente, para $p_{1}=3, \dot{5}$ e 7. A grande maioria dos valores foi positiva, com exceção de algumas combinações para $\mathrm{p}=5$ e 7 . Para este efeito, tam bēm, houve uma boa concordância na classificação dos tratamentos para os diferentes valores de 'p', conforme atestam os coeficientes de correlação de Spearman $\left[\mathrm{r}_{\mathrm{S}(3,5)}=0,983 ; \mathrm{r}_{\mathrm{S}(3,7)}=0,920\right.$ e $\left.\mathrm{r}_{\mathrm{S}(5,7)}=0,968\right]$. Tomando-se $p=5$, por exemplo, o efeito médio de consórcio foi de 1,422 t/ha, que corresponde a $25,3 \%$ da média das cultivares em monocultivo, indicando que em média os tratamentos em consórcio produziram 25,3\% a mais que em monocultivo. Para o feijão, as melhores combinações geralmente 
envolveram as cultivares Manteigão fosco e Goiano precoce, ao passo que as piores combinações envolveram a cultivar S. Cuva 168, sendo as outras três mais ou menos intermediärias a estes extremos. Estes valores indicam, para o feijão, uma correlação negativa entre o efeito geral de consórcio e as médias das cultivares em monocultivo. Entretanto, observa-se que a cultivar Carioca, cuja média foi relativamente alta em monocultivo, apresentou valores relativamente altos para o efeito geral de consórcio.

Quanto ao milho, observa-se que as duas cultivares mais produtivas em monocultivo (híbridos Ag-401 e C-111) apresentaram em mēdia os maiores valores para o efeito geral de consórcio, enquanto que as cultivares menos produtivas em monocultivo (variedades Piranão e Br-105) apresentaram em média os menores valores para o efeito geral de consórcio, indicando, neste caso, a ocorrência de uma correlação positiva entre a magnitude do efeito geral de consórcio e a média das cultivares em monocultivo. E importante ressaltar, entretanto, que a anālise da variância não detectou significância para cultivares de milho em monocultivo. Devido a isso, pode-se afirmar que a maior variação entre as médias das cultivares de milho em consórcio (significativa na análise da variância), se deve às diferenças entre as cultivares quanto ao efeito geral de consórcio.

0 exame destas tabelas $(10,11$ e 12) revela ainda uma boa concordância entre a magnitude do efeito geral de consórcio em valor real e em porcentagem da média das cultivares correspondentes em monocultivo 
$\left[\mathrm{r}_{\mathrm{S}}=0,951,0,953\right.$ e 0,978 , respectivamente, para $\mathrm{p}=3,5$ e 7]. 0 efeito geral de consórcio em porcentagem dá uma idéia da eficiência de uma determinada combinação em consórcio quanto à capacidade de complementação.

$\mathrm{Na}$ Tabela 13 estão apresentadas as estimativas do efeito geral de consórcio calculadas em relação à média da cultivar de milho correspondente em monocultivo, em valor real e em porcentagem, tomandose o valor de 'P' intermediário (5). Com raras exceções, todos os valores foram positivos, indicando uma superioridade do consórcio em relação à média de milho em monocultivo, para praticamente todas as combinações. As estimativas para este mesmo efeito, calculadas em relação à média da cultivar de feijão correspondente em monocultivo, acham-se apresentadas na Tabela 14. Ocorreram valores positivos e negativos, indicando que pa ra algumas combinações o consórcio leva vantagem sobre o monocultivo do ' feijão, ao passo que para outras, não.

0 exame conjunto das Tabelas 11,13 e 14 revela ainda os seguintes aspectos: para a combinação 1,1' o efeito de consórcio em relação à média foi de $3,293 \mathrm{t} / \mathrm{ha}(70,5 \%)$, variando de 2,119 t/ha $(36,2 \%)$ em relação ao monocultivo de milho, a 4,467 t/ha $(127,7 \%)$ em relação ao monocultivo exclusivo do feijão. Logo, para esta combinação sempre haverá vantagem do consórcio, para qualquer proporção de combinação das duas espécies em monocultivo. Esta é a situação para a maioria das combinações. Existem porém situações onde, embora o efeito geral de consórcio seja positivo, para a média em monocultivo, não o é para outras deter minadas proporções em monocultivo. E o caso, por exemplo, das combinações 2,2' e 4,2', em que não houve vantagem do consōrcio em relação ao 
monocultivo exclusivo de milho, ou qualquer proporção próxima a essa, mas a vantagem surgiu com o aumento da proporção do feijão, a partir des te extremo. Uma situação contrária aconteceu com combinações como 4,4' e 5,6', em que não houve vantagem do consórcio em relação ao monocultivo exclusivo do feijão, surgindo a vantagem na medida em que se aumentou a proporção de milho em monocultivo. Finalmente, existem combinações como 2,6' e 4,6' em que não houve vantagem do consórcio em relação à média em monocultivo, e menos ainda em relação ao monocultivo exclusivo do feijão, ocorrendo vantagem apenas com proporções predominantes de milho em monocultivo. Não ocorreram casos onde não houve vantagem do consórcio em relação ao monocultivo para nenhuma proporção das duas espécies em mo nocultivo. De qualquer forma, para qualquer situação é bem fácil calcular a proporção relativa de cada espécie em monocultivo a partir da qual o consórcio é vantajoso. De posse desta informação, e em função das necessidades do agricultor quanto à proporção de cada espécie em monocultivo, pode-se verificar a vantagem ou não da utilização do consōrcio.

4.2.2.3. Avaliação dos tratamentos com base nos parāmetros do modelo proposto

As anālises de variância das tabelas dialélicas (Tabelas 7, 8 e 9) acham-se apresentadas na Tabela 15. Para as três situações, não foi detectada significância apenas para o efeito específico do consōrcio ou capacidade específica de competição. Quanto às demais fontes de variação, todas foram significativas ao nível de $99 \%$ de probabilidade, 
com exceção do efeito de consórcio de cultivares de milho para $\mathrm{p}=5$ (sig nificativo a 95\%) e para $p=7$ (não significativo). A análise comparativa das três situações revela ainda que à medida em que se aumentou o valor de 'p', ou o valor relativo do feijão, os quadrados médios atribuídos às cultivares de milho diminuiram um pouco. Em outras palavras, à medida em que se aumentou o valor de 'p', as cultivares de milho tiveram menor participação na discriminação entre os tratamentos em consórcio. Uma situação contrária, evidentemente aconteceu com o feijão. Como consequência disso, o quadrado médio atribuído ao efeito médio de consórcio também diminuiu com o aumento de 'p', pois o feijão é a espécie dominada e, portanto, a que sofreu a maior redução de produção em consórcio.

$\mathrm{Na}$ Tabela 16 estão apresentadas as estimativas dos parâme tros m (média das cultivares em monocultivo), g (diferença entre_as médias das cultivares de milho e feijão), $a_{i}$ (efeitos de cultivares de mi1ho) e $b_{j}$ (efeitos de cultivares de feijão) para $p=3,5$ e 7 , em equivalentes de milho. São apresentadas juntamente as estimativas dos desvios padrão correspondentes. As estimativas das médias das cultivares em monocultivo foram de 4,487 t/ha, 5,625 t/ha e 6,764 t/ha, respectivamente, para $p=3,5$ e 7 . As estimativas dos efeitos de cultivares de milho variaram de $-0,775 \mathrm{t} / \mathrm{ha}$ a $0,746 \mathrm{t} / \mathrm{ha}$, sendo que o híbrido duplo $\mathrm{C}-111$ apre sentou o efeito mais alto, e a variedade Piranão, o mais baixo. Para o feijão, as estimativas dos efeitos de cultivares variaram de $-2,013 \mathrm{t} / \mathrm{ha}$ a $1,861 t / h a(p=3),-3,356 t / h a$ a $3,101 t / h a(p=5)$ e $-4,698 t / h a$ a 4,342 t/ha $(p=7)$. Nestas condições, a cultivar S. Cuva 168 apresentou o efeito mais alto, e a cultivar Manteigão fosco apresentou o efeito mais baixo. 
E importante observar também nesta tabela que o desvio-padrão associado às estimativas do efeito de cultivares de milho $\left[s\left(\hat{a}_{i}\right)\right]$ é relativamente alto, de modo que estas estimativas não diferem de zero através de um teste 't'. Porém, conforme jā tinha sido verificado anteriormente (Tabela 6), as cultivares de milho não foram estatisticamente diferentes, em monocultivo. Por outro lado, para as demais estimativas da Tabela 16, a precisão foi satisfatória.

As estimativas dos parâmetros $\bar{c}$ (efeito médio de consōrcio), $c_{i}$ (efeitos de consórcio atribuídos às cultivares de milho) e $c_{j}$ (efeitos de consórcio atribuídos às cultivares de feijão), bem como as estimativas dos desvios-padrão correspondentes, acham-se apresentadas na Tabela 17, em equivalentes de milho, para $p=3,5$ e 7 . 0 efeito médio de consórcio foi de 1,712 t/ha, 1,422 t/ha e 1,132 t/ha, respectivamente para $p=3,5$ e 7 . Tais valores correspondem a $38,2 \%, 25,3 \%$ e $16,7 \%$, respectivamente, das médias das cultivares em monocultivo. Portanto, em média os tratamentos em consórcio produziram mais que os tratamentos em monocultivo, para todo o intervalo considerado para a variação do 'p'. A redução do efeito médio de consórcio com o aumento do preço relativo do feijão (p) se deve ao fato de que o feijão é a espécie dominada e, portanto, a que mais sofre redução de produção em consōrcio.

Quanto aos efeitos de consórcio atribuídos às cultivares de milho $\left(c_{i}\right)$, observa-se que os maiores valores referem-se aos híbridos Ag-401 e C-111, enquanto que os menores valores referem-se às variedades Piranão e Br-105. Para o feijão, as melhores cultivares quanto ao efeito de consórcio foram as cultivares Goiano precoce e Manteigão fosco, 
enquanto que a pior cultivar foi a S. Cuva 168. Além disso, comparandose os dados desta tabela com os da Tabela 16, pode-se constatar uma clas sificação bem parecida entre os efeitos de cultivares e consórcio de cul tivares para o milho, mas não foi para o feijão $\quad\left[r_{S}\left(a_{i}, c_{i}\right)=0,771\right.$; $\left.r_{S}\left(b_{j}, c_{j}\right)=-0,771\right]$. Isto indica que para o milho as cultivares superio res em monocultivo tiveram uma tendência de conferir uma contribuição su perior para a produção em consōrcio e vice-versa, enquanto que para o feijão a situação é inversa, isto é, as cultivares piores em monocultivo tiveram uma tendência de conferir uma contribuição superior para a produ ção em consōrcio e vice-versa. Tal evidência jā tinha sido constatada anteriormente, atravēs das estimativas do efeito geral de consórcio.

Outra constatação evidente da comparação das Tabelas 16 e 17, é que para o milho as estimativas dos efeitos de cultivares ( $a_{i}$ ) são de magnitudes semelhantes às das estimativas dos efeitos de consórcio de cultivares $\left(c_{i}\right)$, enquanto que para o feijão as magnitudes das estimativas dos efeitos de cultivares $\left(b_{j}\right)$ são superiores às estimativas dos efeitos de consórcio de cultivares $\left(c_{j}\right)$, indicando que para as duas espécies a contribuição relativa dos dois efeitos para a produção em consórcio foi diferente. Para o feijão, a contribuição relativa dos efeitos de cultivares foi bem maior que para o milho. A razão provav́el disso é que para as cultivares de feijão houve maior variação em monocultivo, ao passo que para as cultivares de milho houve maior variação em consórcio.

As estimativas dos efeitos específicos de consórcio, ou capacidade específica de competição, em equivalentes de milho, acham-se 
apresentadas na Tabela 18 para $p=3,5$ e 7 , juntamente com as estimativas dos desvios-padrão correspondentes. A anālise da variância não revelou significância para este efeito, para o nível convencional de probabilidade (95\%). Entretanto, um exame da Tabela 15 revela que com uma probabilidade de erro um pouco maior $(0,10<\mathrm{P}<0,25$, para $\mathrm{p}=5)$ podese admitir a significância da variação devida a este efeito. Além disso, pela própria magnitude dos mesmos não se pode considerā-los desprezíveis. Considerando-se ainda os desvios padrão de tais estimativas (Tabela 18), pode-se observar que pelo menos três combinações $\left(1,5^{\prime} ; 1,6^{\prime}\right.$ e $\left.3,3^{\prime}\right)$ são, em valor absoluto, de magnitude superior a duas vezes o desvio-padrão, exceto para $p=7$ em 1,6'. Pode-se admitir assim que a não significância da capacidade específica de competição na anālise da variância é uma questão apenas de nível de probabilidade de erro.

A anālise da Tabela 18 revela ainda uma concordância muito grande das estimativas dos parâmetros ' $d_{i j}$ ' para os diferentes valores de 'p', à semelhança do que ocorreu com outras estimativas. Para $p=5$ as estimativas destes parâmetros variaram de $-1,119$ t/ha a $1,042 \mathrm{t} / \mathrm{ha}$, sendo que as piores combinações foram: 1,5' (Ag-401 e Costa Rica), 3,3' (C-111 e Carioca) e 3,6' (C-111 e S. Cuva 168), enquanto que as melhores combinações foram: 1,6' (Ag-401 e S. Cuva 168), 3,4' (C-111 e Rico 23) e 5,2' (Br-126 e Manteigão fosco).

As estimativas da capacidade geral de competição, em equi valentes de milho, para as cultivares de milho $\left(\operatorname{cgc}_{i}\right)$ e feijão $\left(\operatorname{cgc}_{j}\right)$ acham-se apresentadas na Tabela 19, para $p=3,5$ e 7 , bem como as estimativas dos desvios - padrão correspondentes. Da correspondência 
$\operatorname{cgc}_{i}=(1 / 2) a_{i}+c_{i}$ e $c g c_{j}=(1 / 2) b_{j}+c_{j}$, tem-se que a capacidade geral de competição é testada na análise da variância indiretamente através das fontes 'cultivares' e 'consórcio de cultivares', sendo que ambas foram significativas. Observa-se pela Tabela 19 que para os diferentes valores de ' $P$ ' houve pouca mudança na classificação destes efeitos, para cada espécie. Tomando-se $\mathrm{p}=5$, por exemplo, tem-se para o milho uma variação de $-1,095$ t/ha a 0,991 t/ha para a capacidade geral de competição, e para o feijão, uma variação de $-1,066$ t/ha a 0,834 t/ha. As melhores cultivares de milho foram os híbridos Ag-401 e C-111, enquanto que as piores cultivares foram as variedades Piranão e Br-105. Para o feijão, as melhores cultivares foram Carioca e Rico 23, enquanto que as piores cultivares foram Manteigão fosco e Costa Rica. Constata-se ainda que pa ra o milho houve uma boa concordância na classificação dos efeitos de cultivares, consōrcio de cultivares e capacidade geral de competição (Tâ belas 16, 17 e 19). Para o feijão esta correspondência não foi tão perfeita.

\subsubsection{Anālises utilizando outras metodologias}

As anâlises apresentadas nas Tabelas 20 e 21 foram feitas com o objetivo de comparar algumas metodologias tradicionais de análise de consórcio com a metodologia do presente trabalho.

Na Tabela 20 estão apresentados os valores obtidos para o Índice RAE (Razão da Ārea Equivalente). Observa-se que todos os valores foram maiores que 1,0, indicando uma maior eficiência do consōrcio frente ao monocultivo em todas as situações. O RAE médio foi de 1,259, 
indicando uma eficiência média do consōrcio frente ao monocultivo de 25,9\%. No geral para o feijão, os maiores coeficientes ocorreram com as cultivares de feijão Goiano precoce, seguido das cultivares Manteigão fos co e Carica, enquanto que os coeficientes mais baixos ocorreram com as cultivares Costa Rica e S. Cuva 168. Observa-se que cultivares com produções bem diferentes, como Costa Rica e S. Cuva 168 apresentaram em média indices semelhantes, o mesmo ocorrendo com as cultivares Manteigão fosco e Carioca. Quanto às cultivares de milho, não houve tanta discriminação quanto com as de feijão, ocorrendo porém, em média, os maiores Índices para os híbridos Ag-401 e C-111 e, os menores, para as variedades Piranão e Br-105. As combinações de maiores índices foram: 1,1'; $5,2^{\prime} ; 3,1^{\prime} ; 1,3^{\prime} ; 1,6^{\prime}$ e 1,4'. As combinações de mais baixo índice foram: $2,6^{\prime} ; 4,5^{\prime} ; 4,6^{\prime} ; 3,6^{\prime} ; 6,4^{\prime}$ e $1,5^{\prime}$.

Na Tabela 21 acham-se apresentadas as análises de variância conjuntas para os dois sistemas de cultivo (consōrcio e monocultivo), separadamente para cada espécie, bem como os coeficientes de correlação para as médias das cultivares entre os dois sistemas. A análise da variância revelou a ocorrência de variação entre cultivares e sistemas de cultivo para ambas as espécies. Conforme jā foi verificado anteriormente, para o milho ocorreu uma redução média da produção em consórcio de $11,3 \%$, ao passo que para o feijão esta redução foi de 62,9\%. Esta anālise revelou ainda a ocorrência de interação entre cultivares e sistemas de cultivo somente para o feijão. Entretanto, o desdobramento do quadra do médio da interação, de acordo com o processo de ROBERTSON (1959), mos trou que a quase totalidade do quadrado médio da interação $(97,6 \%)$ 
deve-se à diferença de variação entre os tratamentos para dois ambientes (componente A). Além disso, uma anālise da interação de acordo com o modelo multiplicativo de VENCOVSKY e GERALDI (1977), revelou que 95,9\% do quadrado médio da interação deve-se à ação multiplicativa do efeito de ambiente (sistemas, no caso). Tais resultados indicam que a interação que ocorreu para o feijão é predominantemente do tipo que não interfere com a recomendação de cultivares para diferentes ambientes, pois não altera a classificação das mesmas, conforme pode ser constatado pelo exame da Tabela de médias (Tabela 5).

A correlação para as médias dos tratamentos entre os dois sistemas foi alta, ou seja, $r=0,831$ e $r_{S}=0,771$ para o milho e $r=0,977$ e $r_{S}=1,000$ para o feijão, indicando a ocorrência de uma boa concordância entre a classificação das médias nos dois sistemas, para as duas espécies. 


\section{DISCUSSÃO}

\subsection{Avaliação do material com base na metodologia proposta}

Uma constatação bastante importante no presente trabalho foi a ocorrência de uma boa concordância para os resultados obtidos com os três valores considerados para a relação de preços (p), isto é, 3 , 5 e 7, tanto para as análises da variância, como para as estimativas dos parâmetros. Considerando-se que este intervalo (3 a 7) engloba a grande maioria das situações, pode-se concluir que para este tipo de trabalho as conclusões são pouco afetadas pela variação no preço relativo das duas es pécies. Deste modo, para efeito de estudos de comportamento de cultivares pode ser utilizada a relação de preços média. Consequentemente, no presen te trabalho a discussão será realizada tendo-se como base $\mathrm{p}=5$.

A análise da variância revelou a ocorrência de significância para praticamente todas as fontes de variação. Pode-se concluir assim que para o grupo de cultivares estudado ocorreu variação quanto à produção das cultivares 'per si' e também quanto ao efeito geral de consórcio, 
ou capacidade de complementação, para as diferentes combinações em consórcio. O desdobramento desta ūltima fonte de variação revelou ainda a ocorrência de um efeito médio de consórcio significativo, que as cultivares diferem entre si quanto à contribuição para o efeito geral de consórcio, e t'ambém que as combinações diferem entre si quanto à contribuição para o efeito geral de consórcio. Na maioria dos casos o efeito geral de consórcio foi positivo, indicando a ocorrência de complementação, isto é, que as combinações em consórcio produziram mais que a média em monocultivo, e, consequentemente, o efeito médio de consórcio foi positivo.

Com a finalidade de investigar a contribuição dos diversos efeitos para a produção global, na Tabela 22 está apresentado um detalhamento das seis melhores e das seis piores combinações em consórcio, para $\mathrm{p}=5$. Juntamente com a estimativa de cada efeito está apresentada também a classificação do mesmo.

Observa-se inicialmente que as melhores combinações, no ge ral, são aquelas que tiveram uma boa complementação em consórcio, isto é, onde o efeito geral de consórcio foi alto, ao passo que as piores combinações referem-se, no geral, aos casos onde não houve boa complementação em consórcio. Este fato ilustra claramente a importância deste efeito em consōrcio, e indica que boas combinações para o consórcio não podem ser determinadas através do comportamento das cultivares em monocultivo. .

A análise da capacidade geral de competição revela que as seis melhores combinações envolvem as duas cultivares de milho com maior capacidade geral de competição (híbridos Ag-401 e C-111), e as quatro cultivares de feijão com maior capacidade geral de competição (Carioca, 
Rico 23, S. Cuva 168 e Goiano precoce). Observa-se também que na maior parte dos casos tais combinações referem-se a altas capacidades específicas de competição, como por exemplo, a combinação $1,6^{\prime}$, que corresponde à capacidade específica de competição mais alta. Por outro lado, as seis piores combinações envolvem as duas cultivares de feijão com capacidade geral de competição mais baixa (Manteigão fosco e Costa Rica). No geral o mesmo aconteceu com o milho, visto que as piores combinações envolvem as três piores cultivares quanto à capacidade geral de compètição (variedade Piránão, Br-105 e Br-104), com exceção de um caso que envolve o híbrido Ag-401 (maior cgc). Esta combinação porēm (1,5') apresentou a capacidade específica de competição mais baixa. Verifica-se também que, no geral, estas seis piores combinações referem-se a baixas capacidades específicas de competição.

A análise detalhada desta tabela reforça novamente a importância de todos os efeitos do modelo como participantes do rendimento global da combinação. No geral, as boas combinações referem-se a cultivares com boa capacidade geral de competição de cada espécie, enquanto que as combinações ruins referem-se a cultivares com baixa capacidade geral de competição de cada espécie. Alguns desvios desta norma servem para evidenciar a importância da capacidade específica de competição para o rendimento.

Entretanto, tem-se que se considerar que as duas espécies diferem entre si na maneira pela qual atingem uma boa capacidade geral de competição. Conforme já foi relatado, a capacidade geral de competição é função dos componentes 'efeito de cultivares' $\left(a_{i}\right.$ ou $\left.b_{j}\right)$ e 'efeito de 
consórcio atribuído às cultivares' ( $c_{i}$ ou $c_{j}$ ), de acordo com relação $\operatorname{cgc}_{i}=(1 / 2) a_{i}+c_{i}$ e $c g c_{j}=(1 / 2) b_{j}+c_{j}$, de modo que uma alta capacidade ural de competição ocorre quando o balanço entre estes dois efeitos for alto e positivo. Para o feijão, estes dois efeitos foram negativamente correlacionados. Deste modo, as três cultivares com maior 'cgc', isto é, Carioca, Rico 23 e S. Cuva 168, correspondem às de efeito de cultivares mais altos. em monocultivo $\left(b_{j}\right)$. Entretanto, a de maior 'cgc', is to é, Carioca, estā em terceiro lugar quanto ao efeito de cultivares, mas tambēm em terceiro lugar quanto ao efeito de consórcio atribuído às cultị vares, o que resultou no balanço positivo mais alto para a 'cgc'. Consequentemente, a cultivar Carioca foi indicada como a melhor cultivar de feijão para cultivo em consórcio, dentro deste grupo, e seguida pela cultivar Rico 23. Por outro lado, a cultivar S. Cuva 168, que teve o efeito de cultivares mais alto, teve como desvantagem o fato de ser a pior delas quanto ao efeito de consórcio atribuído às cultivares, classificandose assim em terceiro lugar quanto à capacidade geral de competição. Uma situação aparentemente inversa a esta ủltima ocorreu com a cultivar Goiano precoce, que apresentou um dos efeitos de cultivares mais baixo, mas a melhor contribuição para o efeito geral de consórcio, classificando-se em 40 lugar quanto à capacidade geral de competição.

Além disso, tem-se que considerar outros aspectos. Tomando-se como base o feijão, a componente ' $c_{j}$ ', ou efeito de consórcio atribuído às cultivares, é basicamente devida a dois fatores. 0 primeiro deles ē o efeito direto na própria espécie, isto é, a capacidade de produção de cultivar em consórcio em relação à produção em monocultivo. 
Consequentemente, como o feijão é a espécie dominada, esse efeito direto é maior e positivo quando a cultivar sofre uma menor redução de produção em consórcio. 0 segundo, é o efeito indireto na outra espécie, no caso o milho. Consequentemente, uma cultivar ideal de feijão (maior $c_{j}$ ) é aquela que em consórcio mantém a maior capacidade da produção em monocultivo, e também interfere o mínimo possível com o milho. Além disso, evidentemente, deve apresentar um bom nível de produção em monocultivo (maior $\mathrm{b}_{\mathbf{j}}$ ). Dentro do grupo aquí estudado, a cultivar que reuniu melhor tais ca racterísticas foi a Carioca, o que resultou na maior capacidade geral de competição, seguida da cultivar Rico 23. Por outro lado, as duas cultivares que tiveram produções baixas em consōrcio e acarretaram 'reduções maiores no milho (Manteigão fosco e Costa Rica), apresentaram os valores mais baixos para a capacidade geral de competição. Uma outra situação é a da cultivar Goiano precoce, que proporcionalmente sofreu a menor redu- ção de produção em consórcio, foi a que causou o menor prejuízo no milho, mas tem como inconveniente o fato de ter baixa produção em monocultivo, resultando numa capacidade geral de competição intermediāria.

Para o milho, a situação é mais simples, devido à correlação positiva entre os efeitos de cultivares e de consórcio atribuído às cultivares. Deste modo, as melhores cultivares em monocultivo (hỉbridos Ag-401 e C-111) foram também melhores em consórcio (capacidade geral de competição mais alta), enquanto que as piores cultivares em monocultivo (variedades Piranão e Br-105) foram também piores em consórcio (capacidade geral de competição mais baixa). 
Embora as informações da literatura não sejam consistentes, parece haver uma concordância geral entre os pesquisadores de que para o milho o problema da interação não é sério, visto que esta é a espécie dominante e, deste modo, pouco ou nada sofre em consórcio. Por outro lado, para o feijão também existe uma concordância mais ou menos geral de que existem diferenças entre as cultivares quanto à adaptação em consórcio (BEZERRA et aZii, 1980; SANTA CECILIA e VIEIRA, 1980; SILVA, 1980; VIEIRA, 1980 e VIEIRA et alii, 1982). Consequentemente, pode-se admitir que para o feijão as características produtividade e habilidade de competição ecológica com o milho são distintas. DONALD (1963), HAMBLIN et alii (1976) e DAVIS (1981) discutem a importância de se distinguir estas duas características. Em tais condições, segundo FYFE e ROGERS (1965) e DIJKSTRA e de VOS(1972), as cultivares mais adequadas para o consórcio devem ter um melhoramento específico.

Entretanto, é importante considerar aqui uma diferença fun damental entre o grupo de cultivares de milho e o de feijão, que pode em parte ter contribuído para as diferenças nas respostas das duas espécies. As seis cultivares de milho utilizadas, apresentam níveis de produtividade elevados em monocultivo, e, consequentemente, pouca variação. Por outro lado, as seis variedades de feijão, devido à grande variação para uma série de características são bem mais variadas quanto à produtividade em monocultivo. Devido a este fato, as cultivares de feijão podem ter tido maior oportunidade para expressar reações diferenciais de um sistema para outro. Em outras palavras, a interação é uma função da variação entre os tratamentos. Assim, seria interessante verificar o comportamento de um 
grupo de cultivares de milho mais discrepantes, com o intuito de constatar se o tipo de reação continua o mesmo. Pode-se adiantar, porēm, que a ocorrência de interação entre sistemas é uma função também da heterogeneidade entre os ambientes, e para o milho, que é a espécie dominante, os dois ambientes (consórcio e monocultivo) são bem mais parecidos que para o feijão, a espécie dominada. Apenas como exemplo, a partir de uma certa fase do desenvolvimento vegetativo, o feijão consorciado passa a se desen volver em um ambiente sombreado. Por outro lado, a produtividade do mi1ho é em parte determinada após a maturação e retirada do feijão. Todos estes aspectos servem para reforçar a idéia de que não se deve esperar a ocorrência de reações muito diferenciadas entre os dois sistemas, para o milho. Tem-se que considerar ainda que as cultivares utilizadas no presente trabalho eram provenientes de seleção em monocultivo. $\bar{E}$ possível que se estas fossem provenientes de seleção nos dois sistemas, os resultados tivessem sido diferentes. Evidentemente, este é um aspecto a ser investigado.

Conforme foi verificado no presente trabalho, as piores cultivares de milho em consórcio foram as cultivares de porte baixo (variedades Piranão e $\mathrm{Br}-105)$. De fato, a literatura tem mostrado que cultivares de milho de porte baixo não são bem produtivos em consórcio (ANDRADE et alii, 1974; FRANCIS et aZii, 1976a; PINCHINAT e DESIR, 1976; CRUZ et alii, 1982 e RAMALHO et alii, 1983). Além disso, tem sido verificado também que, ao conträrio do que se imaginava, as cultivares de milho de porte baixo não acarretam menor prejuízo no feijão (ANDRADE et alii, 1974; 
FRANCIS et alii, 1976c; CRUZ et alii, 1982), embora BEZERRA NETO

tenha verificado o contrārio. $\bar{E}$ importante considerar que este tipo de comparação não é perfeitamente correto, visto que para a comparação do porte das plantas são utilizadas cultivares de natureza genética diferentes. Para uma comparação mais correta, evidentemente, deveriam ser utilizadas linhas isogênicas. Os resultados da literatura e os do presente trabalho'indicam, porém, que o porte mais baixo da planta de milho não pạ rece acarretar vantagens para o consórcio. Uma explicação possível é que as plantas de porte baixo sofrem maior interferência das plantas de feijão e, consequentemente, perdem uma parte das vantagens de espécie dominante. Também, em relação ao efeito sobre o feijão, de acordo com ANDRADE et alii (1974), a vantagem aparente da variedade Piranão quanto ao menor sombreamento no feijão, devido à arquitetura mais baixa, seria anulada pela maior largura e concentração das folhas próximas ao solo. Esta explicação é compatível com o comportamento desta variedade no presente trabalho. Por outro lado, a cultivar de milho Br-105, que é de porte ba xo, mas não devido ao gene braquítico, causou o menor prejuízo no feijão. Uma constatação semelhante foi feita por DAVIS (1981). Realmente, a vantagem ou não do porte mais baixo das plantas de milho para o consórcio precisa ser melhor investigada.

Todas estas considerações são importantes, porque detalham muito bem o comportamento das cultivares de ambas as espécies em relação aos dois sistemas. Estas informações, evidentemente, são muito úteis para trabalhos de melhoramento em condições de consórcio. Entretanto, é bom ressaltar que para qualquer das espécies e para as condições atuais da 
nossa agricultura, a utilização de cultivares disponíveis, e obtidos em condições de monocultivo, certamente irá atender às necessidades dos agri cultores por um bom tempo ainda. Para isso, é necessário que sejam conve nientemente avaliadas em consórcio. Provavelmente, a médio e a longo prazos seja necessária a condução de trabalhos de melhoramento específicos para as condições de consórcio.

Conforme muitos autores salientam, a condução de um programa de melhoramento simultâneo para as duas espécies é muito difícil, em bora na literatura existam relatos de procedimentos para este fim (HAMBLIN et alii, 1976). Neste sentido, os resultados do presente trabalho fornecem algumas informações importantes. Para o milho, estes resultados indicam um tipo de comportamento em consórcio que não justifica a condução de programas de melhoramento específicos para este sistema. Para o feijão, ao contrário, tais resultados mostraram um tipo de reação mais complexa aos sistemas de cultivo, indicando que as melhores cultivares em monocultivo não o são necessariamente em consórcio e vice-versa. Entre os fatores responsáveis por isso, alguns puderam ser detectados: produtivi dade, agressividade, precocidade e häbito de crescimento. $\therefore$ Em visto deste fato, e considerando-se que o feijão é a espécie dominada, pode-se admitir que esta é a espécie mais indicada para um programa de melhoramento específico para consórcio. Além disso, de acordo com DAVIS (1981), na literatura têm sido relatadas correlações positivas e altamente sịgnificativas para o rendimento do feijão em associação com diferentes tipos de milho. Este fato, segundo o autor, indica que a seleção de feijão para consórcio pode ser feita na presença de uma ünica cultivar de milho, 
o que evidentemente facilita a condução de um programa.

Existem evidentemente, muitos caracteres que devem ser con siderados em um programa de melhoramento específico para o consórcio. Os resultados obtidos no presente trabalho permitem tecer considerações a respeito de alguns deles. Quanto aos caracteres produtividade e agressividade, sobressaem as duas cultivares que foram eleitas as melhores para cultivo em consórcio dentro desse grupo: Carioca e Rico 23. Além de manterem uma boa produtividade em consórcio, em relação ao monocultivo, interferem menos com o milho, isto é, causam menor redução na produção deste (menor agressivìdade). Fica deste modo evidenciada a importância dessas duas características em consórcio: produtividade e agressividade; eví dentemente, elas podem ser melhor exploradas em programas de melhoramento, pois, de acordo com DAVIS (1981), a seleção em consórcio deve buscar genótipos que melhor reunam estas duas características. Este autor praticou seleção divergente em consórcio para rendimento:de milho e feijão, simultaneamente, utilizando-se uma população segregante de feijão (f́amílias $\mathrm{F}_{3}$ ) e uma variedade de milho (variedade Suwan). Em seguida avaliou as famílias selecionadas (famílias $F_{4}$ ) em associação com as populações de milho correspondentes, selecionadas na geração anterior. Verificou que em média os grupos seguiram um comportamento similar de uma geração para outra $(r=0,56 * *$ para o rendimento de feijão e $r=0,59 * *$ para o rendimento do milho). Considerando-se a ocorrência de segregação, bem como o efeito ambiental de uma geração para outra, pode-se admitìr, segundo o autor, a ocorrência de uma herdabilidade aceitável para o rendimento do feijão, bem como para o efeito indireto do genótipo de feijão no rendimento 
do milho.

Quanto à precocidade, tem-se como exemplo a cultivar Goiano precoce, com florescimento em torno de 35 a 40 dias do plantio. Embora tenha sido uma das cultivares menos produtivas, apresenta também características de melhor adaptação ao consórcio, visto que foi a que sofreu a menor redução de produção neste sistema. Além disso foi a cultivar que causou a menor redução na produção do milho. Provavelmente isto é uma consequência da precocidade desta cultivar. Deste modo, o floresci mento do feijão ocorre bem antes que o do milho e assim, os períodos de intensa atividade metabólica de ambas as espécies ficam . bem separados (complementação temporal), o que deve se traduzir em uma maior eficiência na produção de grãos de ambas. De acordo com WILLEY (1979), a defasagem no ciclo de duas espécies é um dos fatores que mais contribuem para a ocorrência de complementação entre as mesmas. Além disso, diversos autores mostraram que o feijão em consórcio produziu bem mais quando o plan tio do mesmo foi antecipado em torno de 15 dias (RAMALHO, s/d; FRANCIS, 1978; FRANCIS et aZii, 1978b; 1978c). Consequentemente, entre "as boas combinações do presente trabalho, encontram-se algumas com a cultivar Goiano precoce; apesar de a mesma não ser bem produtiva em monocultivo. Evidentemente, uma característica como esta também pode ser explorada em programas de melhoramento para o consórcio, a partir de populações segregantes.

Em relação ao hábito de crescimento, os resultados do presente trabalho mostraram que as cultivares de crescimento indeterminado (tipos II e III) sofreram uma maior redução de produção, quando em consórcio, 
que as de crescimento 'determinado (tipo I), de maneira semelhante ao que foi verificado por FRANCIS et a $i$ ii (1978b e 1978c). Segundo estes au tores, este fato é consequência do maior período de crescimento do feijão trepador e a uma competição mais direta por luz durante este período. Além disso, para as cultivares de tipo III pode existir um problema adicional de ordem prática que é a maior dificuldade na colheita causada pelo hábito semi-trepador, o que irá dificultar a retirada das plantas, podendo causar estragos no milho. Evidentemente, em monocultivo as cultivares de tipos II e III normalmente são mais-produtivas. Estes fatos, porém, ilus tram claramente um aspecto vantajoso das cultivares arbustivas para o con sórcio e, deste modo, abre a possibilidade de se tentar obter, através do melhoramento, cultivares arbustivas mais produtivas, e, portanto, mais adaptadas ao consórcio:

$\bar{E}$ importante ressaltar que características como estas mencionadas, e indicadas como importantes para as condições de consórcio, não o são necessariamente em monocultivo, de modo que também não necessariamente serão tomadas como critérios de seleção em programas de melhoramento em monocultivo, justificando assim a seleção em consórcio. Por outro lado, no presente trabalho verificou-se que em consórcio ocorre uma menor discriminação entre as cultivares, bem como uma precisão experimental mais baixa. Em vista disso, FRANCIS et alii (1978c) sugerem que no melhoramento de feijão para consōrcio, a seleção nas gerações iniciais se ja feita em monocultivo, e nas gerações mais avançadas ( $F_{5}$ e $F_{8}$ ), em consōrcio. Isto porque, devido às razões mencionadas, e também devido a uma 
maior produção de sementes em cada ciclo, o monocultivo proporciona uma avaliação mais precisa das linhagens individuais e consequentemente um maior progresso na seleção. Esses autores ressaltam ainda que o risco de rejeição de um genótipo vantajoso para o consórcio devé ser mínimo se as avaliações iniciais forem realizadas em monocultivo.

5.2. Avaliação da metodologia do presente trabalho em comparação com outras convencionais

Um dos procedimentos que têm sido frequentemente utilizados no estudo da interação entre genótipos e sistemas de cultivo (consōrcio vs monocultivo) é o cálculo da correlação para as médias das cultivares nos dois sistemas, podendo ser esta determinada através de um coeficiente de correlação linear simples ( $r$ ) ou através do coeficiente de correlação de posição Spearman $\left(\mathrm{r}_{S}\right)$. Entretanto, tem-se que considerar que esta medida não é fácil de interpretar, isto é, è difícil dizer, em função de uma certa magnitude de correlação e da significância da mèsma, se ocorre ou não interação entre os sistemas. Este procedimento foi discuti do por FRANCIS (1981), e os levantamentos feitos por este autor mostraram na realidade resultados contraditórios. No presente trabalho, por exemplo, foram obtidos os seguintes coeficientes de correlação para as médias das cultivares entre os dois sistemas: Milho: $r=0,831$ e $r_{S}=0,771$; Feijão: $r=0,977$ e $r_{S}=1,000$. Do modo que tem sido feito na literatura, a análise destes resultados leva a concluir uma ausência de interação entre cultivares e sistemas de cultivo, principalmente para o feijão.

Outro tipo de análise que tem sido utilizado no estudo da 
interação entre cultivares e sistemas de cultivo é a própria análise da variância conjunta para os dois sitemas. Este tipo de análise no presente trabalho indicou a existência de interação significativa somente para o feijão. Um estudo mais detalhado desta, porém, mostrou que a interação é predominantemente do tipo que não interfere com a classificação e recomendação de cultivares para diferentes ambientes. De fato, a classificação dos tratamentos foi a mesma para os dois ambientes (consórcio e monocultivo).

Portanto, com base nestes dois tipos de análises convencio nais aplicados ao presente trabalho pode-se recomendar as mesmas cultivares para os dois sistemas. Entretanto, um exame mais detalhado dos dados revela que a realidade não é bem essa, e provavelmente estas análises são falhas justamente por considerarem cada espécie em separado. Realmente, a literatura tem mostrado: resultados inconsistentes com o uso de tais tipos de análises (FRANCIS, 1981) e, de acordo com KASS (1978), neste tipo de estudo é muito importante o efeito de uma espécie sobre a outra.

Deste modo, a análise com a metodologia do presente trabaTho deu informações mais detalhadas. Esta revelou, por exemplo, a não ocorrência de interação para o milho e, que para o conjunto estudado, as melhores cultivares em monocultivo o são também em consórcio. Por outro lado, esta não é a norma para o feijão. A análise revelou para este a ocorrência de interação entre o comportamento das cultivares em monocultivo e o comportamento das mesmas em consórcio, devido a uma correlação negativa entre o efeito de cultivares de feijão em monocultivo $\left(b_{j}\right)$ e a 
sua habilidade de competição, ou efeito de consōrcio atribuído às cultivares $\left(c_{j}\right)$. Foi possível detectar ainda variação na habilidade de competição do feijão quanto à produção do prōprio feijão, bem como quanto à in terferência na produção do milho. Verificou-se, por exemplo, que as cultivares melhores para consórcio, além de manterem um bom nível de produção em consórcio, prejudicaram menos o milho, isto é, foram menos agressivas. Foi possível detectar ainda que caracteres como precocidade no feijão são vantajosos para o consórcio, bem como alguns problemas ligados ao hảbito de crescimento. Finalmente, a análise revelou ainda a existência de combinações específicas de milho e feijão mais vantajosas, isto é, que se complementam bem. Pode-se assim afirmar que a metodologia do presente trabalho forneceu informações bem detalhadas acerca do comportamento das cultivares em consórcio, bem como de algumas causas desse comportámento, informações essas que não são claras atravēs de uma anālise conjunta simples para os dois ambientes ou através da correlação entre os dois ambientes. E importante ressaltar, porém, que esta metodologia foi elaborada para arranjos dialélicos, isto é, quando se tem um grupo de tra tamentos de cada espécie, combinados dois a dois. Não é adaptada para certos arranjos, como, por exemplo, quando se tem alguns tratamentos de uma espécie na presença de um único tratamento de outra espécie.

Outra medida bastante utilizada, com o intuito de avaliar a vantagem do consórcio frente ao moncultivo, é o índice RAE (Razão da Ārea Equivalente). Este mede a vantagem do consōrcio frente ao monocultivo, quanto à proporção relativa de ārea necessária em monocultivo para atingir a mesma produção de ambas as espécies em consórcio. Pela definição 
tem-se que:

$$
\operatorname{RAE}=\frac{\overline{\mathrm{C}}_{\mathrm{m}}}{\overline{\mathrm{M}}_{\mathrm{m}}}+\frac{\overline{\mathrm{C}}_{\mathrm{f}}}{\overline{\mathrm{M}}_{\mathrm{f}}}
$$

Conforme a maioria dos autores relata, percebe-se pela definição que um RAE pode ser alto devido a uma alta produção em consórcio, como também de vido a uma baixa produção em monocultivo, de modo que não faz sentido a comparação entre 'RAE' . obtidos em diferentes combinações. Ele serve apenas para mostrar a eficiência do consórcio para uma dada combinação de cultivares de ambas as espécies.

Uma medida análoga utilizada no presente trabalho é o efei to geral de consórcio $\left(c_{i j}\right)$ que è definido por:

$$
c_{i j}=z_{i j}-1 / 2\left(z_{i i}+z_{j j}\right)
$$

e

$$
c_{i j} \%=\frac{c_{i j}}{1 / 2\left(z_{i i}+z_{j j}\right)} \cdot 100
$$

Este efeito geral de consórcio mede a vantagem do consórcio em relação à média em monocultivo, supondo, portanto, que em monocultivo a ärea é dividida equitativamente para ambas as espécies. 0 ' $c_{i j}$ ' é na realidade de vido a dois componentes, um do milho (m) e outro do feijão (f) e pode ser assim desdobrado:

$$
c_{i j}=c_{i j}^{m}+p c_{i j}^{f}
$$

onde: 


$$
\begin{aligned}
& c_{i j}^{m}=x_{i j}-(1 / 2) x_{i i} ; \\
& c_{i j}^{f}=Y_{i j}-(1 / 2) Y_{j j} \\
& e^{\prime} ' P^{\prime} \text { é a relação de preços entre as duas espécies. }
\end{aligned}
$$

logo:

$$
c_{i j} \%=\frac{c_{i j}^{m}+p c_{i j}^{f}}{1 / 2\left(X_{i i}+p Y_{j j}\right)} \cdot 100
$$

Por outro lado:

$$
\begin{aligned}
& R A E=\frac{\bar{C}_{m}}{\bar{M}_{m}}+\frac{\bar{C}_{f}}{\bar{M}_{f}}=\frac{X_{i j}}{X_{i i}}+\frac{Y_{i j}}{Y_{j j}} \\
& R A E=\frac{(1 / 2) X_{i i}+c_{i j}^{m}}{X_{i i}}+\frac{(1 / 2) Y_{j j}+c_{i j}^{f}}{Y_{j j}} \\
& R A E=1+\frac{c_{i j}^{m}}{X_{i i}}+\frac{c_{i f}^{f}}{Y_{j j}},
\end{aligned}
$$

ou

$$
R A E=1+\frac{c_{i j}^{m}}{x_{i i}}+\frac{p c_{i f}^{f}}{p Y_{j j}}
$$

Da comparação entre I e II tem-se que as duas medidas são devidas aos mesmos componentes e, deste modo, comparáveis. Assim, $c_{i j} \%$ $=\left(\operatorname{RAE}-1\right.$ ) 100, quando $\mathrm{x}_{i \mathrm{i}}=\mathrm{pY}_{j \mathrm{j}}$ (ou $\mathrm{z}_{i i}=\mathrm{z}_{j \mathrm{j}}$ ), isto é, quando a média do milho solteiro equivale à do feijão solteiro, em termos monetários. Esta igualdade também ocorrerá quando $c_{i j}^{m} / x_{i i}=c_{i f}^{f} / Y_{j j}$, isto é, quando a proporção do milho e feijão nos dois sistemas (monocultivo e consórcio) forem iguais. Deste modo, percebe-se que estas duas medidas são bem 
associadas. Assim, por exemplo, a correlação simples ( $r$ ) entre ' $c_{i j} \%^{\prime}$ e 'RAE' para as 36 combinaçōes do presente trabalho, e $\mathrm{p}=5$, foi de 0,888, enquanto que a correlação de Spearman $\left(r_{S}\right)$ foi de 0,915, indicando realmente una concordância entre as duas medidas. Pode-se concluir assim que o teste $F$ para o efeito geral do consórcio $\left(c_{i j}\right)$ é indiretamente um teste para 'RAE'. Em outras palavras, a significância do teste $F$ para o efeito geral de consórcio indica também que deve haver pelo menos um 'RAE' que é estatisticamente diferente de 1,0.

Em vista da correspondência entre as duas medidas, pode-se perguntar: o que é melhor para avaliar a vantagem do consórcio frente ao monocultivo: o 'c $i j$ ' ou o 'RAE'? Em primeiro lugar, é importante ressal tar que por definição eles medem coisas diferentes. 0 'RAE' indica a ärea que seria necessária para se ter em monocultivo, para ambas as espécies, a mesma produção de uma unidade de ārea em consórcio. Admite, portanto, uma proporção fixa de produção de ambas as éspécies, em consórcio e em monocultivo. Assim, este coeficiente também pode ser interpretado como a vantagem do consörcio frente ao monocultivo, supondo que em monocultivo a área seja dividida de modo a manter a mesma relação de produção entre as espécies que existe em consórcio. Percebe-se assim facilmente que não há muito sentido na comparação de diferentes 'RAE', visto que pạ ra cada combinação tem-se diferentes proporções de cada espécie, que não são levadas em conta. Por outro lado, pela sua definição, o 'c $i j$ ' dá uma idéia da vantagem relativa do consórcio sobre o monocultivo, em relação à média das duas espécies em monocultivo. Isto equivale, em termos práticos, a comparar, para uma dada área, a produção em consórcio, com a 
produção em monocultivo da mesma ārea, dividida equitativamente para as duas espécies. Além disso, como leva-se em conta o valor relativo de ambas as espécies, tem-se que o 'c $i j$ ' pode ser utilizado para comparar diferentes combinações. O exemplo apresentado a seguir serve para esclarecer bem estes aspectos, supondo as combinações $1,1^{\prime}$ e $3,1^{\prime}$, para $p=5$ :

$$
\begin{aligned}
& 1,1^{\prime}: z_{11^{\prime}}=7,9640 ; z_{11}=5,8454 ; z_{1^{\prime} 1^{\prime}}=3,4970 \\
& 3,1^{\prime}: z_{31^{\prime}}=8,4070 ; z_{33}=6,3040 ; z_{1^{\prime} 1^{\prime}}=3,4970 \\
& 1,1^{\prime}: c_{11^{\prime}}=3,2928 ; c_{11^{\prime} \%}=70,5 ; \operatorname{RAE}=1,528 \\
& 3,1^{\prime}: c_{31^{\prime}}=3,5065 ; c_{31^{\prime}} \%=71,6 ; \operatorname{RAE}=1,500
\end{aligned}
$$

Este exemplo mostra que a combinação 3,1 ' é mais eficiente do que 1, 1.' quanto à complementação em consórcio e o ' $c_{i j} \%$ ' reflete isto. Entretanto, a comparação do 'RAE' dá uma idéia contrāria, devido à média mais baixa do milho em monocultivo para a combinação 1,1', mostrando que este índice não é adequado a este tipo de comparação.

Deste modo, pode-se admitir que o ' $c_{i j} \%$ ' é mais adequado para comparar diferentes combinações que o 'RAE'. Além disso, a metodologia apresentada neste trabalho tem ainda como vantagem o fato de dar um detalhamento do efeito geral de consórcio $\left(c_{i j}\right)$ através dos seus componen tes: efeito médio de consórcio ( $\bar{c})$, efeito de consórcio atribuído às cultivares de milho $\left(c_{i}\right)$, efeito de consórcio atribuído às cultivares de fei jão $\left(c_{j}\right)$ e efeito específico de consōrcio $\left(d_{i j}\right)$. Também, a variação devido a estes efeitos pode ser testada na análise da variância sem maiores problemas, ao passo que para o 'RAE' existem algumas restrições quanto à anālise da variância (OYEJOLA e MEAD, 1982). 
Entretanto, de acordo com a definição, o efeito geral de consórcio $\left(c_{i j}\right)$ é calculado em relação à média das cultivares das duas es pécies em monocultivo, o que equivale a dividir a área em duas partes iguais em monocultivo, uma para cada espécie. Porém, de acordo com WILLEY e OSIRU (1972), não há razão alguma para supor que as duas espécies devam ser plantadas em áreas iguais em monocultivo. Tem-se que se considerar, porém, que esta é apenas uma das possibilidades, pois em monocultivo pode-se optar por diferentes alternativas em relação à proporção de ca da espécie, inclusive a situação mais extrema, que seria o plantio èm monocultivo de apenas uma das espécies. Percebe-se assim que o efeito geral de consórcio $\left(c_{i j}\right)$ é na realidade uma média da vantagem do consórcio sobre o monocultivo, em relação a todas as combinações de proporção de ārea possíveis para cada espécie, incluindo o monocultivo exclusivo de cada espécie. Deste modo, é importante ter-se uma idéia não só da vantagem do consórcio média $\left(c_{i j}\right)$, mas também da amplitude de variação desta para as diferentes proporções de cada espécie em monocultivo. Além disso, o agricultor pode estar interessado :e m uma determinada proporção das duas espécies em monocultivo, e querer saber a vantagem do consórcio em relação a esta proporção.

Para tais situações, o 'c $i j$ ' pode ser calculado para qualquer proporção de cada espécie em monocultivo, incluindo o monocultivo ex clusivo de ambas. Assim, por exemplo, no presente trabalho calculou-se o efeito geral de consórcio para a média em monocultivo, bem como para os dois monocultivos exclusivos, estabelecendo-se assim um intervalo de variação para este efeito. Desse modo, verificou-se, por exemplo, que para 
a maioria das combinações, e $\mathrm{p}=5$, o. consórcio foi mais vantajoso para qualquer combinação de proporção das espécies em monocultivo. Em outras, o consórcio só se torna vantajoso a partir de uma certa proporção de feijão ou de milho em monocultivo. Estes exemplos ilustram claramente a grande flexibilidade que existe no uso do 'c ${ }_{i j}$ '.

$\widehat{E}$ importante ressaltar, porém, que para o índice 'RAE' tam bém existem outros procedimentos que visam, basicamente, contornar os pro blemas na comparação dos índices (MEAD e STERN, 1979; MEAD e WILLEY, 1980; MEAD e RILEY, 1981). No presente trabalho, foi utilizado para comparação apenas o Índice 'RAE' comum, que è o que tem sido utilizado mais frequentemente em trabalhos de pesquisa, e também é o que tem maior analogia com o 'c $i j$ '. $\bar{E}$ importante ressaltar, porém, que estes outros procedimentos de cálculo do 'RAE' são procedimentos um pouco mais complexos.

A utilização da produção equivalente como variável comum, obtida através da relação de preços entre as duas espécies no mercado, tam bém mostrou-se de bastante utilidade no presente trabalho, principalmente pelo fato de que a análise conjunta envolvendo o consórcio e o monocultivo pode, desse modo, ser feita sem maiores problemas, conforme ressaltam RAMALHO et alii (1983). Além disso, segundo KASS (1978), o conhecimento da relação de preços entre as duas espécies é muito importante para se ve rificar em quais situações o aumento de produção de uma delas em detrimento da outra é compensatório. Assim, no presente trabalho foi constata do que as combinações que maximizam a receita maximizam também o rendimento do milho. Por outro lado, as combinações que maximizam o rendimento do feijão, muitas vezes sacrificam em parte a receita. Estes aspectos 
também foram discutidos por WIJESINHA et alii (1982) que discutem as alternativas possíveis para a escolha dos tratamentos, visando, ou a maximi zação da receita, ou então a maximização da produção de uma das espécies.

Verificou-se também no presente trabalho uma tendência de o monocultivo do feijão se tornar mais vantajoso que o consórcio com o aumento da relação de preços (p) em favor do feijão, o que é esperado, visto que a produção do feijão é bem maior em monocultivo. Assim, para $p=7$ surgiram algumas situações onde o monocultivo do feijão superou prą ticamente todas as combinações em consórcio. Entretanto, em um estudo econômico completo, FRANCIS e SANDERS (1978) verificaram que, para os níveis de produção predominantes na América Latina, o monocultivo do feijão só passou a ser vantajoso a partir de $\mathrm{p}=8$. Estas informações são importantes, visto que para as nossas condições o valor de 'p' médio está em torno de 5 e, para este caso, no presente trabalho, diversas combinações em consórcio superaram o rendimento do melhor feijão em monocultivo. De maneira semelhante, RAMALHO et a $i$ i (1983) constataram que para $p=4,5$ o consórcio proporcionou uma renda bruta que superou a do monocultivo de milho e de feijão em $15,5 \%$ e $18,2 \%$, respectivamente. Estes fatos, aliados às demais vantagens do consörcio explicam, segundo FRANCIS e SANDERS (1978), a predominância do cultivo consorciado entre os agricultores da América Latina.

Finalizando, pode-se afirmar que a metodologia elaborada no presente trabalho, em que se combinam o arranjo dialélico, a relação de preços entre as duas espécies no mercado, bem como uma adaptação dos 
conceitos empregados em genética para os cruzamentos dialélicos, se mostrou bastante eficiente no sentido de dar informações bem claras a respeito do comportamento das cultivares em monocultivo e em consörcio, e da vantagem do consórcio frente ao monocultivo, bem como no sentido de elucidar alguns fatores responsáveis por isso. 
6. CONCLUSOES

Os resultados obtidos no presente trabalho permitiram apon tar as seguintes conclusões:

a. A metodologia elaborada no presente trabalho reuniu o arranjo dialélico como delineamento experimental, as produções equivalentes entre as duas espécies, obtidas através da relação de preços entre elas no mercado, como variável comum, e uma adaptação do modelo de análise de GARDNER e EBERHART (1966) para os cruzamentos dialélicos. Com base nesta metodologia, as produções das duas espécies em consōrcio são explicadas pelos seguintes parâmetros: efeito de cultivares em monocultivo ( ${ }_{i}$ e $b_{j}$ ), efeito geral de consórcio ou vantagem do consórcio sobre o monocul tivo $\left(c_{i j}\right)$, efeito médio de consórcio $(\bar{c})$, efeito de consórcio atribuído às cultivares $\left(c_{i}\right.$ e $\left.c_{j}\right)$, efeito específico de consórcio ou capacidade específica de competição $\left(d_{i j}\right)$ e capacidade geral de competição ou efeito de cultivares em consórcio $\left(\operatorname{cgc}_{i}\right.$ e $\left.c g c_{j}\right)$; 
b. A análise comparativa do parâmetro 'efeito geral de con sórcio' ( $c_{i j}$ ) com o índice 'razão da ārea equivalente'(RAE) mostrou que eles são devido aos mesmos componentes e, devido a isso, bem correlacionados. Entretanto, verificou-se que o ' $c_{i j}$ ' é mais adequado que o 'RAE' para a comparação da eficiência biológica ou capacidade de complementação das diferentes combinações em consórcio;

c. Esta metodologia, aplicada ao estudo de uma amostra de cultivares de milho e de feijão, mostrou-se bastante abrangente para explicar o comportamento das cultivares em consórcio em relação ao comportamento das mesmas em monocultivo, bem como no sentido de detectar algumas propriedades das cultivares relacionadas ao comportamento em consōrcio;

d. Para o milho e o feijão, as conclusões foram pouco afetadas pela variação que normalmente ocorre para a relação de preços no mercado, nas nossas condições, de modo que este tipo de estudo pode ser feito com base em uma relação de preços média;

e. As melhores combinações de milho e feijão.em consórcio foram aquelas onde ocorreu uma alta complementação entre as cultivares, ao contrário das piores combinações, evidenciando a importânicia da eficiência biológica da combinação para a produção conjunta em consórcio;

f. Para as cultivares de milho verificou-se a ocorrência de uma correlação positiva entre os efeitos de cultivares em monocultivo $\left(a_{i}\right)$ e os efeitos de consórcio atribuído às cultivares $\left(c_{i}\right)$. Devido a isso, as cultivares superiores em monocultivo foram também superiores em 
consōrcio e vice-versa, indicando para esta espécie uma ausência de interação entre cultivares e sistemas de cultivo;

g. Para as cultivares de feijão verificou-se a ocorrência de uma correlação negativa entre os efeitos de cultivares em monocultivo $\left(b_{j}\right)$ e os efeitos de consórcio atribuído às cultivares $\left(c_{j}\right)$. Devido a isso, não houve uma boa concordância entre o comportamento das cultivares em consórcio e em monocultivo, indicando, para esta espécie, a ocorrência de interação entre cultivares e sistemas de cultivo. : Consequentemente, recomendou-se a condução de programas de melhoramento de feijão específicos para consórcio, a médio e a longo prazos;

h. No geral, as combinações favorāveis envolveram cultivares com alta capacidade geral de competição de ambas as espécies e viceversa. Alguns desvios desta norma ocorreram devido à magnitude da capacidade específica de competição de determinadas combinações, ilustrando a importância destes dois efeitos para o rendimento conjunto em consórcio;

i. Dentro do grupo de cultivares estudado, as cultivares de milho mais promissoras para os dois sistemas foram os híbridos duplos Ag-401 e C-111. Para o feijão, a cultivar mais promissora em monocultivo foi S. Cuva 168, enquanto que as cultivares mais promissoras em consórcio foram Carioca e Rico 23;

j. Entre as características responsáveis por um bom desempenho em consórcio, para o feijão, puderam ser detectadas as seguintes: alta produtividade em monocultivo, baixa redução da produção em consórcio, pouca interferência com o milho (baixa agressividade) e precocidade. 
Consequentemente, recomendou-se que as caracteristicas alta produtividade, baixa agressividade e precocidade sejam tomadas como critérios de seleção em um programa de melhoramento de feijão para consórcio. 


\section{LITERATURA CITADA}

AGBOOLA, A. e A. FAYEMI, 1972. Fixation and excretion of nitrogen by tropical legumes. Agronomy Journal. Madison, 61:109-112.

AIDAR, H. e C. VIEIRA, 1979. Cultura associada de feijão e milho: III. Efeito de populações de plantas sobre o feijão da sêca. Revista Ceres. Viçosa, 26:465-473.

AIDAR, H., C. VIEIRA, L.M. OLIVEIRA e M. VIEIRA, 1979. Cultura associada de feijão e milho: II. Efeitos de populações de plantas no sistema de plantio simultâneo de ambas as culturas. Revista Ceres. Viçosa, 26: 102-111.

ANDRADE, M.A., M.A.P. RAMALHO e M.J.B. de ANDRADE, 1974. Consorciação de feijoeiro (Phaseolus vulgaris L.) com cultivares de milho (Zea mays L.) de porte diferente. Agros. Lavras, 4:23-30.

BEZERRA NETO, F., 1978. Efeito da arquitetura do milho (Zea mays L.) sobre algumas variedades de feijão (Phaseolus vulgaris L.) em cultura consorciada. Lavras, ESALQ, 62 p. (dissertação de mestrado).

BEZERRA NETO, F., M.A. de ANDRADE e A. JUNQUEIRA NETO, 1980. Comportamento de cultivares de feijão (Phaseolus vulgaris L.) em consórcio com mi 1ho (Zea mays L.). Ciência e Prātica. Lavras, 4:103-108. 
BREESE, E.L. e J. HILL, 1973. Regression analysis of interactions between competing species. Heredity. London, 31:181-200.

BUESTAN, H., 1973. Programa de leguminosas de grano. Guayaquil. Instituto Nacional de Investigação Agropecuária (informe anual).

CROOKSTON, R.K., K.J. TREHARNE, P. LUDFORD e J.L. OZBUN, 1975. Response of beans to shading. Crop Science. Madison, 15:412-416.

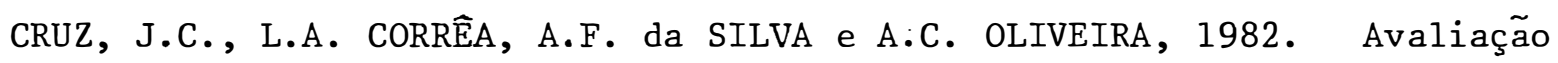
de cultivares de milho associado com feijão. Resumos do XIV Congresso Nacional de milho e sorgo. Florianópolis, 14:112.

DAVIS, J., 1981. Relaciones de competencia entre frijol y mayz en sistemas de asociacion $y$ sus inferencias para el mejoramient genetico. Cali. Centro Internacional de Agricultura Tropical (CIAT), 35 p. (Seminārios internos, Série SE-6-81).

DIJKSTRA, J. e A.L.F. de VOS, 1972. The evaluation of selections of white clover (Trifolium repens L.) in monoculture and in mixture with grass. Euphytica. Wageningen, 21:432-449.

DONALD, C.M., 1963. Competition among crop and pasture plants. Advances in Agronomy. New York, 15:1-118.

DURRANT, A., 1965. Analysis of reciprocal differences in diallel crosses. Heredity. London, 20:573-607.

FEDERER, W.T., 1979. Statistical designs and response models for mixtures of cultivars. Agronomy Journal. Madison, 71:701-706.

FEDERER, W.T., J.C. CONNIGALE, J.N. RUTGER e A.WIJESINHA, 1982. Statistical analysis of yields from uniblends and biblends. of eight dry bean cultivars. Crop Science. Madison, 22:111-115.

FINLAY, K.W. e G.N. WILKINSON, 1963. The analysis of adaptation in a plant breeding programme. Australian Journal of Agricultural. Research. Melbourne, 14:742-754. 
FISHER, N.M., 1974. A comparison of the relative seed yields of eight bean cultivars in pure stand and in mixture with maize. Bean Improvement Cooperative Annual Report, 17:38-40.

FRANCIS, C.A., C.A. FLOR e M. PRAGER, 1976a. Contrastes agroeconomicos en tre el monocultivo de maiz y la asociacion maiz-frijol. Cali. Centro Intérnacional de Agricultura Tropical (CIAT), 27 p. (mimeografado).

FRANCIS, C.A., C.A. FLOR e M. PRAGER, 1976b. Potenciales de la asociacion frijol-maiz in el tropico. Cali. Centro Internacional de Agricultura Tropical (CIAT), 23 p. (mimeografado).

FRANCIS, C.A., C.A. FLOR e S.R. TEMPLE, 1976c. Adapting varieties for intercropped systems in the tropics. Amer. Soc. Agron. Spec. Publ., 27: 235-253.

FRANCIS, C.A., 1978. Multiple cropping potencials of bean and maize. Hort Science. Alexandria, 13:12-17.

FRANCIS, C.A. e J.H. SANDERS, 1978. Economic analysis of bean and maize systems: monoculture versus associated cropping. Field. Crops Research. Amsterdan, $1: 319-335$.

FRANCIS, C.A., C.A. FLOR e M. PRAGER, 1978a. Effects of bean association on yields and yield components of maize. Crop Science. Madison, 18: 760-764.

FRANCIS, C.A., M. PRAGER e D.R. LAING, 1978b. Genotype $x$ environment interactions in climbing bean cultivars in monoculture and associated with maize. Crop Science. Madison, 18:242-246.

FRANCIS, C.A., M. PRAGER, D.R. LAING e C.A. FLOR, 1978c. Genotype $x$ environment interactions in bush bean cuĩtivars in monoculture and associated with maize. Crop Science. Madison, 18:237-242. 
FRANCIS, C.A., 1981. Development of plant genotypes for multiple cropping systems. In: FREY, K.J., Coord. Plant Breeding II. Iowa, The Iowa State University Press, p.179-231.

FYFE, J.L. e H.H. ROGERS, 1965. Effects of varying variety and spacing on yields and composition of mixtures of lucerne and tall fescue. Journal of Agricultural Science. New York; 64:351-359.

GARDNER, C.0. e S.A. EBERHART, 1966. Analysis and interpretation of the variety cross diallel and related populations. Biometrics. Raleigh, $\dot{2} 2: 439-452$.

GARDNER, C.0., 1967. Simplified methods for estimating constants and computing sums of squares for a diallel cross analysis. Fitotecnia Latinoamericana. San José, 4:1-12.

GERALDI, I.0. e J.B. MIRANDA FILHO, 1981. Análise da capacidade de combinação em cruzamentos dialélicos parciais. Relatório Científico do De partamento de Genética, ESALQ/USP. Piracicaba, 15:82-92.

GRIFFING, B., 1956. Concept of general and specific combining ability in relation to diallel crossing systems. Australian Journal of Biological Sciences. Melbourne, 9:463-493.

HALL, R.L., 1974. Analysis of the nature of interference between plants of different species. 1. Concepts and extension of the de Wit analysis to examine effects. Australian Journal of Agricultural Research. Melbourne, 25:739-747.

HAMBLIN, J., J.G. ROWELL e R. REDDEN, 1976. Selection for mixed cropping. Euphytica. Wageningen, 25:97-106.

HAYMAN, B.I., 1954. The analysis of variance of diallel tables. Biometrics. Raleigh, j 0:235-244. 
HILL, J., 1973. Methods of analysing competition with special reference to herbage plants. Journal of Agricultural Science. New York, 81: 91-98.

HILL, J. e Y. SHIMAMOTO, 1973. Methods of analysing competition with special reference to herbage plants. Journal of Agricultural Science. New York, 81:77-89.

HUXLEY, P.A. A A. MAINGU, 1978. Use of a systematic spacing design as an aid to the study. of intercropping: some general consideration. Experimental Agriculture. London, 14:49-56.

JENSEN, N.F., 1952. Intervarietal diversification in at breeding. Agronomy Journal. Madison, 41:30-34

JENSEN, N.F. e W.T. FEDERER, 1964. Adjacent row competition in wheat. Crop Science. Madison, 4:641-645.

JINKS, J.L. e B.I. HAYMAN, 1953. The analysis of diallel crosses. Maize Genetics Cooperation News Letter. Bloomington, 27:48-54.

JINKS, J.L., 1954. The analysis of continuous variation in a diallel cross of Nicotiana rustica varieties. Genetics. Austin, 39:767-788.

KASS, D.L., 1978. Polyculture Cropping Systems: Review and Analysis. Ithaca. New York State College of Agriculture and Life Sciences, 69 p.

MARSAGLIA, G., 1965. Ratios of normal variables and ratios of sums of uniform variables. Journal of the American Statistical Association. Boston, 60:193-203.

MATHER, K., 1949. Biometrical Genetics. London. Methuen \& Co.Ltd., 162p. McGILCHRIST, C.A., 1965. Analysis of competition experiments. Biometrics. Raleigh, 21:975-985. 
MCGILCHRIST, C.A. e B.R. TRENBATH, 1971. A revised analysis of plant competition experiments. Biometrics. Raleigh, 27:659-671. .

MEAD, R. e R.D. STERN, 1979. Statistical aspects of intercropping research. Proceedings of International workshop on Intercropping (ICRISAT). Hyderabad, p.306-317.

MEAD, R. e R.W. WILLEY, 1980. The concept of a 'Land Equivalent Ratio' and advantages in yields from intercropping. Experimental Agriculture. London, 16:1-12.

MEAD, R. e J. RIIEY, 1981. A review of - statistical ideas relevant to intercropping research. Journal of the Royal Statistical Society. London, $144: 462-509$.

MEDINA, J.C., 1972. Aspectos Gerais. Anais do I Simpósio Brasileiro de Feijão. Viçosa, 1:3-106.

MIRANDA FILHO, J.B: e I.O. GERALDI, 1980. Um modelo para a análise de cruzamentos dialélicos parciais. Relatörio Científico do Departamento de Genética, ESALQ/USP. Piracicaba, 14:50-60.

MONTEIRO, A.A.T., C. VIEIRA e C.C. SILVA, 1981. Yields of twenty bean cultivars under two cropping systems. Bean Improvement Cooperative Annual Report, 24:49-50.

NORRINGTON-DAVIES, J., 1967a. Application of diallel analysis to experiments in plant competition. Euphytica. Wageningen, 16:391-406.

NORRINGTON-DAVIES, J., 1967b. Diallel analysis of competition between grass species. Journal of Agricultural Science. New York, 71:223-231.

OLIARI, L., S.A. VIEIRA e J. THOMAZ, 1975. Feijāo-diagnóstico: Santa Catarina-Paranā-São Paulo. Goiānia. Centro Nacional de Pesquisa de Arroz e Feijão, 88 p. (mimeografado). 
OYEJOLA, B.A. e R. MEAD, 1982. Statistical assessment of different ways of calculating land equivalent ratios (LER). Experimental Agriculture. London, 18:125-138.

PEARCE, S.C. e B. GIILIVER, 1978. The statistical analysis of data from intercropping experiments. Journal of Agricultural Science. New York, $91: 625-632$.

PEARCE, S.C. e B. GILLIVER, 1979. Graphical assessment of intercropping methods. Journal of Agricultural Science. New York, 93:51-58.

PINCHINAT, A.M: e S. DESIR, 1976. Produccion agronomica y economica de maiz y frijol comun asociados, según tipo y población de plantas. Turrialba. Turrialba, 26:237-240.

RAMALHO, M.A.P., E.O. FINCH e A.F. da SILVA, 1982. Mecanização do plantio simultâneo de milho e feijão consorciados. Sete Lagoas. Centro Nacional de Pesquisa de Milho e Sorgo (EMBRAPA), 21 p: (Circular Técnica no 7).

- RAMALHO, M.A.P., A.C. OLIVEIRA e J.C. GARCIA, 1983. Recomendações para o planejamento e análise de experimentos com as culturas de milho e feijão consorciadas. Sete Lagoas. Centro Nacional de Pesquisa de Milho e Sorgo (EMBRAPA), 74 p. (Documentos no 02).

RAMALHO, M.A.P., (s/d). Consorciação milho-feijão. Sete Lagoas. Centro Nacional de Pesquisa de Milho..e Sorgo (EMBRAPA), 35 p. (mimeografado).

ROBERTSON, A., 1959. The sampling variance of the genetic correlation coefficient. Biometrics. Raleigh, 15:469-485.

SAKAI, K.I., 1961. Competitive ability in plants: its inheritance and some related problems. Proceedings of the Sympesium of the Society of Biology, 15:245-263. 
SANTA CECILIA, F.C., 1977. Comportamento de variedades de feijão (Phaseolus vulgaris L.) de diferentes hábitos de crescimento, cultivadas em associação com o milho. Viçosa, U.F.V., 83 p. (tese de doutoramento).

SANTA CECILIA, F.C. e C. VIEIRA, 1978. Associated cropping of beans and maize. I. Effects of bean cultivars with different growth habits. Turrialba. Turrialba, 28:19-23.

SILVA, J.F.A.F., 1980. Comportamento de cultivares de feijão (Phaseolus vulgaris L.) consorciados com milho. Viçosa, U.F.V., 40 p. (dissertação de mestrado).

SILVA, C.C. e C. VIEIRA, 1981. Cultura associada de feijão e milho. V. Avaliação de um sistema. Revista Ceres. Viçosa, 28:194-206.

VENCOVSKY, R., 1978. Herança Quantitativa. In: PATERNIANI, E., Coord. Melhoramento e produção do milho no Brasil. Piracicaba, Ed. Fundação Cargill, p.122-201.

VENCOSVKY, R. e I.0. GERALDI, 1977. Um modelo multiplicativo aplicado à anālise de produção de grãos. Relatōrio Científico do Departamento de Genética, ESALQ!USP. Piracicaba, 11:157-165.

VIEIRA, C., 1980. Plantio de feijão na cultura do milho. Informe Agropecuārio (EPAMIG). Belo Horizonte, 6:45-48.

VIEIRA, S.A., J.R. BEN e F.L.C. GASTAL, 1980. Avaliação do cultivo de milho e feijão nos sistemas exclusivo e consorciado. Pesquisa Agropecuāria Brasileira. Brasília, 15:19-26.

VIEIRA, C., M.A.P. RAMALHO e J.M. CHAGAS, 1982. Milho e feijão em cultivo consorciado. Informe Agropecuārio (EPAMIG). Belo Horizonte, 8:1315. 
WIJESINHA, A., W.T. FEDERER, J.R.P. CARVALHO e T.A. FORTES, 1982. Some statistical analysis for a maize and bean intercropping experiment. Crop Science. Madison, 22:660-666.

WILLIAMS, E.J., 1962. The analysis of competition experiments. Australian Journal of Biological Sciences. Melbourne, 15:509-525.

WILLEY, R.W. e S.O. OSIRU, 1972. Studies on mixtures of maize (Zea mays L.) and bean (Phaseolus vulgaris L.) with particular reference to plant population. Journal of Agricultural Science. New York, 79:517529.

WILLEY, R.W., 1979. Intercropping - Its importance and research needs. Part 1 e 2. Field Crop Abstracts. Aberystwyth, 32:1-10 e 73-85.

WILLEY, R.W. e R. RAO, 1980. A competitive ratio for quantifying competition between intercrops. Experimental Agriculture. London, 16: $117-125$.

YATES, F. e W.G. COCHRAN, 1938. The analysis of groups of experiments. Journal of Agricultural Science. New York;. 28:556-580. 
TABELAS 
Tabela 1. Dados experimentais: Produção de grãos ( $t / h a$ ) de milho (M) e fei jão (F), nas quatro repetições (I, II, III e IV), dos 36 tratamentos em consórcio $\left(1 \times 1^{\prime}, 1 \times 2^{\prime}, \ldots, 6 \times 6^{\prime}\right)$. Delineamento em blocos casualizados.

\begin{tabular}{|c|c|c|c|c|c|c|c|c|}
\hline \multirow{2}{*}{$\begin{array}{l}\text { Trata } \\
\text { mento }\end{array}$} & \multicolumn{2}{|c|}{ I } & \multicolumn{2}{|c|}{ II } & \multicolumn{2}{|c|}{ III } & \multicolumn{2}{|c|}{ IV } \\
\hline & $M$ & F & M & F & M & F & M & F \\
\hline $1 \times 1^{\prime}$ & 7,1360 & 0,3837 & 3,6127 & 0,2715 & 6,6026 & 0,2820 & 8,7286 & 0,2179 \\
\hline $1 \times 2^{\prime}$ & 5,8690 & 0,2017 & 3,6931 & 0,2250 & 7,5649 & 0,1170 & 4,2124 & 0,1530 \\
\hline $1 \times 3^{\prime}$ & 5,8030 & 0,6727 & 7,3853 & 0,5875 & 7,0577 & 0,5306 & 5,6662 & 0,4497 \\
\hline $1 \times 4^{\prime}$ & 6,9614 & 0,4063 & 5,3694 & 0,6215 & 5,6532 & 0,5645 & 8,3609 & 0,4605 \\
\hline $1 \times 5^{\prime}$ & 5,0659 & 0,2070 & 2,8544 & 0,2404 & 7,1614 & 0,3234 & 4,3441 & 0,2504 \\
\hline $1 \times 6^{\prime}$ & 8,4702 & 0,3672 & 5,5569 & 0,5813 & 7,3391 & 0,4503 & 6,4647 & 0,6307 \\
\hline $2 \times 1^{\prime}$ & 4,9762 & 0,3648 & 4,9456 & 0,3298 & 5,0804 & 0,4697 & 5,0449 & 0,3824 \\
\hline $2 \times 2^{\prime}$ & 4,5420 & 0,2465 & 2,9159 & 0,1998 & 4,5021 & 0,1979 & 3,1746 & 0,2691 \\
\hline $2 \times 3^{\prime}$ & 5,8515 & 0,7096 & 3,3619 & 0,9825 & 4,2816 & 0,4733 & 4,1910 & 0,4484 \\
\hline $2 \times 4^{\prime}$ & 4,3975 & 0,6644 & 2,1383 & 0,4492 & 4,9111 & 0,8910 & 3,0830 & 0,6432 \\
\hline $2 \times 5^{\prime}$ & 5,0325 & 0,4976 & 2,4994 & 0,4025 & 3,7772 & 0,3832 & 3,9981 & 0,4592 \\
\hline $2 \times 6^{\prime}$ & 5,3207 & 0,4669 & 3,2946 & 0,4504 & 4,5005 & 0,8218 & 2,9984 & 0,3421 \\
\hline $3 \times 1^{\prime}$ & 7,8608 & 0,3277 & 6,5646 & 0,2676 & 8,2162 & 0,1999 & 5,7506 & 0,2521 \\
\hline $3 \times 2^{\prime}$ & 7,3789 & 0,1881 & 3,9895 & 0,20 & 7,2553 & 0,18 & 7,5001 & 0,1661 \\
\hline $3 \times 3^{\prime}$ & 5,9557 & 0,6111 & 4,2995 & 0,6268 & 6,6210 & 0,30 & 4,8861 & 0,3272 \\
\hline $3 \times 4^{\prime}$ & 6,2473 & 0,7050 & 5,1758 & 0,4051 & 7,0791 & 0,51 & 7,9493 & 0,4859 \\
\hline $3 \times 5^{\prime}$ & 6,1235 & 0,3490 & 3,2277 & 0,37 & 7,1259 & 0,40 & 5,8989 & 0,3766 \\
\hline $3 \times 6^{\prime}$ & 3,9928 & 0, & 4,4906 & 0,6 & 5,4174 & 0 & 4,5216 & 0,4376 \\
\hline $4 \times 1^{\prime}$ & 5,0459 & 0 & & 0,4 & 4,4421 & 0 , & 4,1644 & 0,3544 \\
\hline $4 \times 2^{\prime}$ & 3,8471 & & 2 , & & 4, & 0 & 2 , & 0,4002 \\
\hline $4 \times 3^{\prime}$ & 6,5 & 0 & & & 4, & 0 , & & 505 \\
\hline $4 \times 4^{\prime}$ & 3,9886 & 0, & 2 , & & 3 & 0 & 86 & 0,5294 \\
\hline $4 \times 5^{\prime}$ & 4,9792 & 0,2922 & 2,7443 & & 3 , & 0,3 & 2 & 0,3899 \\
\hline $4 \times 6^{\prime}$ & 5,0107 & 0,4698 & 3,6028 & 0,5123 & 3 , & 0,5433 & 2,2588 & 0,4572 \\
\hline $5 \times 11^{\prime}$ & 4,8989 & 0,3169 & 3,7188 & 0,3422 & 4, & 0 & 5,6165 & 831 \\
\hline $5 \times 2^{\prime}$ & 6,5418 & 0,1820 & 4,0256 & 0,2348 & 5,1377 & 0,1479 & 6,2467 & 0,2985 \\
\hline $5 \times 3^{\prime}$ & 5,5943 & 0,6974 & 2,8011 & 0,6281 & 4,2739 & 0,3669 & 5,2964 & 0,6452 \\
\hline $5 \times 4^{\prime}$ & 4,8833 & 0,4960 & 4,8551 & 0,4847 & 5,2646 & 0,4818 & 3,4867 & 0,6525 \\
\hline $5 \times 5^{\prime}$ & 5,1990 & 0,3072 & 3,8674 & 0,4927 & 4,6556 & 0,3152 & 5,1374 & 0,3331 \\
\hline $5 \times 6^{\prime}$ & 5,5159 & 0,6804 & 2,8298 & 0,4448 & 5,2387 & 0,5714 & 4,9886 & 0,5048 \\
\hline $6 \times 1^{\prime}$ & 3,9465 & 0,4817 & 4,2044 & 0,3903 & 5,6875 & 0,2798 & 5,9909 & 0,3192 \\
\hline $6 \times 2^{\prime}$ & 4,2842 & 0,2286 & 3,1600 & 0,1223 & 5,0779 & 0,4724 & 6,5399 & 0,2866 \\
\hline $6 \times 3^{\prime}$ & 5,1717 & 0,3528 & 5,1379 & 0,5244 & 5,2300 & 0,4114 & 6,7617 & 0,4595 \\
\hline $6 \times 4 !^{\prime}$ & 4,2816 & 0,5315 & 3,7476 & 0,4423 & 4,5509 & 0,4968 & 5,3305 & 0,3361 \\
\hline $6 \times 5^{\prime}$ & 3,9582 & 0,4444 & 3,7039 & 0,5629 & 5,5861 & 0,3430 & 4,0476 & 0,3036 \\
\hline $6 \times 6^{\prime}$ & 5,2342 & 0,6593 & 3,7901 & 1,0346 & 3,6120 & 0,4175 & 4,0626 & 0,5088 \\
\hline
\end{tabular}

1: $\mathrm{Ag}-401 ; 2: \mathrm{Br}-105 ; 3: \mathrm{C}-111$ 4: Piranão; 5: $\mathrm{Br}-126 ; 6: \mathrm{Br}-104$
1': G.precoce; 2': M.fosco; 3': Carioca; 4': Rico 23; 5': C.Rica; 6': S.Cuva 168. 
Tabela 2. Dados experimentais: Produção de grãos ( $t / h a)$ de milho e feijão, nas quatro repetições (I, II, III e IV), dos seis tratamentos em monocultivo. Delineamento em blocos casualizados

\begin{tabular}{lcccccccccc}
\hline $\begin{array}{l}\text { Trat. } \\
\text { Milho }\end{array}$ & II & III & IV & $\begin{array}{c}\text { Trat. } \\
\text { Feijão }\end{array}$ & I & II & III & IV \\
\hline 1 & 6,7232 & 3,7445 & 6,6537 & 6,2604 & $1^{\prime}$ & 1,0521 & 0,4444 & 0,8951 & 0,4060 \\
2 & 5,6119 & 3,9872 & 7,0450 & 5,1347 & $2^{\prime}$ & 0,5566 & 0,3502 & 0,4877 & 0,4749 \\
3 & 7,1897 & 5,0746 & 7,2738 & 5,6780 & $3^{\prime}$ & 1,3921 & 0,9211 & 1,6973 & 1,7138 \\
4 & 3,5256 & 5,5022 & 5,5711 & 4,5325 & $4^{\prime}$ & 1,4318 & 1,0751 & 1,6295 & 1,7749 \\
5 & 4,3940 & 4,1037 & 5,4087 & 6,9957 & $5^{\prime}$ & 1,1202 & 0,6900 & 0,9262 & 1,2501 \\
6 & 5,5157 & 4,3709 & 6,3186 & 6,7773 & $6^{\prime}$ & 1,7755 & 1,0688 & 1,9165 & 2,2742 \\
\hline
\end{tabular}

1: Ag-401; 2: Br-105; 3: C-111; 1': G.precoce; 2': M.fosco; 3': Carioca; 4: Piranão; 5: Br-126; 6: Br-104. 4':Rico 23; 5': C.Rica; 6': S.Cuva 168.

Tabela 3. Valores e significâncias dos quadrados médios, obtidos nas anā lises de variância dos dados de produção de grãos para os tratamentos em consórcio e em monocultivo, coeficientes de variação experimental e eficiência dos látices

\begin{tabular}{|c|c|c|c|c|c|c|}
\hline & \multicolumn{3}{|c|}{ Consórcio } & \multicolumn{3}{|c|}{ Monocultivo } \\
\hline & GL & QM Milho & QM Feijão & GL & QM Milho & QM Feijão \\
\hline Repetições & 3 & $18,7375^{\frac{1}{*}}$ & $0,0271^{n s}$ & 3 & $3,9782^{*}$ & $0,3946^{\frac{1}{*}}$ \\
\hline Tratamentos & 35 & $4,5299^{* *}$ & $0,0792^{* \frac{1}{*}}$ & 5 & $1,1189^{\mathrm{ns}}$ & $0,9991^{\frac{1}{\pi}}$ \\
\hline Resíduo & 105 & 0,8626 & 0,0144 & 15 & 0,9165 & 0,0524 \\
\hline C.V.\% & & 18,8 & 28,3 & & 17,2 & 20,1 \\
\hline Ef. lātice \% & & 100,3 & 104,8 & & - & - \\
\hline
\end{tabular}


Tabela 4. Médias observadas (quatro repetições) da produção de grãos de milho ( $t / h a)$ dos 36 tratamentos em consórcio e dos 6 tratamen tos em monocultivo, arranjados em uma tabela dialélica

\begin{tabular}{ccccccccc}
\hline & $1^{\prime}$ & $2^{\prime}$ & $3^{\prime}$ & $4^{\prime}$ & $5^{\prime}$ & $6^{\prime}$ & Média & Monoc. \\
\hline 1 & 6,5200 & 5,3348 & 6,4780 & 6,5862 & 4,8564 & 6,9577 & 6,1222 & 5,8454 \\
2 & 5,0118 & 3,7836 & 4,4215 & 3,6325 & 3,8268 & 4,0286 & 4,1175 & 5,4447 \\
3 & 7,0980 & 6,5310 & 5,4406 & 6,6129 & 5,5940 & 4,6056 & 5,9804 & 6,3040 \\
4 & 4,4262 & 3,3365 & 4,8423 & 3,4776 & 3,2714 & 3,7166 & 3,8451 & 4,7828 \\
5 & 4,7136 & 5,4880 & 4,4914 & 4,6224 & 4,7148 & 4,6432 & 4,7789 & 5,2255 \\
6 & 4,9573 & 4,7655 & 5,5753 & 4,4776 & 4,3240 & 4,1747 & 4,7124 & 5,7456 \\
\hline Média & 5,4545 & 4,8732 & 5,2082 & 4,9015 & 4,4312 & 4,6877 & 4,9261 & 5,5580 \\
\hline
\end{tabular}

Tabela 5. Médias observadas (quatro repetições) da produção de grãos de feijão ( $t / h a)$ dos 36 tratamentos em consórcio e dos 6 tratamentos em monocultivo, arranjados em uma tabela dialélica

\begin{tabular}{cccccccc}
\hline & $1^{\prime}$ & $2^{\prime}$ & $3^{\prime}$ & $4^{\prime}$ & $5^{\prime}$ & $6^{\prime}$ & Média \\
\hline 1 & 0,2888 & 0,1742 & 0,5601 & 0,5132 & 0,2553 & 0,5074 & 0,3832 \\
2 & 0,3867 & 0,2283 & 0,6535 & 0,6619 & 0,4356 & 0,5203 & 0,4810 \\
3 & 0,2618 & 0,1861 & 0,4681 & 0,5282 & 0,3767 & 0,5997 & 0,4034 \\
4 & 0,3716 & 0,2481 & 0,5044 & 0,5552 & 0,3532 & 0,4956 & 0,4214 \\
5 & 0,2938 & 0,2158 & 0,5844 & 0,5288 & 0,3621 & 0,5504 & 0,4226 \\
6 & 0,3678 & 0,2775 & 0,4371 & 0,4517 & 0,4135 & 0,6550 & 0,4338 \\
\hline Média & 0,3284 & 0,2217 & 0,5346 & 0,5398 & 0,3661 & 0,5547 & 0,4242 \\
Monoc. & 0,6994 & 0,4674 & 1,4311 & 1,4778 & 0,9966 & 1,7588 & 1,1385 \\
\hline
\end{tabular}

1: $\mathrm{Ag}-401 ; 2: \mathrm{Br}-105 ; 3: \mathrm{C}-111$;

4: Piranão; 5: $\mathrm{Br}-126 ; 6: \mathrm{Br}-104$.
1': G.precoce; 2 ': M. fosco; 3 ' : Carioca; $4^{\prime}$ : Rico 23; 5': C.Rica; 6': S.Curva 168. 
Tabela 6. Valores e significâncias dos quadrados médios obtidos nas anā lises de variância dos ensaios em monocultivo, e no desdobramento do quadrado médio de tratamentos em consórcio, de acordo com o arranjo fatorial

F.V.

Consórcio Monocultivo

GL QM Milho QM Feijão GL QM Milho QM Feijão

$\begin{array}{lrclllc}\text { Tratamentos } & 35 & 4,5299^{* *} & 0,0792^{* *} & 5 & 1,1189^{\text {ns }} & 0,9991^{* *} \\ \text { Cult. Milho (M) } & 5 & 21,2728^{* *} & 0,0262^{\text {ns }} & - & 1,1189^{\text {ns }} & - \\ \text { Cult.Feijão(F) } & 5 & 3,1866^{* *} & 0,4616^{* *} & - & - & 0,9991^{* *} \\ \text { M x F } & 25 & 1,4500^{*} & 0,0134^{\text {ns }} & - & - & - \\ \text { Resíduo } & 105 & 0,8626 & 0,0144 & 15 & 0,9165 & 0,0524\end{array}$

ns, $* e^{* *}$ : não significativo, significativo a $5 \%$ e $1 \%$ de probabilidade, respectivamente

Tabela 7. Valores médios (quatro repetições) obtidos para a produção de grãos conjunta de milho e feijão ( $t / h a$ ) dos 36 tratamentos em consórcio e dos 6 tratamentos de cada espécie em monocultivo, em equivalentes de milho, para $\mathrm{p}=3$

\begin{tabular}{ccccccccc} 
& $1^{\prime}$ & $2^{\prime}$ & $3^{\prime}$ & $4^{\prime}$ & $5^{\prime}$ & $6^{\prime}$ & Média & Monoc. \\
1 & 7,3864 & 5,8574 & 8,1583 & 8,1258 & 5,6223 & 8,4799 & 7,2717 & 5,8454 \\
2 & 6,1719 & 4,4685 & 6,3820 & 5,6182 & 5,1336 & 5,5895 & 5,5606 & 5,4447 \\
3 & 7,8834 & 7,0893 & 6,8449 & 8,1975 & 6,7241 & 6,4047 & 7,1906 & 6,3040 \\
4 & 5,5410 & 4,0808 & 6,3555 & 5,1432 & 4,3310 & 5,2034 & 5,1092 & 4,7828 \\
5 & 5,5950 & 6,1354 & 6,2446 & 6,2088 & 5,8011 & 6,2944 & 6,0466 & 5,2255 \\
6 & 6,0607 & 5,5980 & 6,8866 & 5,8327 & 5,5645 & 6,1397 & 6,0137 & 5,7456 \\
\hline Média & 6,4397 & 5,5382 & 6,8120 & 6,5210 & 5,5294 & 6,3519 & 6,1987 & 5,5580 \\
Monoc. & 2,0982 & 1,4021 & 4,2932 & 4,4335 & 2,9899 & 5,2763 & 3,4155 & - \\
\hline
\end{tabular}

1: $\mathrm{Ag}-401 ; 2: \mathrm{Br}-105 ; 3: \mathrm{C}-111$

4: Piranão; 5: $\mathrm{Br}-126 ; 6: \mathrm{Br}-104$. $1^{\prime}:$ G.precoce; 2': M.fosco; 3': Carioca; $4^{\prime}$ : Rico 23; 5': C.Rica; 6': S. Cuva 168. 
Tabela 8. Valores médios (quatro repetições) obtidos para a produção de grãos conjunta de milho e feijão ( $t / h a$ ) dos 36 tratamentos em consórcio e dos 6 tratamentos de cada espécie em monocultivo, em equivalentes de milho, para $\mathrm{p}=5$

\begin{tabular}{ccccccccc}
\hline & $1^{\prime}$ & $2^{\prime}$ & $3^{\prime}$ & $4^{\prime}$ & $5^{\prime}$ & $6^{\prime}$ & Média & Monoc. \\
\hline 1 & 7,9640 & 6,2058 & 9,2785 & 9,1522 & 6,1329 & 9,4947 & 8,0380 & 5,8454 \\
2 & 6,9453 & 4,9251 & 7,6890 & 6,9420 & 6,0048 & 6,6301 & 6,5227 & 5,4447 \\
3 & 8,4070 & 7,4615 & 7,7811 & 9,2539 & 7,4775 & 7,6041 & 7,9975 & 6,3040 \\
4 & 6,2842 & 4,5770 & 7,3643 & 6,2536 & 5,0374 & 6,1946 & 5,9518 & 4,7828 \\
5 & 6,1826 & 6,5670 & 7,4134 & 7,2664 & 6,5253 & 7,3952 & 6,8916 & 5,2255 \\
6 & 6,7963 & 6,1530 & 7,7608 & 6,7361 & 6,3915 & 7,4497 & 6,8812 & 5,7456 \\
\hline Média & 7,0966 & 5,9816 & 7,8812 & 7,6007 & 6,2616 & 7,4614 & 7,0471 & 5,5580 \\
Monoc. & 3,4970 & 2,3368 & 7,1553 & 7,3892 & 4,9831 & 8,7939 & 5,6926 & - \\
\hline
\end{tabular}

Tabela 9. Valores médios (quatro repetições) obtidos para a produção de grãos conjunta de milho e feijão ( $t / h a$ ) dos 36 tratamentos em consórcio e dos 6 tratamentos de cada espécie em monocultivo, em equivalentes de milho, para $p=7$

\begin{tabular}{ccccccccc}
\hline & $1^{\prime}$ & $2^{\prime}$ & $3^{\prime}$ & $4^{\prime}$ & $5^{\prime}$ & $6^{\prime}$ & Média & Monoc. \\
\hline 1 & 8,5416 & 6,5542 & 10,3987 & 10,1786 & 6,6435 & 10,5095 & 8,8044 & 5,8454 \\
2 & 7,7187 & 5,3817 & 8,9960 & 8,2658 & 6,8760 & 7,6707 & 7,4848 & 5,4447 \\
3 & 8,9306 & 7,8337 & 8,7173 & 10,3103 & 8,2309 & 8,8035 & 8,8044 & 6,3040 \\
4 & 7,0274 & 5,0732 & 8,3731 & 7,3640 & 5,7438 & 7,1858 & 6,7946 & 4,7828 \\
5 & 6,7702 & 6,9986 & 8,5822 & 8,3240 & 7,2495 & 8,4960 & 7,7368 & 5,2255 \\
6 & 7,5319 & 6,7080 & 8,6350 & 7,6395 & 7,2185 & 8,7597 & 7,7488 & 5,7456 \\
\hline Média & 7,7534 & 6,4249 & 8,9504 & 8,6804 & 6,9937 & 8,5709 & 7,8956 & 5,5580 \\
Monoc. & 4,8958 & 3,2715 & 10,0175 & 10,3448 & 6,9764 & 12,3114 & 7,9696 & - \\
\hline
\end{tabular}

1: $\mathrm{Ag}-401 ; 2: \mathrm{Br}-105 ; 3: \mathrm{C}-111$; 4: Piranão; 5: Br-126; 6: Br-104. $1^{\prime}:$ G.precoce; 2': M.fosco; 3': Carioca; $4^{\prime}$ : Rico 23; 5': C.Rica; 6': S. Cuva 168. 
Tabela 10. Valores do efeito geral de consórcio $\left(c_{i j}\right)$ para a produção de grãos, em relação à média das cultivares das duas espécies em monocultivo, em valor real ( $t / h a$ ) e em porcentagem desta (entre parêntesis) e estimativa do desvio padrão correspondente. Dados em equivalentes de milho para $\mathrm{p}=3$

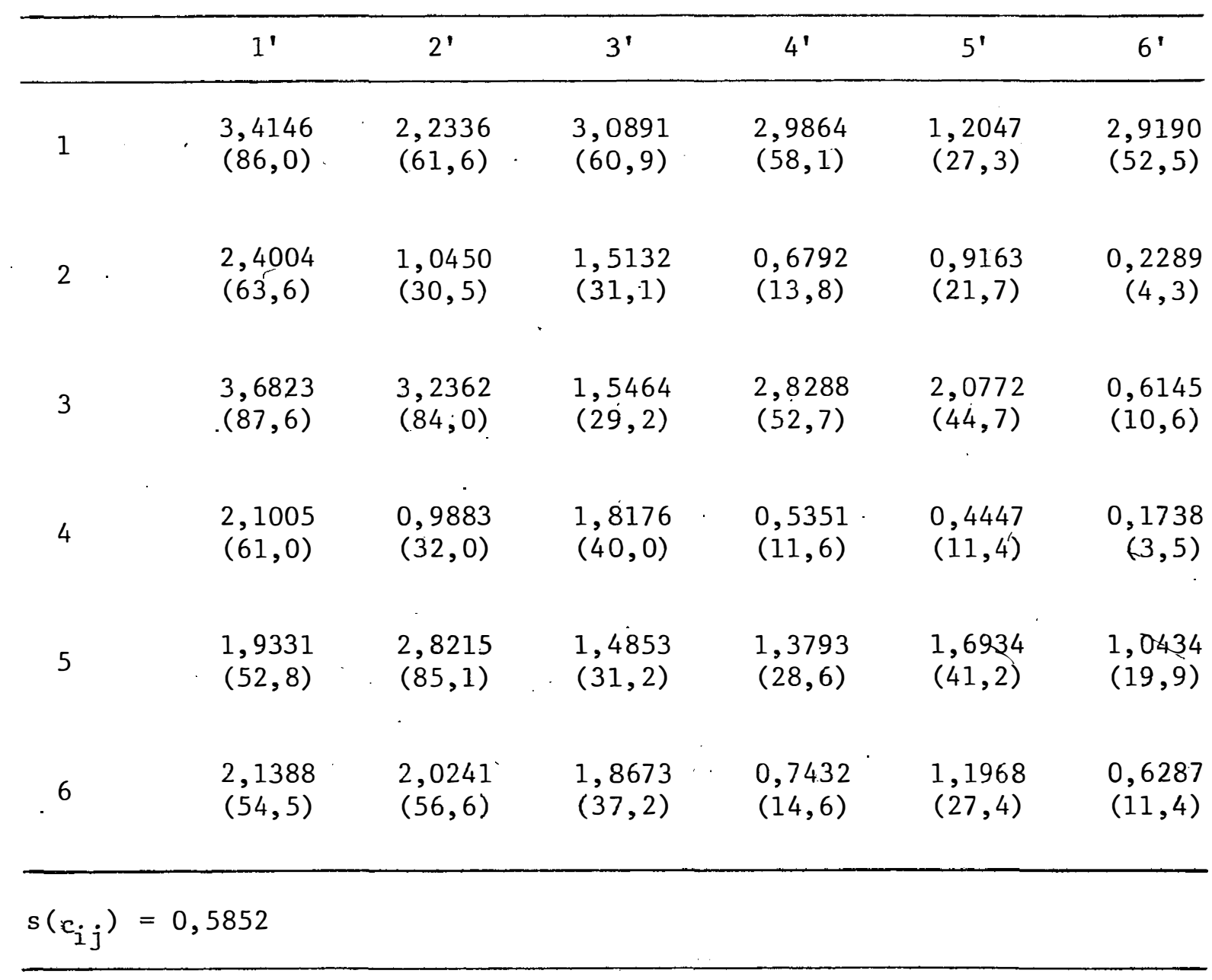

1: Ag-401; 2: Br-105; 3: C-111; 1': G.precoce; 2': M.fosco; 3': Carioca; 4: Piranão; 5: Br-126; 6: Br-104. 4': Rico 23; 5': C.Rica; 6': S.Cuva 168. 
Tabela 11. Valores do efeitó geral de consórcio $\left(c_{i j}\right)$ para a produção de grãos, em relação à média das cultivares das duas espécies em monocultivo, èm valór real ( $t /$ ha) e em porcentagem desta (entre parêntesis) e estimativa do desvio-padrão correspondente. Dados em equivalentes de milho, para $\mathrm{p}=5$

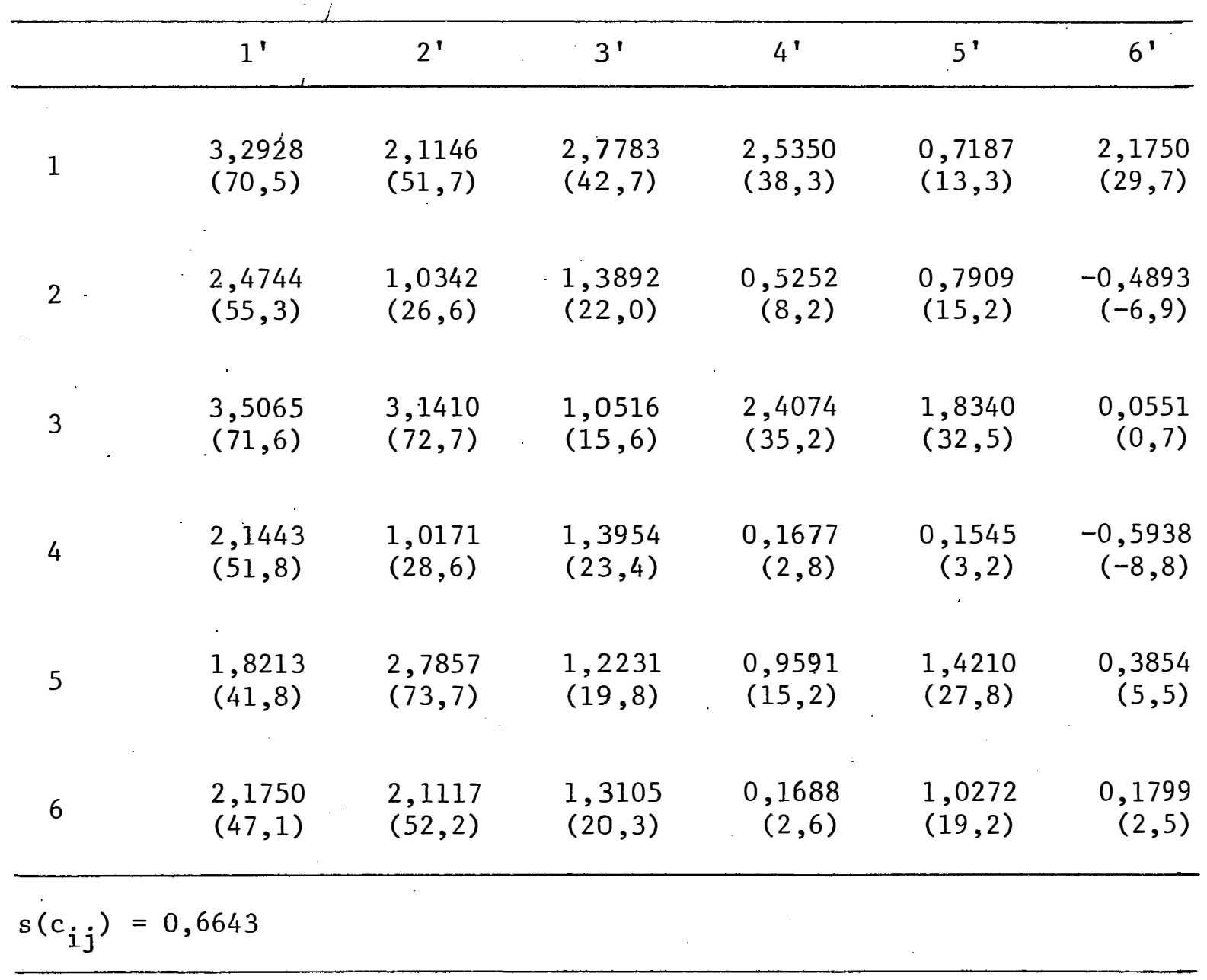

1: Ag-401; 2: Br-105; 3: C-111; 1': G.precoce; 2': M.fosco; 3': Carioca; 4: Piranão; 5: Br-126;6:Br-104. 4': Rico 23; 5': C.Rica; 6': S.Cuva 168 . 
Tabela 12. Valores do efeito geral de consórcio $\left(c_{i j}\right)$ para a produção de grãos, em relação à média das cultivares das duas espécies em monocultivo, em valor real $(t / h a)$ e em porcentagem desta (entre parêntesis) e estimativa do desvio-padrão correspondente. Dados em equivalentes de milho para $p=7$

\begin{tabular}{|c|c|c|c|c|c|c|}
\hline & $1^{\prime}$ & $2^{\prime}$ & $3^{\prime}$ & $4^{\prime}$ & $5^{\prime}$ & $6^{\prime}$ \\
\hline 1 & $\begin{array}{l}3,1710 \\
(59,0)\end{array}$ & $\begin{array}{l}1,9956 \\
(43,8)\end{array}$ & $\begin{array}{l}2,4675 \\
(31,1)\end{array}$ & $\begin{array}{l}2,0836 \\
(25,7)\end{array}$ & $\begin{array}{r}0,2327 \\
(3,6)\end{array}$ & $\begin{array}{l}1,4310 \\
(15,8)\end{array}$ \\
\hline 2 & $\begin{array}{l}2,5484 \\
(49,3)\end{array}$ & $\begin{array}{l}1,0234 \\
(23,5)\end{array}$ & $\begin{array}{l}1,2652 \\
(16,4)\end{array}$ & $\begin{array}{r}0,3712 \\
(4,7)\end{array}$ & $\begin{array}{l}0,6655 \\
(10,7)\end{array}$ & $\begin{array}{c}-1,2075 \\
(-13,6)\end{array}$ \\
\hline 3 & $\begin{array}{l}3,3307 \\
(59,5)\end{array}$ & $\begin{array}{l}3,0458 \\
(63,6)\end{array}$ & $\begin{array}{r}0,5568 \\
(6,8)\end{array}$ & $\begin{array}{l}1,9860 \\
(23,9)\end{array}$ & $\begin{array}{l}1,5908 \\
(24,0)\end{array}$ & $\begin{array}{r}-0,5043 \\
(-5,4)\end{array}$ \\
\hline 4 & $\begin{array}{l}2,1881 \\
(45,2)\end{array}$ & $\begin{array}{l}1,0459 \\
(26,0)\end{array}$ & $\begin{array}{l}0,9732 \\
(13,2)\end{array}$ & $\begin{array}{r}-0,1997 \\
(-2,6)\end{array}$ & $\begin{array}{r}-0,1357 \\
(-2,3)\end{array}$ & $\begin{array}{c}-1,3614 \\
(-15,9)\end{array}$ \\
\hline 5 & $\begin{array}{l}1,7095 \\
(33,8)\end{array}$ & $\begin{array}{l}2,7.499 \\
(64,7)\end{array}$ & $\begin{array}{l}0,9609 \\
(12,6)\end{array}$ & $\begin{array}{r}0,5389 \\
(6,9)\end{array}$ & $\begin{array}{l}1,1486 \\
(18,8)\end{array}$ & $\begin{array}{r}-0,2726 \\
(-3,1)\end{array}$ \\
\hline 6 & $\begin{array}{l}2,2112 \\
(41,6)\end{array}$ & $\begin{array}{l}2,1993 \\
(48,8)\end{array}$ & $\begin{array}{r}0,7537 \\
(9,6)\end{array}$ & $\begin{array}{r}-0,4056 \\
(-5,0)\end{array}$ & $\begin{array}{l}0,8576 \\
(13,5)\end{array}$ & $\begin{array}{r}-0,2689 \\
(-3,0)\end{array}$ \\
\hline & & & & & & \\
\hline
\end{tabular}

1: $\mathrm{Ag}-401 ; 2: \mathrm{Br}-105 ; 3: \mathrm{C}-111 ; \quad 1^{\prime}:$ G.precoce; 2': M.fosco; 3': Carioca; 4: Piranão; 5: Br-126; 6:Br-104. 4': Rico 23; 5': C.Rica; 6': S.Cuva 168. 
Tabela 13. Valores do efeito geral de consórcio $\left(c_{i j}\right)$ para a produção de grãos, em relação à média da cultivar de milho em monocultivo, em valor real ( $t / h a$ ) e em porcentagem desta (entre parêntesis), e estimativa do desvio-padrão correspondente. Dados em equivalentes de milho, para $p=5$

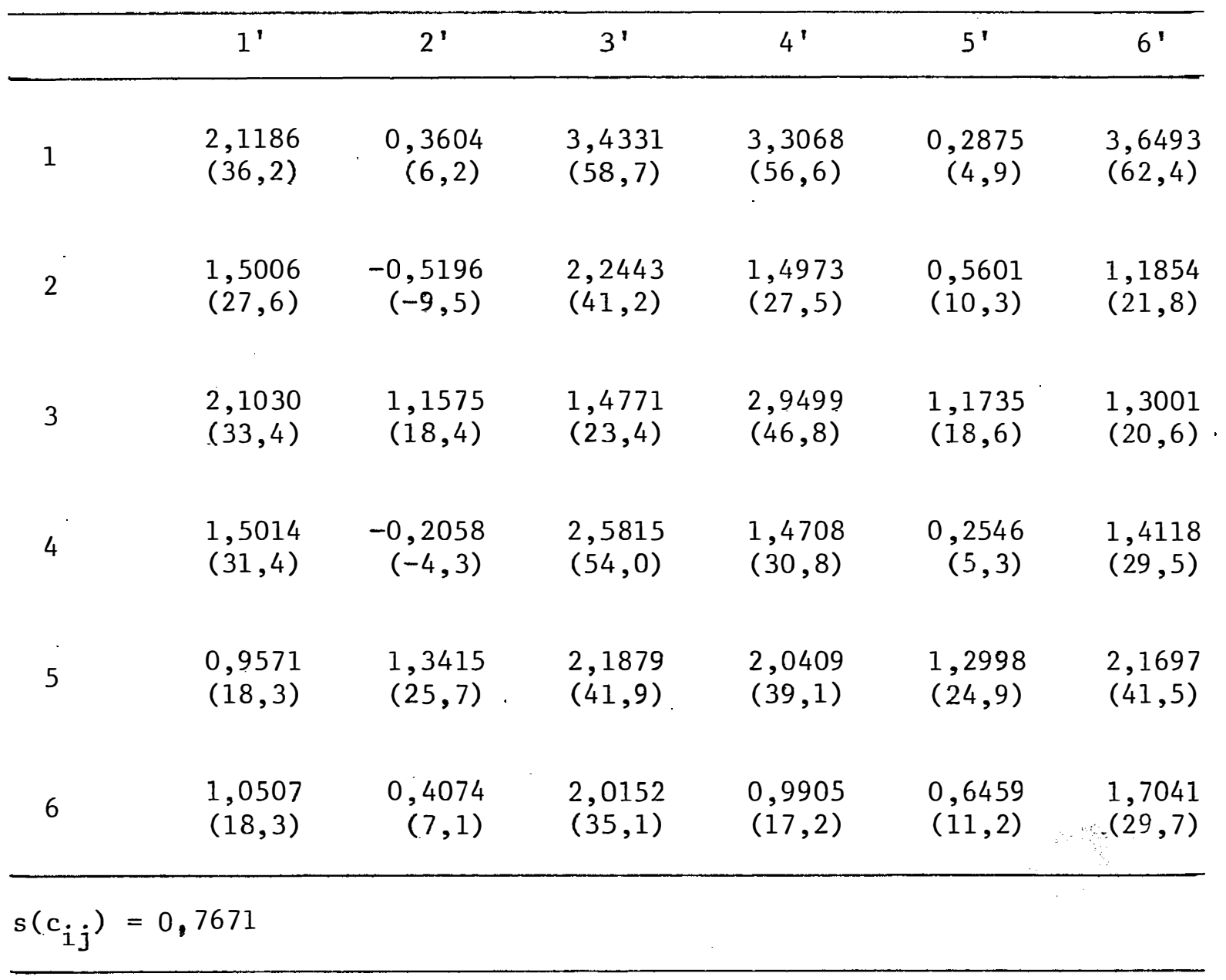

1: Ag-401; 2: Br-105; 3: C-111; 1': G.precoce; 2': M.fosco; 3': Carioca; 4: Piranão; 5: Br-126; 6:Br-104. 4': Rico 23; 5': C.Rica; 6': S.Cuva 168. 
Tabela 14. Valores do efeito geral de consórcio $\left(c_{i j}\right)$ para a produção de grãos, em relação à média da cultivar de feijão em monocultivo, em valor real ( $t / h a$ ) e em porcentagem desta (entre parêntesis), e estimativa do desvio-padrão correspondente. Dados em equivalentes de milho, para $\mathrm{p}=5$

\begin{tabular}{|c|c|c|c|c|c|c|}
\hline & $1^{\prime}$ & $2^{\prime}$ & $3^{\prime}$ & $4^{\prime}$ & $5^{\prime}$ & $6^{\prime}$ \\
\hline 1 & $\begin{array}{r}4,4670 \\
(127,7)\end{array}$ & $\begin{array}{r}3,8690 \\
(165,6)\end{array}$ & $\begin{array}{l}2,1232 \\
(29,7)\end{array}$ & $\begin{array}{l}1,7630 \\
(23,9)\end{array}$ & $\begin{array}{l}1,1498 \\
(23,1)\end{array}$ & $\begin{array}{r}0,7008 \\
(8,0)\end{array}$ \\
\hline 2 & $\begin{array}{l}3,4483 \\
(98,6)\end{array}$ & $\begin{array}{c}2,5883 \\
(110,8)\end{array}$ & $\begin{array}{r}0,5337 \\
(7,5)\end{array}$ & $\begin{array}{r}-0,4472 \\
(-6,1)\end{array}$ & $\begin{array}{l}1,0217 \\
(20,5)\end{array}$ & $\begin{array}{l}-2,1638 \\
(-24,6)\end{array}$ \\
\hline 3 & $\begin{array}{r}4,9100 \\
(140,4)\end{array}$ & $\begin{array}{r}5,1247 \\
(219,3)\end{array}$ & $\begin{array}{r}0,6258 \\
(8 ; 8)\end{array}$ & $\begin{array}{l}1,8647 \\
(25,2)\end{array}$ & $\begin{array}{l}2,4944 \\
(50,1)\end{array}$ & $\begin{array}{c}-1,1898 \\
(-13,5)\end{array}$ \\
\hline 4 & $\begin{array}{l}2,7872 \\
(79,7)\end{array}$ & $\begin{array}{l}2,2402 \\
(95,9)\end{array}$ & $\begin{array}{r}0,2090 \\
(2,9)\end{array}$ & $\begin{array}{l}-1,1356 \\
(-15,4)\end{array}$ & $\begin{array}{c}0,0543 \\
(1,1)\end{array}$ & $\begin{array}{l}-2,5993 \\
(-29,6)\end{array}$ \\
\hline 5 & $\begin{array}{l}2,6856 \\
(76,8)\end{array}$ & $\begin{array}{r}4,2302 \\
(181,0)\end{array}$ & $\begin{array}{r}0,2581 \\
(3,6)\end{array}$ & $\begin{array}{r}-0,1228 \\
(-1,7)\end{array}$ & $\begin{array}{l}1,5422 \\
(31,0)\end{array}$ & $\begin{array}{l}-1,3987 \\
(-15,9)\end{array}$ \\
\hline 6 & $\begin{array}{l}3,2993 \\
(94,4)\end{array}$ & $\begin{array}{r}3,8162 \\
(163,3)\end{array}$ & $\begin{array}{r}0,6055 \\
(8,5)\end{array}$ & $\begin{array}{r}-0,6531 \\
(-8,8)\end{array}$ & $\begin{array}{l}1,4084 \\
(28,3)\end{array}$ & $\begin{array}{c}-1,3442 \\
(-15,3)\end{array}$ \\
\hline
\end{tabular}

1: $\mathrm{Ag}-401 ; 2: \mathrm{Br}-105 ; 3: \mathrm{C}-111 ; \quad 1^{\prime}:$ G.precoce; 2': M.fosco; 3': Carioca; 4: Piranão; 5:Br-126; 6:Br-104. 4': Rico 23; 5': C.Rica; 6': S.Cuva 168. 
Tabela 15. Valores e significâncias dos quadrados mëdios, obtidos nas análises de variância das tabelas dialélicas da produção de grãos conjunta. Valores em equivalentes de milho, para $\mathrm{p}=3$, $p=5$ e $p=7$

\begin{tabular}{|c|c|c|c|c|}
\hline \multirow{2}{*}{ F.V. } & \multirow{2}{*}{ GL } & \multicolumn{3}{|c|}{ Quadrados médios } \\
\hline & & $\mathrm{p}=3$ & $p=5$ & $p=7$ \\
\hline Tratamentos & 47 & $1,9809^{* *}$ & $2,0972^{* *}$ & $3,2382^{* *}$ \\
\hline Dif. grupos & 1 & $13,7709^{\frac{*}{*} *}$ & $0,0543^{\mathrm{ns}}$ & $17,4466^{* *}$ \\
\hline Cult. Milho & 5 & $3,7894^{* *}$ & $3,4911^{* *}$ & $3,2241^{* *}$ \\
\hline Cult. Feijão & 5 & $3,1155^{* \pm}$ & $8,1912^{* *}$ & $15,9210^{* *}$ \\
\hline \multicolumn{5}{|c|}{ Efeitos de Consōrcio: } \\
\hline Geral & 36 & $1,2446^{* *}$ & $1,1140^{\frac{*}{*} \pi}$ & $1,0840^{* \pm}$ \\
\hline Médio & 1 & $26,3768^{* *}$ & $18,1956^{\frac{7}{2 t}}$ & $11,5288^{* 2 \pi}$ \\
\hline Cult. Milho & 5 & $1,0346^{* *}$ & $0,8824^{*}$ & $0,75 i 1^{\text {ns }}$ \\
\hline Cult. Feijão & 5 & $0,8673^{\frac{*}{*} *}$ & $1,5674^{* *}$ & $2,5349^{* 2 \pi}$ \\
\hline Específico & 25 & $0,3568^{\mathrm{ns}}$ & $0,3864^{\mathrm{ns}}$ & $0,4427^{n s}$ \\
\hline Resíduo médio & 135 & 0,2283 & 0,2942 & 0,3943 \\
\hline
\end{tabular}

ns, e $^{* *}:$ não significativo, significativo a $5 \%$ e $1 \%$ de probabilidade, respectivamente. 
Tabela 16. Estimativas dos parâmetros $a_{i}$ (efeito de cultivares de mi1ho), $b_{j}$ (efeito de cultivares de feijão), m (média das cultivares em monocultivo) eg (diferença entre as médias das cul tivares de milho e feijão) para a produção de grãos e estimativas dos desvios-padrão correspondentes. Dados em equivalen tes de milho, para $p=3, p=5$ e $p=7$

\begin{tabular}{|c|c|c|c|c|c|c|c|}
\hline$\hat{a}_{i}$ & $p=3$ & $p=5$ & $p=7$ & $\widehat{\mathrm{b}}_{j}$ & $p=3$ & $p=5$ & $p=7$ \\
\hline$\hat{a}_{1}$ & 0,2874 & 0,2874 & 0,2874 & $\hat{b}_{1}$ & $-1,3173$ & $-2,1955$ & $-3,0737$ \\
\hline$\hat{a}_{2}$ & $-0,1133$ & $-0,1133$ & $-0,1133$ & $\widehat{b}_{2}$ & $-2,0135$ & $-3,3558$ & $-4,6981$ \\
\hline$\hat{a}_{3}$ & 0,7460 & 0,7460 & 0,7460 & $\widehat{\mathrm{b}}_{3}$, & 0,8777 & 1,4628 & 2,0479 \\
\hline$\hat{a}_{4}$ & $-0,7752$ & $-0,7752$ & $-0,7752$ & $\hat{\mathrm{b}}_{4}$, & 1,0180 & 1,6966 & 2,3752 \\
\hline$\hat{a}_{5}$ & $-0,3325$ & $-0,3325$ & $-0,3325$ & $\widehat{b}_{5}$, & $-0,4256$ & $-0,7094$ & $-0,9932$ \\
\hline$\hat{a}_{6}$ & 0,1876 & 0,1876 & 0,1876 & $\widehat{b}_{6}$, & 1,8608 & 3,1013 & 4,3418 \\
\hline$s\left(\hat{a}_{i}\right)$ & 0,4362 & 0,4951 & 0,5732 & $s\left(\widehat{b}_{j}\right)$ & 0,4362 & 0,4951 & 0,5732 \\
\hline$\widehat{\mathrm{m}}$ & 4,4868 & 5,6253 & 6,7638 & $\hat{\mathrm{g}}$ & 1,0712 & $-0,0673$ & $-1,2058$ \\
\hline$s(\widehat{m})$ & 0,1379 & 0,1566 & 0,1813 & $s(\widehat{\dot{g}})$ & 0,1379 & 0,1566 & 0,1813 \\
\hline
\end{tabular}

1: Ag-401; 2: Br-105; 3: C-111; 4: Piranão; 5: Br-126; 6: Br-104.
1': G.precoce; 2': M.fosco; 3': Carioca; 4': Rico 23; 5': C.Rica; 6': S.Cuva 168. 
Tabela 17. Estimativas dos parâmetros $c_{i}$ (efeito de consórcio das cultivares de milho), $c_{j}$ (efeito de consórcio das cultivares de feijão) e $\bar{c}$ (efeito médio de consórcio) para a produção de grãos e estimativas dos desvios-padrão correspondentes. Dados em equivalentes de milho, para $p=3, p=5$ e $p=7$

\begin{tabular}{|c|c|c|c|c|c|c|c|}
\hline$\hat{c}_{i}$ & $p=3$ & $p=5$ & $p=7$ & $\hat{c}_{j}$ & $p=3$ & $p=5$ & $p=7$ \\
\hline$\hat{c}_{1}$ & 0,9292 & 0,8471 & 0,7650 & $\widehat{c}_{1}$, & 0,8997 & 1,1472 & 1,3947 \\
\hline$\hat{c}_{2}$ & $-0,5814$ & $-0,4678$ & $-0,3541$ & $\hat{c}_{2}$ & 0,3462 & 0,6123 & 0,8783 \\
\hline$\hat{c}_{3}$ & 0,6189 & 0,5774 & 0,5358 & $\hat{c}_{3}$, & 0,1744 & 0,1026 & 0,0308 \\
\hline$\hat{c}_{4}$ & $-0,7020$ & $-0,7077$ & $-0,7135$ & $\hat{c}_{4}$, & $-0,1867$ & $-0,2948$ & $-0,4029$ \\
\hline$\hat{c}_{5}$ & 0,0141 & 0,0107 & 0,0074 & $\hat{c}_{5}$, & $-0,4565$ & $-0,4309$ & $-0,4053$ \\
\hline$\hat{\mathrm{c}}_{6}$ & $-0,2788$ & $-0,2597$ & $-0,2406$ & $\hat{c}_{6}$, & $-0,7772$ & $-1,1364$ & $-1,4957$ \\
\hline$s\left(\hat{c}_{i}\right)$ & 0,2816 & 0,3196 & 0,3700 & $s\left(\hat{c}_{j}\right)$ & 0,2816 & 0,3196 & 0,3700 \\
\hline $\bar{c}$ & 1,7119 & 1,4219 & 1,1318 & - & - & - & - \\
\hline$s(\overline{\bar{c}})$ & 0,1593 & 0,1808 & 0,2093 & - & - & - & - \\
\hline
\end{tabular}

1: $\mathrm{Ag}-401 ; 2: \mathrm{Br}-105 ; 3: \mathrm{C}-111$, 4: Piranão; 5: Br-126; 6: Br-104. $1^{\prime}:$ G.precoce; 2': M.fosco; 3': Carioca; 4': Rico 23;5': C.Rica; 6': S. Cuva 168. 
Tabela 18. Estimativas dos parâmetros $d_{i j}$ (efeito específico de consórcio, ou capacidade específica de competição) para a produção de grãos, e estimativas dos desvios-padrão correspondentes. Dados em equivalentes de milho para $p=3, p=5$ e $p=7$

\begin{tabular}{|c|c|c|c|c|c|c|c|}
\hline & & $1^{\prime}$ & $2^{\prime}$ & $3^{\prime}$ & $4^{\prime}$ & $5^{\prime}$ & $6^{\prime}$ \\
\hline 1 & $\begin{array}{l}p=3 \\
p=5 \\
p=7\end{array}$ & $\begin{array}{l}-0,1263 \\
-0,1234 \\
-0,1206\end{array}$ & $\begin{array}{l}-0,7538 \\
-0,7666 \\
-0,7795\end{array}$ & $\begin{array}{l}0,2734 \\
0,4065 \\
0,5396\end{array}$ & $\begin{array}{l}0,5318 \\
0,5606 \\
0,5895\end{array}$ & $\begin{array}{l}-0,9801 \\
-1,1195 \\
-1,2590\end{array}$ & $\begin{array}{l}1,0550 \\
1,0424 \\
1,0299\end{array}$ \\
\hline 2 & $\begin{array}{l}p=3 \\
p=5 \\
p=7\end{array}$ & $\begin{array}{l}0,3703 \\
0,3732 \\
0,3761\end{array}$ & $\begin{array}{l}-0,4316 \\
-0,5320 \\
-0,6324\end{array}$ & $\begin{array}{l}0,2081 \\
0,3323 \\
0,4564\end{array}$ & $\begin{array}{l}-0,2647 \\
-0,1343 \\
-0,0038\end{array}$ & $\begin{array}{l}0,2423 \\
0,2677 \\
0,2931\end{array}$ & $\begin{array}{l}-0,1243 \\
-0,3069 \\
-0,4894\end{array}$ \\
\hline 3 & $\begin{array}{l}p=3 \\
p=5 \\
p=7\end{array}$ & $\begin{array}{l}0,4517 \\
0,3601 \\
0,2684\end{array}$ & $\begin{array}{l}0,5591 \\
0,5296 \\
0,5000\end{array}$ & $\begin{array}{l}-0,9590 \\
-1,0504 \\
-1,1419\end{array}$ & $\begin{array}{l}0,6845 \\
0,7028 \\
0,7212\end{array}$ & $\begin{array}{l}0,2027 \\
0,2656 \\
0,3284\end{array}$ & $\begin{array}{l}-0,9392 \\
-0,8077 \\
-0,6761\end{array}$ \\
\hline 4 & $\begin{array}{l}p=3 \\
p=5 \\
p=7\end{array}$ & $\begin{array}{l}0,1908 \\
0,2829 \\
0,3750\end{array}$ & $\begin{array}{l}-0,3679 \\
-0,3093 \\
-0,2507\end{array}$ & $\begin{array}{l}0,6331 \\
0,5784 \\
0,5238\end{array}$ & $\begin{array}{l}-0,2883 \\
-0,2518 \\
-0,2153\end{array}$ & $\begin{array}{l}-0,1089 \\
-0,1289 \\
-0,1489\end{array}$ & $\begin{array}{l}-0,0590 \\
-0,1715 \\
-0,2840\end{array}$ \\
\hline 5 & $\begin{array}{l}p=3 \\
p=5 \\
p=7\end{array}$ & $\begin{array}{l}-0,6926 \\
-0,7585 \\
-0,8244\end{array}$ & $\begin{array}{l}0,7493 \\
0,7409 \\
0,7325\end{array}$ & $\begin{array}{l}-0,4152 \\
-0,3123 \\
-0,2093\end{array}$ & $\begin{array}{l}-0,1601 \\
-0,1788 \\
-0,1975\end{array}$ & $\begin{array}{l}0,4238 \\
0,4192 \\
0,4146\end{array}$ & $\begin{array}{l}0,0946 \\
0,0893 \\
0,0840\end{array}$ \\
\hline 6 & $\begin{array}{l}p=3 \\
p=5 \\
p=7\end{array}$ & $\begin{array}{l}-0,1940 \\
-0,1343 \\
-0,0747\end{array}$ & $\begin{array}{l}0,2448 \\
0,3374 \\
0,4299\end{array}$ & $\begin{array}{r}0,2596 \\
0,0455 \\
-0,1686\end{array}$ & $\begin{array}{l}-0,5033 \\
-0,6987 \\
-0,8940\end{array}$ & $\begin{array}{l}0,2201 \\
0,2959 \\
0,3716\end{array}$ & $\begin{array}{r}-0,0272 \\
0,1542 \\
0,3357\end{array}$ \\
\hline & $=$ & $32 （ \mathrm{p}=$ & 0,4520 & $(p=5) e$ & \multicolumn{3}{|c|}{$0,5233(\mathrm{p}=7)$} \\
\hline
\end{tabular}

1: $\mathrm{Ag}-401 ; 2: \mathrm{Br}-105 ; 3: \mathrm{C}-111 ; \quad 1^{\prime}: \mathrm{G}$. precoce; 2': Ḿ.fosco; 3': Carioca; 4: Piranão; 5: Br-126;6:Br-104. 4': Rico 23;5': C.Rica;6': S. Cuva 168. 
Tabela 19. Estimativas dos parâmetros $\operatorname{cgc}_{i}$ (capacidade geral de competição das cultivares de milho) e cgc ${ }_{j}$ (capacidade geral de competição das cultivares de feijão), para a produção de grãos e estimativas dos desvios-padrão correspondentes. Dados em equi valentes de milho, para $p=3, p=5$ e $p=7$

\begin{tabular}{|c|c|c|c|c|c|c|c|}
\hline$\hat{\operatorname{cg} c}{ }_{i}$ & $p=3$ & $p=5$ & $p=7$ & $\widehat{c g} c_{j}$ & $p=3$ & $p=5$ & $p=7$ \\
\hline$\hat{\mathrm{cg}} \mathrm{c}_{1}$ & 1,0730 & 0,9909 & 0,9088 & $\hat{c} \widehat{g} c_{1}$, & 0,2410 & 0,0494 & $-0,1422$ \\
\hline$c \widehat{g} c_{2}$ & $-0,6381$ & $-0,5244$ & $-0,4108$ & $c \widehat{g} c_{2}$ & $-0,6605$ & $-1,0656$ & $-1,4707$ \\
\hline$\hat{\mathrm{cg}} \mathrm{c}_{3}$ & 0,9919 & 0,9504 & 0,9088 & $c \hat{g} c_{3}$ & 0,6133 & 0,8340 & 1,0548 \\
\hline$c \widehat{g} c_{4}$ & $-1,0896$ & $-1,0953$ & $-1,1010$ & $c \widehat{g} c_{4}$, & 0,3223 & 0,5535 & 0,7848 \\
\hline$\widehat{c g} c_{5}$ & $-0,1522$ & $-0,1555$ & $-0,1588$ & $c \widehat{g} c_{5}$, & $-0,6693$ & $-0,7856$ & $-0,9019$ \\
\hline$\hat{\mathrm{cg}} \mathrm{c}_{6}$ & $-0,1850$ & $-0,1659$ & $-0,1468$ & $c \widehat{g} c_{6}$, & 0,1532 & 0,4142 & 0,6753 \\
\hline$s\left(c \hat{g} c_{i}\right)$ & 0,1781 & 0,2021 & 0,2340 & $s\left(\hat{c} c_{j}\right)$ & 0,1781 & 0,2021 & 0,2340 \\
\hline
\end{tabular}

1: Ag-401; 2: Br-105; 3: C-111; 4: Piranão; 5: $\mathrm{Br}-126 ; 6: \mathrm{Br}-104$. $1^{\prime}$ : G.precoce; $2^{\prime}$ : M.fosco; 3': Carioca; 4': Rico 23; 5': C.Rica; 6': S. Cuva 168. 
Tabela 20. Valores obtidos para o Indice-Razão da Area Equivalente (RAE) nas 36 combinações em consórcio

\begin{tabular}{ccccccc}
\hline & $1^{\prime}$ & $2^{\prime}$ & $3^{\prime}$ & $4^{\prime}$ & $5^{\prime}$ & $6^{\prime}$ \\
\hline 1 & 1,528 & 1,285 & 1,500 & 1,474 & 1,087 & 1,479 \\
2 & 1,473 & 1,183 & 1,269 & 1,115 & 1,140 & 1,036 \\
3 & 1,500 & 1,434 & 1,190 & 1,406 & 1,265 & 1,072 \\
4 & 1,457 & 1,228 & 1,365 & 1,103 & 1,038 & 1,059 \\
5 & 1,322 & 1,512 & 1,268 & 1,242 & 1,266 & 1,202 \\
6 & 1,389 & 1,423 & 1,276 & 1,085 & 1,167 & 1,099 \\
\hline $1:$ Ag-401; 2: Br-105; 3: C-111; & 1': G.precoce; 2': M. fosco; 3': Carioca; \\
4: Piranão; 5: Br-126; 6: Br-104. & 4': Rico 23; 5':C.Rica; 6': S.Cuva 168.
\end{tabular}

Tabela 21. Quadrados médios obtidos na anālise da variância da interação entre cultivares e sistemas de cultivo [Consórcio (c) e Monocultivo (m)] e coeficientes de correlação entre as médias das cultivares nos dois sistemas, para a produção de grãos de mitho e de feijão. Análises realizadas com as médias das cultivares nos dois sistemas, relacionadas nas Tabelas 4 e 5

\begin{tabular}{|c|c|c|c|}
\hline F.V. & GL & QM Milho & QM Feijão \\
\hline Cultivares (C) & 5 & $0,9968 \div *$ & $0,2022 * \%$ \\
\hline Sistemas (S) & 1 & $1,1980 * \frac{\pi}{*}$ & $1,5307 * *$ \\
\hline$C \times S$ & 5 & $0,1693^{\mathrm{ns}}$ & $0,0668 * *$ \\
\hline Componente $\mathrm{A}^{(\mathrm{a})}$ & - & - & $0,0652(97,6 \%)$ \\
\hline Componente B & - & - & $0,0016 \quad(2,4 \%)$ \\
\hline Resíduo Médio(b) & 120 & 0,1268 & 0,0028 \\
\hline$\dot{\mathrm{r}}(\overline{\mathrm{c}}, \overline{\mathrm{m}})$ & & 0,831 & 0,977 \\
\hline $\mathrm{r}_{\mathrm{S}}(\overline{\mathrm{c}}, \overline{\mathrm{m}})$ & & 0,771 & 1,000 \\
\hline
\end{tabular}

a: Referem-se aos dois componentes da fórmula de desdobramento do quadrado médio da interação de ROBERTSON (1959).

b: Resíduo médio ponderado, dividido pela média harmônica do número de re petições $\left(r_{\bar{h}}=6,8571\right)$.

ns, $\star$ e $\star * *$ : não significativo, significativo a $5 \%$ e $1 \%$ de probabilidade, respectivamente. 


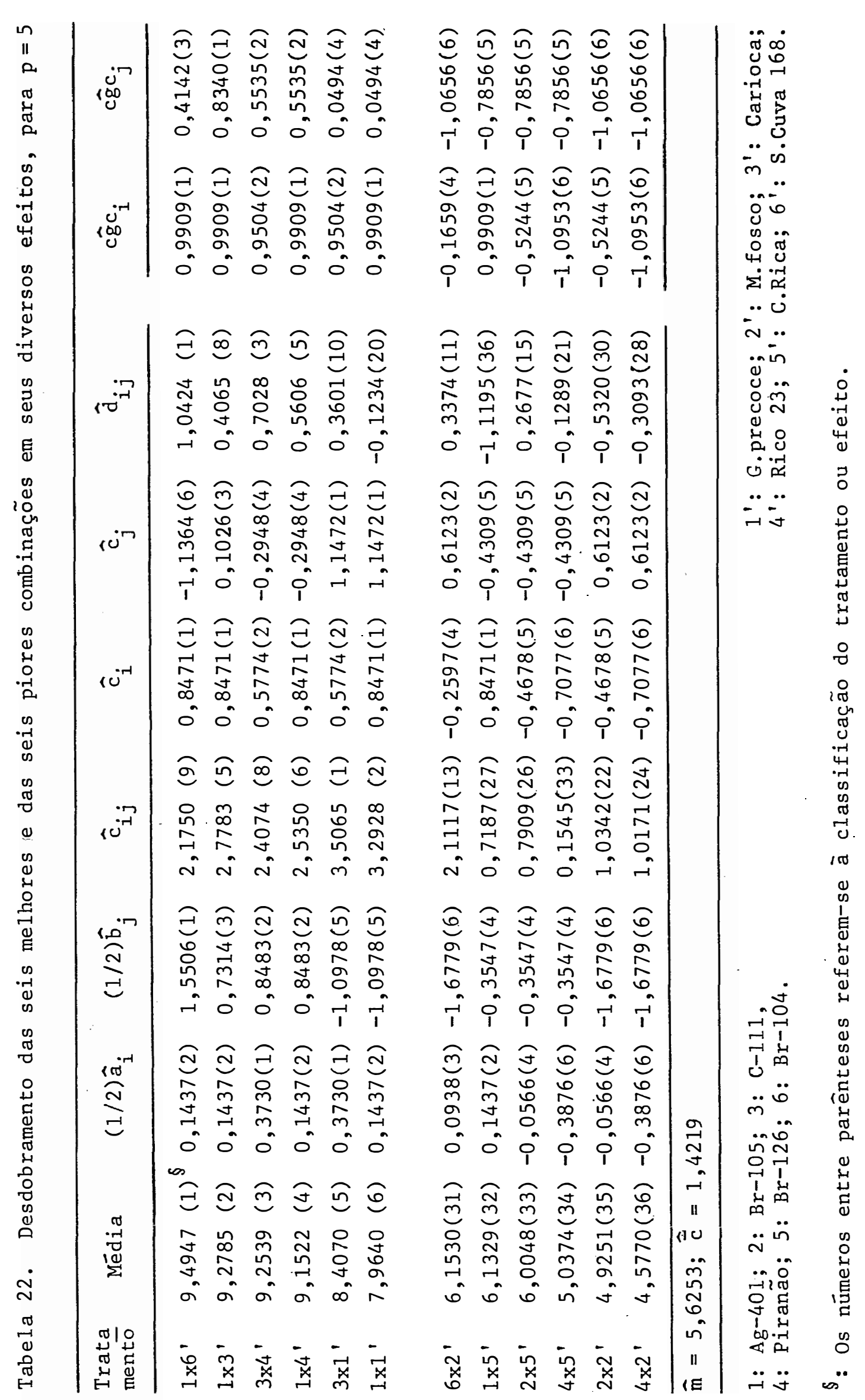

